\title{
EFEITO DO AMBIENTE E DE CULTIVARES NOS COMPONENTES DA PRODUÇÃO E NAS CARACTERISTIICAS TECNOLÓGICAS DA FIBRA E DO FIO DE ALGODÃO
}

EDERALDO JOSÉ CHIAVEGATO

Engenheiro Agrônomo

Orientador: Prof. Dr. Jairo Teixeira Mendes Abrahão

Tese apresentada à Escola Superior de Agricultura "Luiz de Queiroz", da Universidade de São Paulo, para obtenção do titulo de Doutor em Agronomia, Área de Concentração: Fitotecnia.

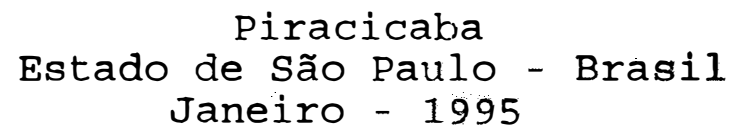


CAIALOGACAB NA PULLLICACAB - . 1:

DIVISAO DE BIBLIOIECA E DOCLMEMTACAO - LAMPUS "LUIL DE GUEJROI"/USF

\section{Chisueqato, Ederaldo Josét, I \\ $i r$ \\ c532e Efeito do ambiente e de cultivares nos componentes da producto e nas caracteristicas tecnolónicas da fibra e do tio de alnodgo. Piracicaba,} 1995.

$115 p$.

Tese - ESALQ.

Riblionrafia.

1. Alqadzo - Interar;o Bendtipo-ambiente 2. Alqodzo - Produça 3. Aloodzo Variedade 4. Fibra de aloodto - Fropriedade 1. Escola Superior de Aoricultura Luiz de Queiroz, Piracicaba 


\section{EFEITO DO AMBIENTE E DE CULTIVARES NOS COMPONENTES DA PRODUÇÃO E NAS CARACTERISTICACAS TECNOLÓGICAS DA FIBRA E DO FIO DE ALGODÃO}

EDERALDO JOSÉ CHIAVEGATO

Aprovada em 23 de fevereiro de 1995

Comissão Julgadora:

Prof.Dr. Jairo Teixeira Mendes Abrahão......... ESALQ/USP

Prof.Dr. Geraldo José Aparecido Dario........... ESALQ/USP

Prof.Dr. Antonio Cesar Bolonhezi............ FE/UNESP

Dr. Carlos Antonio Menezes Ferraz............ IAC/SAA

Dr. Nelson Paulieri Sabino............... IAC/SAA

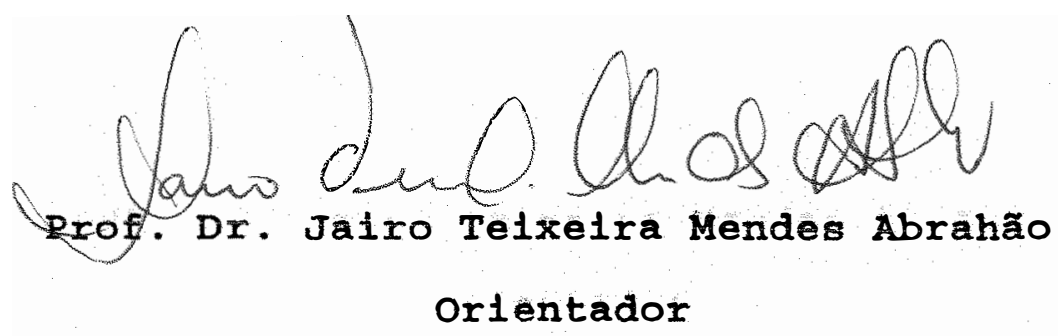


Aos meus pais

IRMA e REYNALDO

que me legaram os meios,

OFEREÇO

$\grave{A}$ minha esposa

LISETE

e meus filhos

VERIDIANA, MARÍLIA e REYNALDO

estímulo para os meus objetivos,

DEDICO 


\section{AGRADECIMENTOS}

Expressamos os nosso agradecimentos a todos aqueles que direta ou indiretamente contribuíram para a execução desse trabalho, e especialmente queremos estender nossa gratidão e reconhecimento:

Ao Prof. Dr. Jairo Teixeira Mendes Abrahão e ao Pesquisador Científico Dr. Milton Geraldo Fuzatto pela orientação, presença constante e valiosas sugestões durante a realização dos trabalhos, revisão dos originais e especialmente pela amizade e apreço;

Ao Departamento de Agricultura da Escola Superior de Agricultura "Luiz de Queiroz", pela possibilidade de realização do curso de pós-graduação;

Às Seções de Algodão e Tecnologia de Fibras do Instituto Agronômico pelos dados experimentais utilizados nesse trabalho;

Aos Pesquisadores Científicos Drs. Imre Lajos Gridi-Papp, Edivaldo Cia, Luiz Henrique Carvalho, Nelson Machado da Silva, Nelson Paulieri Sabino, Júlio Isao Kondo, Popílio Angelo Cavaleri, Rose Marry Araújo Gondim T'omaz e Luis Reynaldo Ferracciú Alleoni pelo apoio e colaboração;

À Sra. Maria Cristina dos Santos e Maria de Lourdes Siqueira pela dedicação e afinco nos trabalhos datilográficos; 
Ao Instituto Agronômico do Estado de São Paulo (IAC) pela oportunidade do treinamento e ao Conselho Nacional de Desenvolvimento Científico e Tecnológico (CNPq) pela bolsa de pós-graduação. 


\section{SUMÁRIO}

Página

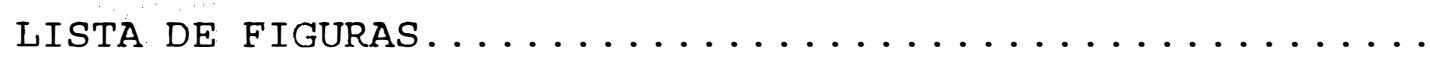

viii

LISTA DE TABELAS.

RESUMO

SUMMARY

xix

1. INTRODUÇÃO.

2. REVISÃO DE LITERATURA.

2.1. Influências do ambiente e de cultivares.......

2.1.1. Fatores edafoclimáticos.

2.1.2. Práticas agrícolas

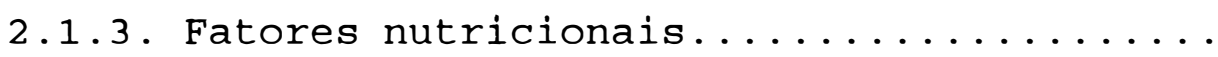

2.1.4. Incidência de pragas e moléstias........

2.2. Interação genótipo $\mathrm{x}$ ambiente e correlações...

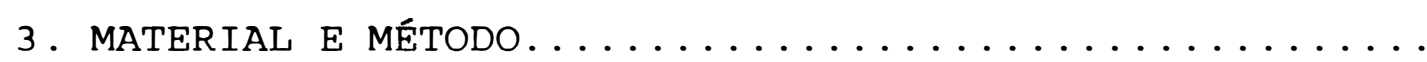

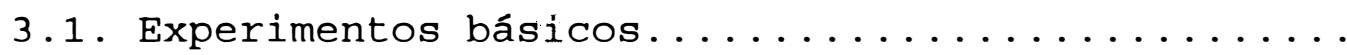

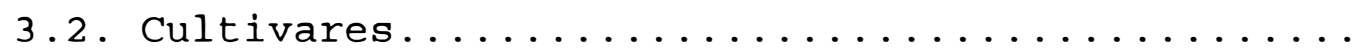

3.3. Características estudadas...............

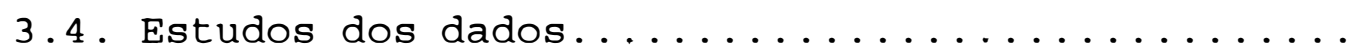

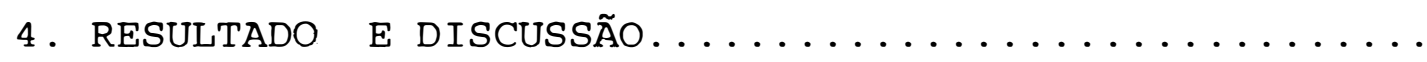

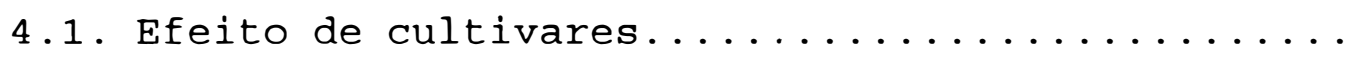

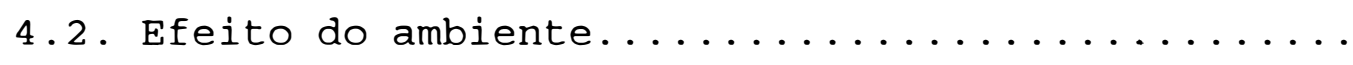

4.2.1. Efeito do ambiente em componentes da produção. 
vii.

4.2.2. Efeito do ambiente en características da

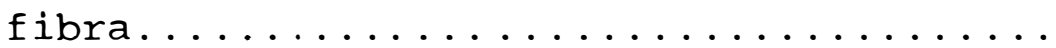

4.2.3. Reflexos do efeito do ambiente na quali-

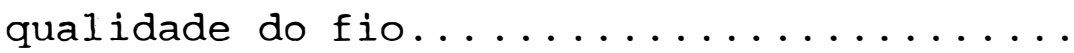

4.3. Correlações entre produção de algodão em caroço e demais características.

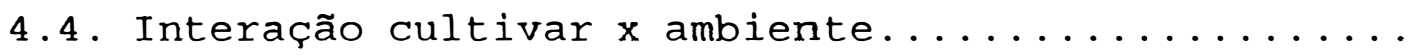

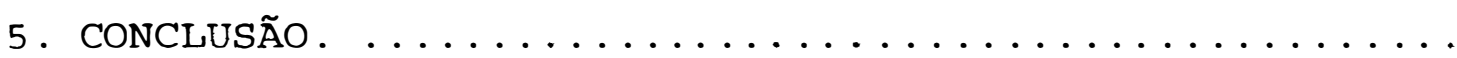

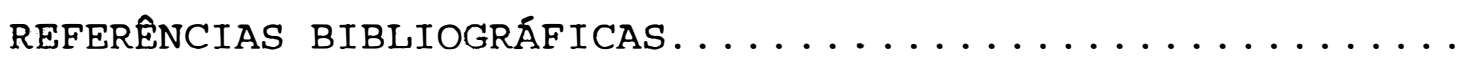

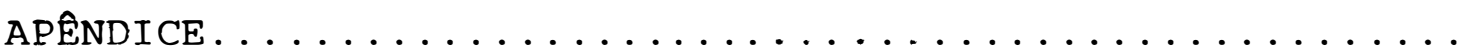




\section{LISTA DE FIGURAS}

Página

1. Representação gráfica da produção de algodão em caroço dos quatro cultivares segundo a variação do ambiente...

2. Representação gráfica do peso de um capulho dos quatro cultivares segundo a variação do ambiente..........

3. Representação gráfica do peso de cem sementes dos quatro cultivares segundo a variação do ambiente........

4. Representação gráfica da porcentagem de fibra dos quatro cultivares segundo a variação do ambiente.........

5. Representação gráfica do comprimento de fibra dos quatro cultivares segundo a variação do ambiente.........

6. Representação gráfica da uniformidade de fibra dos quatro cultivares segundo a variação do ambiente......

7. Representação gráfica da tenacidade da fibra dos quacultivares segundo a variação do ambiente...........

8. Representação gráfica do índice Micronaire dos quatro cultivares segundo a variação do ambiente..........

9. Representação gráfica da maturidade da fibra dos quatro cultivares segundo a variação do ambiente.........

10. Representação gráfica da tenacidade do fio dos quatro cultivares segundo a variação do ambiente..........

11. Representação gráfica da elongação do fio dos quatro cultivares segundo a variação do ambiente.......... 


\section{LISTA DE TABELAS}

Página

1. Identificação dos ambientes, loc:alidade de instalação dos experimentos selecionados e número de experimentos

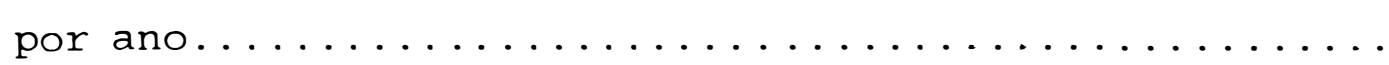

2. Ocorrências identificadas nos quarenta ambientes sele-

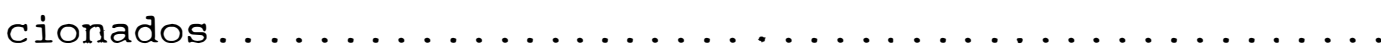

3. Análise da variância conjunta dos dados médios de produção de algodão em caroço, componentes da produção e características tecnológicas da fibra e do fio para

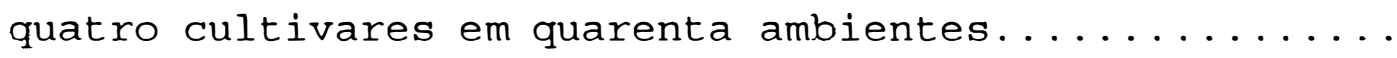

4. Valores dos componentes da produção obtidos para quatro cultivares em quarenta ambientes de cultivo do algodoeiro no Brasil, nos anos aģrícolas de 1987/88 a

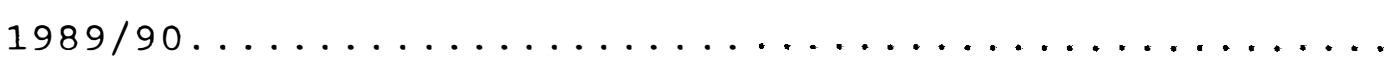

5. Valores das características tecnológicas da fibra obtidos para quatro cultivares em quarenta ambientes de cultivo do algodoeiro no Brasil, nos anos agrícolas

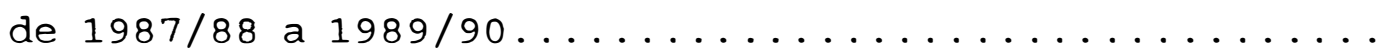

6. Correlação simples e regressão múltipla associando a tenacidade do fio com as características da fibra para

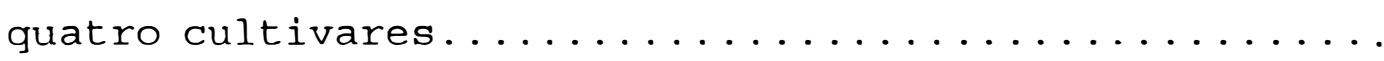


7. Correlação simples e regressão múltipla associando a elongação do fio com as características da fibra para

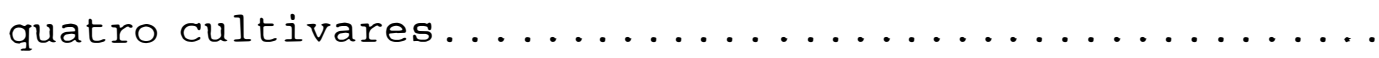

8. Valores das características do fio de algodão obtidos a partir de fibras produzidas por quatro cultivares em quarenta ambientes de cultivo no Brasil, nos anos a-

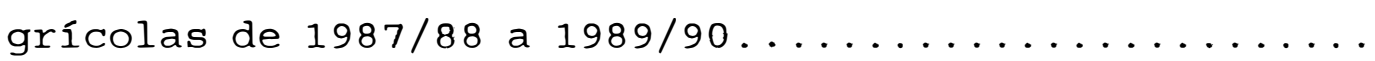

9. Correlações lineares entre produção de algodão em caroço e componentes da produção e características tecnológicas da fibra e do fio, baseadas nos dados de

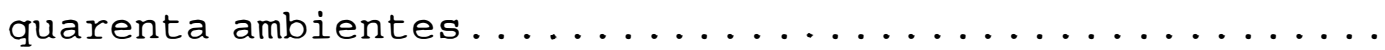

10. Correlações lineares entre produção de algodão em caroço e componentes da produção e características tecnológicas da fibra e do fio, baseadas nos dados de trinta e um ambientes da região Meridional.........

11. Correlações lineares entre produção de algodão em caroço e componentes da produção e características tecnológicas da fibra e do fio, baseadas nos dados de se-

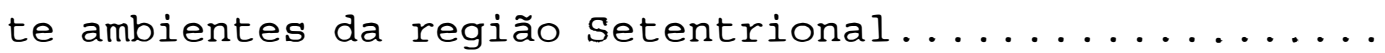

12. Estimativas dos parâmetros de estabilidade e adaptabilidade de quatro cultivares para produção de algodão em caroço, segundo a metodologia de CRUZ et alii

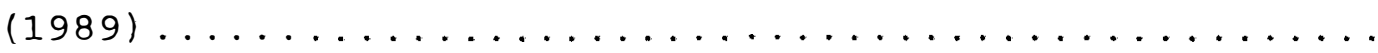


13. Estimativas dos parâmetros de estabilidade e adaptabilidade de quatro cultivares de algodão para o peso de um capulho, segundo a metodologia de CRUZ et alii

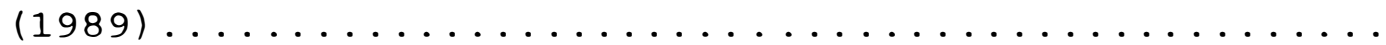

14. Estimativas dos parâmetros de estabilidade e adaptabilidade de quatro cultivares de algodão para o peso de cem sementes, segundo a metodologia de CRUZ et alii

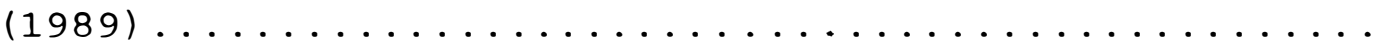

15. Estimativas dos parâmetros de estabilidade e adaptabilidade de quatro cultivares de algodão para porcentagem de fibras, segundo a metodologia de CRUZ et alii

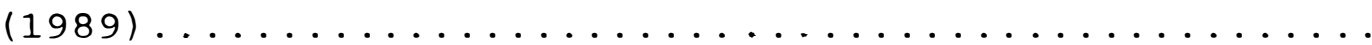

16. Estimativas dos parâmetros de estabilidade e adaptabilidade de quatro cultivares de algodão para o comprimento de fibra, segundo a metodologia de CRUZ et alii

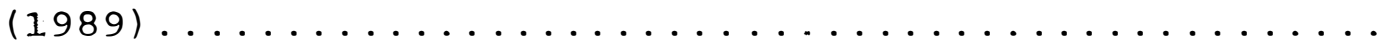

17. Estimativas dos parâmetros de estabilidade e adaptabilidade de quatro cultivares de algodão para uniformidade de comprimento, segundo a metodologia de CRUZ

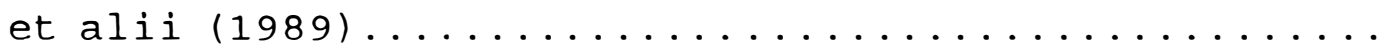

18. Estimativas dos parâmetros de estabilidade e adaptabilidade de quatro cultivares de algodão para a tenacidade da fibra, segundo a metodologia de CRUZ et alii

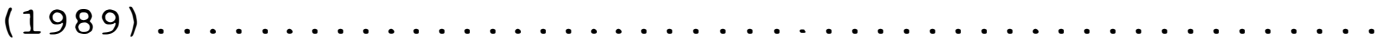


19. Estimativas dos parâmetros de estabilidade e adaptabiadaptabilidade de quatro cultivares de algodão para o o Índice Micronaire, segundo a metodologia de CRUZ

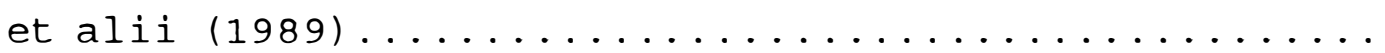

20. Estimativas dos parâmetros de estabilidade e adaptabilidade de quatro cultivares de algodão para a maturidade da fibra, segundo a metodologia de CRUZ et alii

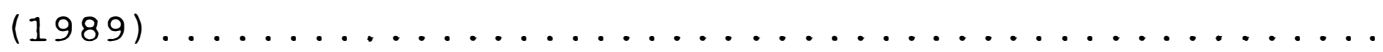

21. Estimativas dos parâmetros de estabilidade e adaptabilidade de quatro cultivares de algodão para a tenacidade do fio, segundo a metodologia de CRUZ et alii

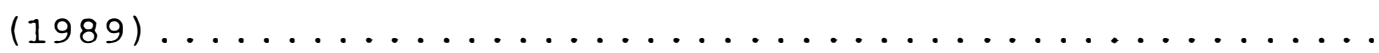

22. Estimativas dos parâmetros de estabilidade e adaptabilidade de quatro cultivares de algodão para a elongaÇão do fio, segundo a metodologia de CRUZ et elii

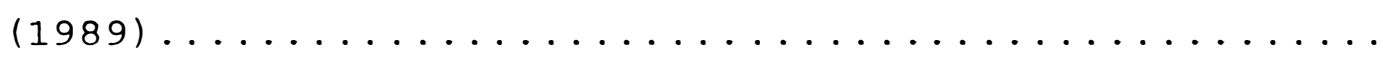

23. Valores médios da produção de algodão em caroço de quatro cultivares, avaliados em quarenta ambientes; médias gerais de ambientes (Yj) e de cultivares (Yi); quadrados médios residuais (QMR) e coeficientes de va-

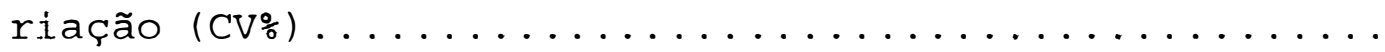

24. Valores médios do peso de um capulho de quatro cultivares, avaliados em quarenta ambientes; médias gerais de ambientes (Yj) e de cultivares (Yi); quadrados médios residuais (QMR) e coeficientes de variação (CV\%).. 
25. Valores médios do peso de cem sementes de quatro cultivares, avaliados em quarenta ambientes; médias gerais de ambientes $(Y j)$ e de cultivares $(Y i)$; quadrados médios residuais (QMR) e coeficientes de variação

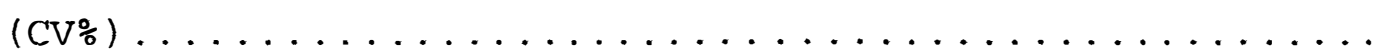

26. Valores médios da porcentagem de fibra de quatro cultivares, avaliados em quarenta ambientes; médias gerais de ambientes $(Y j)$ e de cultivares ( $Y i)$; quadrados médios residuais (QMR) e coeficientes de variação

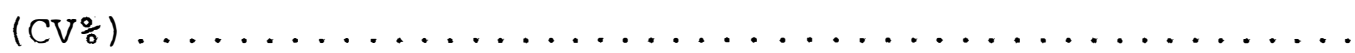

27. Valores médios do comprimento da fibra de quatro cultivares, avaliados em quarenta ambientes; médias gerais de ambientes ( $Y j$ ) e de cultivares (Yi); quadrados médios residuais (QMR) e coeficientes de variação

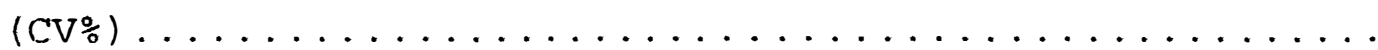

28. Valores médios da uniformidade da fibra de quatro cultivares, avaliados em quarenta ambientes; médias gerais de ambientes ( $Y j$ ) e de cultivares (Yi); quadrados médios residuais (QMR) e coeficientes de variação

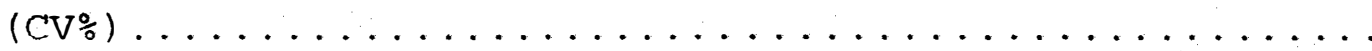

29. Valores médios do índice Micronaire de quatro cultivares, avaliados em quarenta ambientes; médias gerais de ambientes (Yj) e de cultivares (Yi); quadrados médios residuais (QMR) e coeficientes de variação

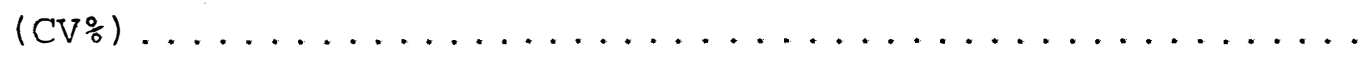


xiv.

30. Valores médios da tenacidade da fibra de quatro cultivares, avaliados em quarenta ambientes; médias gerais de ambientes (Yj) e de cultivaress (Yi); quadrados médios residuais (QMR) e coeficientes de variação (CV\%)..

31. Valores médios da maturidade da fibra de quatro cultivares, avaliados em quarenta ambientes; médias gerais de ambientes (Yj) e de cultivares (Yi); quadrados médios residuais (QMR) e coeficientes de variação (CV\%)..

32. Valores médios da tenacidade do fio de quatro cultivares, avaliados em quarenta ambientes; médias gerais de ambientes (Yj) e de cultivares (Yi); quadrados médios residuais (QMR) e coeficientes de variação (CV\%) .......

33. Valores médios da elongação do fio de quatro cultivares avaliados em quarenta ambientes; médias gerais de ambientes (Yj) e de cultivares (Yi); quadrados médios residuais (QMR) e coeficientes de variação (CV\%) ...... 


\section{EFEITO DO AMBIENTE E DE CULTIVARES NOS COMPONENTES DA \\ PRODUÇÃO E NAS CARACTERÍSTICAS TECNOLÓGICAS \\ DA FIBRA E DO FIO DE ALGODÃO}

Autor: EDERALDO JOSÉ CHIAVEGATO Orientador: Prof. Dr. JAIRO TEIXEIRA MENDES ABRAHÃO

RESUMO

O efeito de cultivares e do ambiente - definido como o conjunto indiscriminado de condições e fatores, adversos ou favoráveis, presente no local de cultivo - sobre os componentes da produção de algodão e as características tecnológicas da fibra e a qualidade do fio, foi estudado a partir de dados obtidos em experimentos regionais de cultivares. Mediante associação de 33 localidades e 3 anos, foram definidos 40 ambientes para o estudo do comportamento dos cultivares brasileiros IAC 19, IAC 20, CNPA Precoce 1 e CNPA Acala 1.

Além dos efeitos principais, uma interação cultivar $x$ ambiente altamente significativa foi observada para todas as características, o que permitiu realizar estudos de estabilidade e adaptabilidade dos cultivares, pelo método de regressão linear bi-segmentada. Estudos de correlação entre a 
xvi.

produção de algodão em caroço e as demais características foram realizados assim como análises de regressão múltipla para verificar as características da fibra responsáveis pela tenacidade e elongação do fio.

o efeito do ambiente, para todas as características estudas, foi bem superior ao de cultivares, tendo na média destes, provocado variações de 820 a $4440 \mathrm{~kg} / \mathrm{ha}$ na produção de algodão em caroço; 4,97 a 8,32g no peso de um capulho; 10,62 a $14,53 \mathrm{~g}$ no peso de cem sementes e 34,05 a $42,62 \%$ na porcentagem de fibra.

Nas características da fibra, a dispersão devida ao ambiente (na média dos cultivares) foi de 24,56 a 29,91 mm para o comprimento (Fibrógrafo, "2,5\%"); 40,75 a 48,38\% para a uniformidade; 3,51 a 5,13 para o índice Micronaire; 21,06 a 26,92 g/Tex para a tenacidade (Pressley 1/8"); e 55,97 a 76,79\% no caso da maturidade.

o comprimento, a uniformidade e a tenacidade da fibra foram responsáveis por cerca de $60 \%$ da variação na tenacidade do fio ( $\mathrm{Ne} 22$ ) e em consequência do efeito exercido sobre eles, o ambiente provocou dispersão na tenacidade do fio de 12,71 a 16,78 (RKM). Para a elongação do fio, que dependeu em $65 \%$ da variação do comprimento, da uniformidade e do Micronaire, a oscilação devido à influência do ambiente na fibra, foi de 5,78 a 7,92\% .

Além de se diferenciarem quanto à produtividade e às demais características, os cultivares revelaram diversidade quanto à resposta ao ambiente. De modo geral, o IAC 19 e o IAC 20 mostraram-se mais estáveis e previsíveis. Foram também mais 
responsivos às melhorias do ambiente com respeito à produção de algodão em caroço, e apresentaram adaptabilidade regular às diversas condições de cultivo para as demais características. Por outro lado, os cultivares CNPA Precoce 1 e CNPA Acala 1 mostraramse menos estáveis e previsíveis, provavelmente em consequência da maior susceptibilidade a doenças e nematóides. Para algumas características, principalmente as de fibra, o CNPA Acala 1 mostrou ser também mais sensível a condições adversas. Nenhum dos cultivares foi responsivo à melhoria do ambiente, com respeito às características da fibra.

Considerando as consequências práticas, outros aspectos são apontados e discutidos tais como: a) distanciamento da realidade prática na fixação de valores absolutos ou faixas de variação restritas como padrões de qualidade para as características de fibra, principalmente o índice Micronaire; b) a necessidade de condições e/ou cuidados especiais para assegurar boa qualidade de fibra, em vista da ausência ou baixa correlação entre a produtividade de algodão em caroço e os valores das características da fibra; c) a possibilidade, sob condições desfavoráveis, de produzix fibra com características bem abaixo das requeridas para determinados usos ou produtos finais, apesar da utilização de cultivares apropriados como o CNPA Acala 1; d) a falta de consistência em usar valores das características estudas, ainda que médios, como critério usual para descrição de cultivares; e) a conveniência de considerar a estabilidade e adaptabilidade de cultivares nos programas de melhoramento e nos ensaios para introdução e recomendações de cultivares, e fl a obrigatoriedade de 
xviii.

resistência múltipla a doenças e nematóides nos cultivares destinados à maioria das atuais regiões de cultivo de algodão no Brasil. 


\section{EFFECT OF ENVIRONMENT AND CULTIVARS ON COTTON YIELD \\ COMPONENTS, FIBER PROPERTIES AND YARN QUALITY}

Author: EDERALDO JOSÉ CHIAVEGATO

Adviser: Prof. Dr. JAIRO TEIXEIRA MENDES ABRAHÃO

\section{SUMMARY}

The effect of cultivars and environment - defined as the joint influence of indiscriminated, adverse or favorable conditions and factors prevailing in the cultivated sites - on the cotton yield components as well as on the fiber properties and yarn quality was studied. Using data obtained in regional tests of cultivars, it was possible to stablish, 40 environments comprising the association of 33 localities and 3 years, in which the behaviour of the brazilian cotton cultivars IAC 19, IAC 20, CNPA Precoce 1 and CNPA Acala 1 was investigated.

Besides the main effects, a highly significant interaction cultivar $x$ environment was observed for all traits, which allowed subsequent analysis of cultivar stability and adaptability, by means of a bi-segmented linear regression model. Correlation studies between yield and the other traits, as well as multiple regression analysis of yarn tenacity and elongation on the fiber properties were also accomplished. 
For all the considered traits, the effect of environment was considerably higher than the cultivar influence. In the average, for all the studied genotypes, environment caused variations from 820 to $4440 \mathrm{~kg} / \mathrm{ha}$ on seed cotton yield; 4.97 to $8.32 \mathrm{~g}$ on boll weight; 10.62 to $14.43 \mathrm{~g}$ on the weight of 100 seeds; and 34.05 to $42.61 \%$ on the fiber percentage.

Concerning to fiber properties, dispersion due to environment (in the average of cultivars), was from 24.56 to $29.91 \mathrm{~mm}$ for fiber length (Fibrograph, 2.5\%); 40.75 to $48.38 \%$ for uniformity; 3.51 to 5.13 for Micronaire index; 21.06 to $26.92 \mathrm{~g} / \mathrm{Tex}$ for tenacity (Pressley $1 / 8$ Gauge); and 55.97 to $76.79 \%$ in the case of maturity.

Regarding to yarn (Ne 22), length, uniformity and tenacity were the significant fiber traits responsible for $60 \%$ of variation of yarn tenacity. The dispersion observed is this trait, due to effect of environment on fiber was, consequently, from 12.71 to 16.78 (RKM). Yarn elongation depended in $65 \%$ of variation ocurred in length, uniformity and Micronaire, and presented a range due to influence of environment on fiber, from 5.78 to $7.92 \%$.

Cultivars differed not only with respect to yield components and fiber properties but also in their response to environment variation. In general the cultivars IAC 19 and IAC 20 showed to be more stable and predictable. They were also more responsive to the environment improvement, with respect to yield, and showed regular adaptability to the several growing conditions, regarding to the other traits. Otherwise, the cultivar CNPA Precoce 1 and CNPA Acala 1 showed to be less stable and predictable, 
probably as a consequence of their great suscetibility to diseases and nematodes. For some traits, mainly fiber properties, CNPA Acala 1 showed also to be more susceptible to adverse conditions. None of te cultivars was responsive to the improved conditions, in the case of fiber properties.

Considering the practical consequences, other aspects are pointed out and discussed, such as: a) gap in the practical reality in fixing absolute values or restrict ranges as quality patterns for fiber properties, mainly for Micronaire index; b) the need of special cares and/or conditions to assure good fiber scores, face to the absence of or low correlation between seed cotton productivity and fiber traits values; c) the possibility, under unfavorable conditions of attaining fiber grades well below the required for special uses or end-products, despite the utilization of adequate cultivars as CNPA Acala 1; d) the lack of consistency of employing values for the traits in question, even as a mean data, as usual criterion for cultivar description; e) the convenience of taking into account genotype stability and adaptability in cotton breeding programs as well as in tests for cultivar introduction and recommendation; and f) the requirement for multiple resistance to diseases and nematodes by the cultivars delivered to the greatest part of the considered cotton growing regions of Brazil. 


\section{INTRODUÇÃO}

O algodoeiro, apesar da qualidade e multiplicidade de uso de suas sementes é cultivado essencialmente para a produção de fibras. Reconhecida como a mais importante das fibras téxteis devido às qualidades tecnológicas e às inigualáveis condições de uso, tem sentido ao longo dos anos uma forte concorrência das fibras sintéticas. Atualmente, a fibra de algodão contribui com cerca de $50 \%$ do consumo mundial, e ao redor de $70 \%$ do consumo brasileiro de fibras téxteis.

A cultura do algodoeiro no Brasil teve início com os primeiros colonos portugueses que aqui aportaram. Atualmente (safra 1994/95), ocupa cerca de $1.200 \mathrm{mil}$ hectares distribuídos em pelo menos dezessete Estados brasileiros sob as mais variadas condições de ambiente. Dessa área, resulta uma produção anual ao redor de $1.400 \mathrm{mil}$ toneladas de algodão em caroço ou $480 \mathrm{mil}$ toneladas de pluma, insuficiente para atender à demanda interna atual de $780 \mathrm{mil}$ toneladas de pluma. Essa produção é predominantemente dependente do algodoeiro de ciclo anual Gossypium hirsutum L. var. latifolium Hutch., o qual concentra-se na região Meridional, responsável por cerca de $90 \%$ da produção nacional (FERREIRA， 1994). 
O êxito da economia algodoeira, em qualquer parte, depende diretamente do equilíbrio de atendimento dos interesses dos três segmentos básicos que igualmente sustentam esse setor agroindustrial . Tais segmentos, a saber, a cotonicultura, a indústria do beneficiamento e a indústria da manufatura, demandam interesses específicos e não raro conflitantes. Esse atendimento requer esforços simultâneos para aumento da produção e do rendimento em fibra e no aprimoramento da qualidade desta. Isso implica conseguir em um cultivar a melhoria simultânea de no mínimo 20 características, entre agronômicas e tecnológicas da fibra e do fio, as quais, no geral, se correlacionam negativamente. Entretanto, apenas o potencial genético não assegura o êxito da cultura, dependendo-se para isso da ação combinada de fatores genéticos e de fatores controláveis e incontroláveis do ambiente (FUZATTO, 1987).

A dependência e as conseqüências resultantes desses fatores tem acirrado a concorrência com as fibras sintéticas, as quais garantem uma previsibilidade da oferta e de padrões e uniformidade das características requeridas pelo segmento industrial, em função dos novos processos e tecnologias de fiação. Consequentemente, essa conjuntura tem concorrido para que 0 conceito sobre a qualidade da fibra do algodão sofra modificações e, principalmente, para que aumentem as exigências quanto à padronização dessa matéria prima.

Em nosso meio, o estudo desse problema deve considerar a ampla distribuição geográfica da cultura do algodoeiro anual no Brasil, compreendendo as regiões Meridional (sul do Estado 
da Bahia ao norte do Estado do Paraná) e Setentrional (Estados no nordeste inclusive o Estado do Pará) do país. Como essas regiões apresentam diferenças pronunciadas de ambiente e ainda fatores específicos dentro de cada região, tais como o tipo e fertilidade do solo, condições climáticas e meteorológicas, nível tecnológico e de utilização de insumos, pragas, doenças e nematóides, dentre outros, é oportuno verificar e quantificar as influências de conjuntos desses fatores sobre a produtividade do algodoeiro e a qualidade da fibra produzida. A partir disso pode-se verificar se apenas a utilização de cultivares adequados para a solução dos problemas, tendo em vista o processo evolutivo dos segmentos envolvidos na cadeia téxtil, atende também uma das necessidades mais importantes da cotonicultura moderna que consiste na estabilidade da produção e na uniformidade do algodão produzido.

Neste trabalho procurou-se verificar e quantificar o efeito do ambiente - definido como o conjunto de condições e fatores adversos ou favoráveis, presentes no local de cultivo - e de quatro cultivares utilizados na cotonicultura brasileira, sobre os componentes da produção e nas propriedades da fibra do algodoeiro. Buscou-se, também, averiguar a existência de interação entre genótipos e ambientes, e, em caso afirmativo, a possibilidade de contar com cultivares mais estáveis e/ou mais adaptáveis a determinados ambientes, considerando as características agronômicas e tecnológicas da fibra e do fio estudadas. 


\section{REVISÃO DE LITERATURA}

o hábito indeterminado de crescimento do algodoeiro torna-o morfológicamente complexo, uma vez que os desenvolvimentos vegetativo e reprodutivo ocorrem simultaneamente (MAUNEY, 1984). Desse modo, é considerável o efeito que o ambiente exerce não só sobre o crescimento vegetativo dessa planta como também nos componentes da produção e na qualidade da fibra. No tocante aos componentes da produção, 80 - 90\% dos frutos originam-se de flores abertas no primeiro mês de florescimento. Vários fatores ambientes influem positiva ou negativamente na viabilização das flores e dos frutos (maçãs), desde 23 dias antes da antese e por um período que se completa em 50 dias (GRIDI-PAPP, 1965). Nesse período ocorrem também o processo de formação e desenvolvimento da fibra, que compreende as fases de alongamento (da fibra) e deposição de celulose as quais ocorrem predominantemente a partir de 15 até 55 dias após a antese (BENEDICT, 1984). Segundo SHUBERT et alii (1973) embora as fases de alongamento e deposição de celulose ocorram simultaneamente, em um determinado momento existe uma interface entre elas. De qualquer 
maneira, deve-se considerar que todo esse processo biológico se dá sob considerável e decisiva influência do ambiente.

A revisão que se segue foi dividida em duas partes: a) efeito de variações previsíveis e imprevisíveis do ambiente e do cultivar nos componentes da produção e nas características tecnológicas da fibra, enfocando neste ítem, principalmente as condições edafoclimáticas, práticas agrícolas inadequadas, condições nutricionais e incidências de pragas e moléstias; b) possíveis interações genótipos $\mathrm{x}$ ambientes para estas características, assim como correlações entre elas.

\section{1 - Influências do ambiente e de cultivares}

\subsubsection{Fatores edafoclimáticos}

Encontram-se na literatura, diversos estudos, normalmente conduzidos em condições artificiais, que demonstram o efeito de fatores de natureza climática nos componentes da produção e nas características da fibra. Entre esses estudos, GIPSON \& JOHAM (1968a e 1968b) trabalhando com diferentes cultivares de algodão "Upland" verificaram que a temperatura exerceu uma marcante influência na velocidade de crescimento das maçãs e nas propriedades da fibra. Constataram que a diminuição da temperatura noturna reduzia a elaboração de celulose, conseqüentemente resultando fibras imperfeitas. O índice Micronaire foi o mais afetado negativamente e os maiores comprimentos da fibra foram observados nas temperaturas intermediárias. Cabe ressaltar também 
que os cultivares foram influenciados diferentemente quanto aos efeitos das variações de temperaturas nas características de fibra. HESKETH \& LOW (1968) estudaram, durante o período de desenvolvimento das maçãs, o efeito da temperatura (dia/noite) nos componentes da produção e qualidade da fibra em diferentes cultivares e verificaram que em temperaturas mais baixas, o peso das sementes e a porcentagem de fibra apresentaram valores mais altos, enquanto decrescia o índice Micronaire. O comprimento da fibra apresentou uma queda linear com os aumentos das temperaturas e a resistência da fibra aumentou com a elevação das temperaturas diurnas e noturnas, atingindo valores tão altos quanto aqueles normalmente observados em G. barbadense. EVENSON (1969) trabalhando em condições de campo, verificou uma forte correlação $(r=0,713)$ entre o declínio da temperatura média do ar durante o período de desenvolvimento das maçãs (antese até abertura do fruto) e o declínio dos valores do índice Micronaire.

GIPSON \& RAY (1969) verificaram que temperaturas noturnas abaixo de $20^{\circ} \mathrm{C}$ reduziram o comprimento da fibra e essa redução foi mais acentuada em cultivares de fibras mais longas.

QUISENBERRY \& GIPSON (1974) observaram que sob condições de baixas temperaturas noturnas durante o período de florescimento e da maturação das maçãs, a qualidade das sementes (peso e porcentagem de germinação) foi prejudicada. Além disso, quando semeadas em condições de campo resultaram em emergência mais lenta e as plantas que se originaram tiveram um menor crescimento e mostraram-se menos produtivas. 
TONDEUR et alii (1989) trabalhando com um cultivar em condições controladas, testaram seis combinações diferentes entre temperatura e fotoperíodo e verificaram que a porcentagem de fibra aumentou com a elevação da temperatura noturna sob um fotoperíodo de 14-10 horas. Observaram também que a parede primária das fibras pareceu ter sido mais afetada pelas condições térmicas e fotoperíodo, enquanto que a parede secundária e as demais características da fibra tiveram pequenas variações.

HAN (1991) estudando fatores climáticos em diferentes regiões algodoeiras, verificou que a resistência da fibra aumentou com o aumento da temperatura mínima diária. Observou também que temperatura e fotoperíodo afetaram a maturidade e a finura enquanto que temperatura e suprimento de água afetaram o comprimento da fibra.

ABRAHÃO (1979) estudou a variação da quantidade de energia solar incidente em dois momentos diferentes da fase reprodutiva (início e pleno florescimento) do cultivar IAC 17 e verificou que a menor quantidade de energia solar incidente (tratamento com cobertura) provocou entre outras conseqüências, menor produção de algodão em caroço e em pluma e reduções significativas nos caracteres agronômicos de laboratório (peso de fibras, peso de sementes, número de sementes, porcentagem de fibras, índices de fibras e peso de capulhol e nas características tecnológicas das fibras, com especial ênfase para maturidade. A redução da energia solar incidente mostrou-se mais prejudicial à cultura a partir do início do que a partir de pleno florescimento. 
Estes resultados foram obtidos em comparação com as condições a céu aberto.

$$
\text { CABANGBANG \& MANGUIAT (1989) avaliaram as }
$$

condições de ambiente: baixa precipitação e alta radiação solar e alta precipitação e baixa radiação solar. Os autores verificaram que a produção e os seus componentes foram mais afetados pelo o número de dias chuvosos, do que pela quantidade de chuva ou pelo nível da radiação solar. Verificaram também que sob alta precipitação e baixa radiação solar, o número de maçãs foi maior porém com menor peso. Por outro lado, sob baixa precipitação e alta radiação solar, a média total de produção foi maior. o número de dias chuvosos correlacionou negativamente com peso de capulho e produção enquanto que longos períodos de chuva fizeram decrescer a produção, principalmente quando ocorreram nos últimos dois mesès antes da colheita.

\subsubsection{Práticas agrícolas}

BILBRO \& RAY (1973) estudando a época de semeadura durante cinco anos, para três cultivares, observaram que quando a época foi retardada, houve redução na porcentagem, no índice Micronaire e no comprimento da fibra. Por outro lado, a resistência aumentou e a elongação da fibra manteve-se inalterada. Segundo os autores, os prejuízos verificados eram esperados uma vez que os períodos de frutificação e maturação ocorreram sob baixas temperaturas. 
GUTKNECHT (1984) comparando respectivamente dados observados em vários países africanos, sobre os efeitos da época tardia de semeadura e a época normal para dois cultivares apresentou os seguintes resultados: para porcentagem da fibra: cultivar BJA, 33,5 e $36,8 \%$ e HG9, 34,5 e 37,2\%. Observou também que a semeadura em época tardia causou efeito depressivo na porcentagem de fibras. Entretanto, nas qualidades tecnológicas da fibra, proporcionou ganho de $0,3 \%$ no comprimento, $0,75 \mathrm{~g} / \mathrm{Tex} \mathrm{na}$ resistência, e diminuições de $0,5 \%$ na uniformidade de comprimento e $0,4 \%$ no índice Micronaire.

FUZATTO (1987) compara também o efeito prejudicial da época tardia de semeadura em face da época correta, em um cultivar no Brasil e apresenta os seguintes dados para as características de fibra: comprimento, 26,6 e 27,3 mm; uniformidade de comprimento, 45,1 e 46,3\%; Índice Micronaire, 4,1 e 4,5 e maturidade, 55,0 e $60,0 \%$, respectivamente.

ABDALLA et alii (1989) estudando diferentes épocas e modalidades de semeadura tais como espaçamentos e densidade de plantas na linha, verificou que o atraso na semeadura e o maior número de plantas na linha prejudicaram o índice Micronaire, o índice de sementes e aumentou a porcentagem de fibra.

$$
\text { EL-ZIK et alii (1990) trabalhando no Texas, EUÁ, }
$$

estudaram a antecipação da época de semeadura para diversos cultivares e verificaram os seguintes efeitos da semeadura na época correta sobre as características da fibra: comprimento, + 0,05 pol; resistência, + $1,8 \mathrm{~g} / \mathrm{Tex}$; Índice Micronaire, - 0,41; uniformidade de comprimento, $+0,7 \%$ e elongação, $+0,2 \%$. 
SILVA et alii (1984) estudaram os efeitos de três densidades de semeadura $(57.000,80.000$ e 133.000 plantas/ha) e três níveis de umidade $(25 \%, 50 \%$ e $75 \%$ da água do solo consumida pelas plantas) em tres cultivares (CNPA 2H, BR1 e CNPA 76-6873) e verificaram que no nível mais baixo de umidade, o peso médio do capulho aumentou e a resistência da fibra diminuiu. No nível intermediário de umidade a uniformidade do comprimento diminuiu e o Índice Micronaire aumentou. Comparando as densidades de plantio, observaram que o peso médio do capulho aumentou na menor densidade. TELLYAEV \& YAKUBOV (1991) estudaram os efeitos da freqüência e da profundidade do cultivo entre as linhas de plantas no nível de infecção de murcha de Verticillium dahliae Kleb. com reflexos nas características de fibra. Verificaram que tanto o nível de infecção quanto a qualidade da fibra dependem dessas práticas de cultivo. A infecção foi menor $(19,8 \%)$ com 5 cultivos na profundidade de 5-6 cm e maior $(52,3 \%)$ com 8 cultivos na faixa de profundidade de 10-12 a 18-20 cm. Inversamente, a qualidade da fibra melhora com a redução da infecção pelo patógeno. A porcentagem de fibra foi semelhante nos diferentes tratamentos.

CANUTO (1978) estudou diferentes épocas de colheita para o cultivar IAC 13-1 conduzido sob irrigação no nordeste brasileiro e verificou que o atraso na colheita beneficiou o peso médio do capulho é o teor de óleo da semente, aumentou o índice Micronaire e reduziu a porcentagem, o comprimento e a resistência da fibra. 
FUZATTO (1987) observou que o atraso na colheita em comparação com a colheita em época normal prejudicou as seguintes características da fibra: comprimento 26,7 e 27,8 mm; uniformidade de comprimento 42,8 e 45,0\% índice Micronaire 3,7 e 4,3, maturidade 47,0 e 54,0\% e resistência 20,6 e 21,4 g/Tex.

Estudando os efeitos de fitorreguladores de crescimento, FERRAZ et alii (1977) verificaram redução na porcentagem de fibra pelo uso de cloreto de clorocolina e CARVALHO et alii (1986) verificaram que o cloreto de chlormequat reduziu essa mesma característica em $0,6 \%$ comparado com a testemunha. GUTKNECHT (1984) observou também que aplicações de inseticida podem alterar a porcentagem de fibra. Comparando com plantas sem produtos químicos, verificou que pulverizações semanais com organo-fosforado e piretróide aumentaram em 0,3 e $0,7 \%$ respectivamente essa característica.

EL-SABBAGH et alii (1989) estudaram alguns produtos utilizados no controle de Helicoverpa zea (Bod.) e os efeitos na qualidade da fibra e do fio em cinco cultivares (um egípcio e 4 americanos). Verificaram que $\circ$ número médio de convoluções/mm e reversões/mm foram aumentados com o uso de DC702FL e Deenate FL respectivamente, quando comparados com o controle. Diferenças entre cultivares $e$ interações entre cultivar $\mathbf{x}$ tratamento foram significativas para ambos os parâmetros. Todos os produtos reduziram a resistência e a elongação do fio sendo que o Curacron 720EC mostrou o maior efeito. As interações entre cultivares $\mathrm{x}$ tratamentos para resistência e elongação do fio foram altamente significativas. 


\subsubsection{Fatores nutricionais}

Segundo FUZATTO et alii (1965), os efeitos provocados pelo uso de fertilizantes nos componentes da produção e nas características da fibra, via de regra só apresentam significância estatística quando os testes são efetuados em condições de grande deficiência em elementos nutritivos.

SILVA et alii (1971) trabalhando com ensaios de adubação em solos altamente deficientes em potássio, observaram para as características agronômicas e tecnológicas da fibra, entre os tratamentos não adubados e adubados, os seguintes valores: peso de capulho 5,43 a $6,23 \mathrm{~g}$; peso de cem sementes 9,93 a 10,90g; índice de fibra 7,22 a 7,93; Índice Micronaire 4,25 a 4,57; comprimento 25,82 a $26,23 \mathrm{~mm}$ e uniformidade de comprimento 42,4 a $43,3 \%$, respectivamente.

SABINO et alii (1976a) estudaram os efeitos de nitrogênio e potássio na qualidade da fibra em solos de alta, média e baixa resposta das plantas à adubação potássica e verificaram que os efeitos da adubação nitrogenada foram significativos para o comprimento e uniformidade de comprimento nos solos de média resposta e para resistência das fibras nos solos de baixa reposta. Para a adubação potássica observaram que nos solos de alta resposta ocorreu aumento na maturidade, finura e uniformidade de comprimento e nos solos de média resposta esse elemento concorreu para aumentar a finura e a uniformidade de comprimento.

FUZATTO (1987) apresenta dados médios observados em experimentos de adubação conduzidos no Instituto Agronômico, 
destacando os efeitos da presença e ausência de elementos no solo, para as características da fibra. Na presença de fósforo o comprimento atingiu $27,2 \mathrm{~mm}$ e na ausência $25,5 \mathrm{~mm}$. Na presença e ausência de potássio, foram obtidos os seguintes resultados: comprimento "span 2,5\%", 26,3 e $26,3 \mathrm{~mm}$; comprimento "span 50\%", 12,0 e 10,9 mm; uniformidade de comprimento 45,8 e 41,6\%; índice Micronaire 4,5 e 3,4 e maturidade 60,7 e 47,3\%, respectivamente.

SABINO et alii (1991) avaliando especificamente o efeito da adubação fosfatada (superfosfato simples) nas características agronômicas e tecnológicas da fibra, em diferentes cultivares, verificaram que o fósforo concorreu para aumentar o peso de capulho, o peso de cem sementes e a tenacidade da fibra, independentemente do cultivar utilizado.

Com referência à adubação boratada CARVALHO (1988) observou acréscimo médio de $3 \%$ sobre o peso de capulho e diminuição de $3 \%$ no peso de cem sementes. Com relação à qualidade da fibra, foi observado acréscimo de $2 \%$ no comprimento. Para o mesmo elemento, SILVA et alii (1982) verificaram que a maturidade da fibra decresceu em até $8 \%$

SABINO et alii (1994a) estudaram o efeito da adubação nitrogenada sobre as principais características agronômicas e tecnológicas da fibra em solos de alta, média e baixa resposta esperada das plantas à essa adubação e concluíram o seguinte: Em solos continuamente adubados, onde a reação da planta a nitrogênio é alta em termos de produtividade, os efeitos benéficos da adubação podem se estender às características do capulho (peso de capulho e de sementes) e às propriedades 
tecnológicas (comprimento, uniformidàde de comprimento, maturidade, índice Micronaire e resistência).

SABINO et alii (1994b) estudaram durante 10 anos - efeito da calagem em duas fases de aplicação sobre as características agronômicas e tecnológicas da fibra do cultivar IAC 18, em solo ácido e pobre em potássio. Foi verificado que nos primeiros cinco anos o calcário afet:ou positivamente o peso de um capulho, elevando-o de 5,42 para $6,30 \mathrm{~g}$ e diminuiu o peso das sementes de 12,53 para $12,10 \mathrm{~g}$. Quanto às propriedades tecnológicas da fibra, observaram que a calagem reduziu o comprimento de 27,00 para 26,70 mm, o índice Micronaire de 4,97 para 4,71, a maturidade de 60,49 para 58,25\% e a tenacidade de 22,35 para 21,69 g/Tex. Na segunda fase (últimos cinco anos) dos trabalhos, foi confirmado o efeito positivo do calcário sobre o peso de um capulho de 6,00 para $6,74 \mathrm{~g}$ e no peso de cem sementes de 40,10 para 40,31g. Verificou-se também o efeito depressivo do calcário na porcentagem de fibra de 40,47 para 39,79\%. Com relação às propriedades tecnológicas da fibra, a calagem mostrou-se tão prejudicial quanto na primeira fase. Segundo os autores a ação negativa do calcário é devida a desequilíbrios com relação à adubação potássica .

\subsubsection{Incidência de pragas e molêstias}

FERRAZ et alii (1968) relataram resultados médios de experimentos referentes a efeitos do ataque de pragas na qualidade da fibra. Na média de sete cultivares, observaram-se valores normais de 4,5 para o índice Micronaire e $30 \mathrm{~mm}$ para o 
comprimento da fibra. Para as mesmas características quando na presença de pragas, foram observados os seguintes valores: para broca da raiz 4,1 e 28mm; ácaro rajado 3,9 e 29mm e lagarta rosada 4,0 e 28mm, respectivamente. Da mesma maneira, FUZATTO (1987) compara os prejuízos do ácaro rajado nas características da fibra na média de experimentos considerados normais e aqueles infestados respectivamente: comprimento 27,3 e 25,8mm; Micronaire 4,5 e 4,0, maturidade 55,3 e $45,5 \%$; resistência do fio, 13,8 e 12,6 RKM e elongação do fio 6,6 e 5,7\%. Do mesmo modo para a largata "Curuquerê", Micronaire 4,2 e 3,1 e maturidade 55,3 e 40,5\%.

BUGBEE \& SAPPENFIELD (1970) estudando

comportamento de cultivares com diferentes graus de susceptibilidade à murcha causada por Verticillium albo-atrum RK \& Berth., verificaram que esse patógeno reduziu a produção, o peso do capulho, o índice Micronaire, o comprimento da fibra e a resistência do fio. Considerando esse mesmo patógeno, FUZATTO (1987) Compara os valores observados para o Índice Micronaire 4,7 e 3,8 e a maturidade da fibra 56,4 e 43,2\% em solos normais e solos com o patógeno respectivamente.

CARVALHO \& LIMA (1982) estudaram a influência da ramulose, causada por Colletotrichum gossypii Southw. var. cephalosporioides Costa \& Viegas nos componentes da produção e características da fibra comparando com plantas normais. Verificaram reduções para as seguintes características: peso de capulho de 6,15 para 5,66g; peso de cem sementes de 12,03 para $11,60 \mathrm{~g}$ e índice Micronaire de 5,1 para 4,7. 
FUZATTO (1987) demonstra os prejuízos nas características da fibra verificados em um cultivar cultivado em solo naturalmente infectado com Fusarium oxysporum Schlect. f.sp. vasinfectum (Atk.) Snyd. \& Hans. Comparando fibras oriundas de plantas cultivadas em solos normais e solo infectado; apresenta os seguintes valores para as características: comprimento 27,3 e $25,7 \mathrm{~mm}$; Índice Micronaire 4,5 e 4,0 e maturidade 55,8 e 45,9\%. Da mesma forma, faz referências aos danos causados por nematóides comparando os solos sem nematóides e solo com o parasita: resistência 21,0 e 17,6 g/Tex, maturidade 55,3 e 50,4\%, resistência do fio 13,8 e 11,6 RKM e elongação do fio 6,5 e 5,8\%.

SMITH et alii (1991) avaliaram os efeitos prejudiciais de nematóides nas características da fibra comparando os resultados observados em solos tratados e não tratados com nematicidas. Observaram diferenças no Micronaire, porcentagem de fibras maduras, finura e comprimento entre os tratamentos.

COOK \& NAMKEN (1992) em outro estudo sobre o tratamento de solo para o controle de nematóides observaram uma alta porcentagem de sementes imaturas oriundas das áreas não controladas, resultando conseqüentemente num baixo índice de sementes.

\subsection{Interação genótipo x ambiente e correlações}

MILLER et alii (1959) avaliaram quinze cultivares em nove locais durante três anos na Carolina do Norte, EUA, com o objetivo de estimar as magnitudes relativas a diversos tipos de 
interações cultivar $x$ ambiente nos testes regionais de cultivares. Verificaram que em relação à produção, as interações cultivar $\mathbf{x}$ local e cultivar $x$ ano foram muito pequenas e não significativas estatisticamente. Entretanto, a interação cultivar $\mathrm{x}$ local $\mathrm{x}$ ano foi de substancial magnitude e altamente significativa. Segundo os autores, essa interação de segunda ordem observada indicou que os cultivares comportaram-se diferentemente quando cultivados em diferentes ambientes, mas que não ocorreram efeitos consistentes de local ou de ano na resposta diferencial dos cultivares durante o período dos testes. Na análise individual dos ensaios verificou-se que a distribuição das chuvas e infestações de bicudo foram fatores importantes que determinaram resposta diferencial entre os cultivares. Com relação aos componentes da produção e características tecnológicas da fibra, com exceção para finura, a exemplo do que foi observado para produção, verificou-se uma grande interação de segunda ordem a qual foi maior do que as interações de primeira ordem. Em todos os casos, entretanto, os componentes de interação foram muito pequenos, relativamente, quando comparados com a variação do cultivar. Os autores concluíram que a maior variação dos cultivares encobre os efeitos da interação cultivar, $\mathrm{x}$ ambiente para as características agronômicas e tecnológicas da fibra.

Resultados semelhantes aos anteriores foram observados por MILLER et alii (1962) conduzindo testes regionais de cultivares na Carolina do Norte e no Texas, EUA, e por BRIDGE et. alii (1969) no Delta do Mississippi, EUA. 
ABOU-EL-FITTOUH et alii (1969) analisaram a performance de quatro cultivares em 39 locais no "Cotton Belt" dos EUA, durante dois anos com o objetivo de caracterizar a natureza das interações cultivar $x$ ambiente sob uma gama de fatores ambientes e procuraram identificar algumas das variações do ambiente associadas a essas interações. Conforme os resultados, os componentes de interação foram importantes para a produção, mas relativamente menos importantes para as características agronômicas e tecnológicas da fibra. Com relação às variáveis ambientes estudadas, a temperatura teve a mais alta associação com a interação. Há que se ressaltar que as demais variáveis estudadas tais como: umidade relativa, insetos e doenças, foram comprometidas durante a realização dos trabalhos.

MURRAY \& VERHALEN (1970) estudaram o comportamento de onze cultivares em três locais em Oklahoma, EUA, por um período de 3 anos. Variações significativas para ano foram observadas para o comprimento e resistência da fibra. Entretanto, os autores concluíram que essas variações não devem ser consideradas, uma vez que foram muito pequenas quando comparadas com as variações relativas aos cultivares. Foi observada também uma grande e significativa variação da produção por local. As interações de segunda ordem para produção e índice Micronaire foram também grandes e significativas enquanto que as interações de primeira ordem para essas características foram muito pequenas. Resultados semelhantes foram observados por OMRAN et alii (1983) e por ALABI e ECHEKWU (1989) estudando testes regionais de cultivares na 
Nigéria e por GONZALEZ (1988) trabalhando nas regiões de cultivo de algodão no Paraguai.

BILBRO e RAY (1973) estudaram o efeito de três épocas tardias de semeadura na produção e nas propriedades da fibra durante 5 anos para três cultivares. Verificaram que a produção, a porcentagem de fibra e o índice Micronaire variaram significativamente entre os anos, indicando que estas características são mais influenciadas de ano para ano do que o comprimento, a resistência e a elongação. Observaram também que as interações anos $x$ datas de semeadura foram significativas para todas as características. Na média geral dos testes, as diferenças entre os cultivares foram significativas para todas as características estudadas $e$ as interações cultivares $x$ anos $e$ culotivares $\mathrm{x}$ datas de semeadura não foram significativas.

Em nosso meio foram relatados dados relativos a Ensaios Nacionais para sete cultivares em 29 locais no ano agrícola de 1977/78 (EMBRAPA, 1981) e outros sete cultivares, sendo que, alguns comuns ao ano anterior, em 31 locais no ano de 1978/79 (EMBRAPA, 1982). Os locais escolhidos representam as regiões de cultivo do algodoeiro de ciclo anual no Brasil compreendendo localidades situadas em dez Estados. Os autores verificaram forte interação entre cultivares e regiões, tornando necessária as interpretações dos dados por grandes regiões (Centro-sul, Centro-Leste e Nordeste) e concluíram que parte da interação cultivar x região observada, foi devida à adaptabilidade regional dos genótipos estudados em função das condições locais onde cada um foi selecionado. Verificaram também para as características 
tecnológicas da fibra e do fio produzido, uma tendência para interação com regiões, diminuindo nas regiões Nordeste e Centro-Leste, a diferença entre os cultivares, beneficiando àqueles selecionados na região Centro-sul.

Ainda em nosso meio, foram estudados os dados relativos aos Ensaios Regionais de Cultivares e Linhagens Paulistas referentes a 58 experimentos conduzidos nos anos agrícolas de $1975 / 76$ e 1976/77 nas principais regiões algodoeiras dos Estados de São Paulo, Paraná e Goiás para seis tratamentos comuns aos dois anos (CAMPINAS, 1980). Os autores verificaram que embora tenha havido diferença entre os dois anos considerados, não foram observadas interações no que diz respeito ao comportamento dos cultivares estudados. Analisando os dados no conjunto dos dois anos, verificaram uma interação no comportamento de dois cultivares, com respeito à produção, conforme o nível de produtividade nos experimentos. Nos dois anos seguintes, 1977/78 e 1978/79, GRIDI-PAPP et alii (1985) avaliaram 58 experimentos, e agruparam regionalmente aqueles conduzidos no Estado de São Paulo (Centro-Leste, Norte, Noroeste, Oeste e Sul), para diferentes cultivares e linhagens. Nesse trabalho os autores identificaram uma tendência de interação entre os cultivares e os anos em questão, possivelmente em função de grandes diferenças climáticas ocorridas no período. Verificaram que o cultivar IAC 19 apresentou maior estabilidade da produção com relação aos anos, quando comparado com os demais. Evidências de interação de cultivares com as regiões de cultivo foram observadas e foram atribuidas, em grande parte, à ocorrência de moléstias (murcha de Fusarium, de Verticillium 
ramulose e nematóides) sem descartar entretanto a possível influência das condições edafoclimáticas regionais. Com relação às características agronômicas e às propriedades tecnológicas da fibra e do fio, os autores não verificaram interação dos cultivares com as regiões mencionadas, uma vez que os eventuais destaques, positivos ou negativos para certas características, em certas regiões, foram inconsistentes. Assim sendo, os autores sugerem que principalmente os destaques negativos, parecem ser devidos a fatores circunstanciais locais, compreendendo tanto adversidades climáticas quanto deficiências tecnológicas na condução da cultura. Nos moldes apresentados acima, GRIDI-PAPP et alii (1993) estudaram durante os anos agrícolas de 1979/80 e 1980/81, setenta experimentos agrupados nas mesmas regiões citadas anteriormente, com a inclusão da região algodoeira do Estado de Minas Gerais. Com relação aos cultivares foi acrescentado o IAC 20 aos demais, os quais foram comuns aos dois anos. Na análise dos dados, observaram interações significativas entre cultivares e localidades tanto para produção como para outras características, atribuindo-as à ocorrência de doenças e nematóides em alguns experimentos, aos quais os cultivares reagiram diferentemente. Do mesmo modo que verificado nos ensaios anteriores, os autores atribuem mais a fatores adversos locais a diferença em qualidade da fibra, observada entre regiões de cultivo no Estado de são Paulo, do que propriamente às condições inerentes a essas regiões .

A despeito da importância dos conhecimentos da interação de genótipos com ambientes, estes não proporcionam informações detalhadas sobre o desempenho de cada cultivar frente 
às variações ambientes. Por essa razão, estudos de estabilidade e adaptabilidade, buscando maiores informações para a identificação de genótipos e cultivares de comportamento previsível em diferentes condições ambientes. têm sido considerados (VENCOVSKY \& BARRIGA, 1992), JALALUDDIN \& HARRISON, 1993 e CRUZ e REGAZZI, 1994).

Estudos dessa natureza têm sido feitos com várias espécies como o algodoeiro perene G. hirsutum L. var. marie-galante Hutch., (SOUZA \& HOLANDA, 1993), trigo (CARVALHO et alii, 1983 e JALALUDDIN \& HARRISON, 1993), feijão (DUARTE \& ZIMMERMANN, 1994), milho (SOUZA et alii, 1991 e STORCK \& VENCOVSKY, 1992), cevada (OOSTEROM et alii, 1993), gergelim (FREIRE et alii, 1994), aveia (HELMS, 1993), batata (MALUF et alii, 1983 e SINGH et alii, 1988), arroz (SILVEIRA \& VENCOVSKY, 1982).

Com respeito ao algodoeiro anual, alguns estudos são encontrados na literatura relacionados com a determinação de parâmetros para avaliar a estabilidade da produção em linhagens e cultivares. Por outro lado, não foram encontrados esses estudos no tocante às características tecnológicas da fibra.

KALSY \& SINGH (1974) admitem que o algodoeiro é fortemente influenciado pelos anos e flutuações ambientes e conseqüentemente, para se obter maiores produções e melhor qualidade do produto é necessário que os cultivares recomendados para amplas regiões de cultivo, devam ser bem adaptáveis a diferentes ambientes. Desse modo, os autores testaram seis linhagens de algodoeiro "Upland" durante quatro anos agrícolas e avaliaram a estabilidade da produção pelos métodos de FINLAY \& WILKINSON (1963) e EBERHART \& RUSSElıL (1966). Observaram uma alta 
significância para a interação linhagem $x$ ambiente e pelos cálculos dos parâmetros de estabilidade puderam observar que algumas linhagens produzem bem em condições favoráveis e outras em condições desfavoráveis do ambiente. As duas linhagens mais estáveis ou seja, com os menores desvios de regressão, no entanto, apresentaram valores de produção abaixo da média.

BILBRO \& RAY (1976) estudaram em Oklahoma e no Texas, EUA, a adaptabilidade e estabilidade da produção em diversos cultivares integrantes dos ensaios regionais durante três períodos. Conforme o método de EBERHART \& RUSSELL (1966), o coeficiente de regressão (b) foi usado para medir a adaptabilidade e o coeficiente de determinação $\left(r^{2}\right)$ a estabilidade. Considerando que um cultivar ideal deveria apresentar produção acima da média, ser adaptável a todos os ambientes $(b=1)$ e estável ( $r^{2}$ igual ao da testemunha), observaram que: na análise de todos os ambientes, muitos cultivares mostraram-se adaptados a todos os ambientes e com exceção de um, foram também estáveis. Verificaram ainda que a produção foi o parâmetro mais divergente, seguido da adaptabilidade, sendo a estabilidade 0 menos divergente.

QUIÑNES (1980) avaliou dezesseis cultivares quanto à estabilidade da produção em quatro experimentos e dois anos, em regiões algodoeiras da Venezuela. Para tanto, utilizou a metodologia proposta por EBERHART \& RUSSELL (1966). Pelos resultados observou-se que dois cultivares (Stoneville 7A e Atlas 67) apresentaram altos rendimentos médios e os coeficientes de regressão $(b=1,32$ e $b=1,19)$ significativamente diferentes de 1,0 . Esses coeficientes caracterizaram esses dois cultivares como 
adaptados a ambientes favoráveis. Apresentaram também, pequenos desvios da regressão, os quais indicam uma boa consistência quanto às respostas esperadas. Um outro cultivar teve uma boa produção média, coeficiente de regressão próximo a $1,0 \quad(b=1,08)$ e pequenọ desvios da regressão. Desse modo, foi considerado de boa adaptabilidade geral.

SANTANA et alii (1983) testaram em 20 ambientes no Norte e Nordeste, a estabilidade da produção pelo método citado acima, para nove cultivares originalmente selecionados em diferentes regiões, tais como: IAC 12-2 RB, IAC 13-1, IAC 16, IAC 17 e IAC 18 no Estado de São Paulo, SL 7-1 e SL-8 em Minas Gerais e Allen 333-57 e BR1 no Nordeste. Os dados foram analisados separadamente em dois anos agrícolas. No primeiro ano foram testados os cultivares IAC 13-1, IAC 16, IAC 18, SL-8, Allen 333-57 e BR1 e no segundo, IAC 12-2 RB, IAC 13-1, IAC 17, IAC 18, SL 7-1, Allen 333-57 e BR1. Na análise dos dados dos cultivares comuns aos dois anos observou-se que o cultivar Allen 333-57 apesar de ser o mais produtivo foi também o mais instável, assim como o IAC 13-1. Os cultivares BR1 e IAC 18 revelaram-se os mais estáveis. Analisando os anos separadamente observaram que no primeiro, 0 cultivar SL 7-1 juntamente com os anteriores mostraram-se estáveis porém, instáveis no ano seguinte.

OMRAN et alii (1983) trabalhando na Nigéria, compararam a estabilidade da produção de seis novas linhagens e três cultivares em nove ambientes ( 3 anos e 3 locais). Utilizando a metodologia de EBERHART \& RUSSELL (1966), verificaram que uma linhagem $\left(\bar{x}=0,57, b=1,00, S^{2}=0,02 \Leftrightarrow R^{2}=0,90\right)$ produziu tanto quanto 
a testemunha $\left(\bar{x}=0,57, b=0,93, S^{2}=0,02\right.$ e $\left.R^{2}=0,89\right)$ porém, foi mais estável. Outra linhagem $\left(\bar{x}=0,60, b=1,07, \quad S^{2}=0,03\right.$ e $\left.R^{2}=0,89\right)$ apresentou a maior produção e estabilidade nos ambientes favoráveis. Resultados semelhantes foram obtidos por GONZALEZ (1988) estudando diferentes cultivares no Paraguai, NIZAMA et alii (1988), RAO et alii (1989) e CHAHAL et alii (1990) na India.

FUZATTO et alii (1993) avaliaram em face da ocorrência de doenças e nematóides, a estabilidade da produção dos cultivares IAC 20 e Deltapine Acala 90, e das linhagens IAC 19-809 e IAC 89/96. Estudaram treze experimentos conduzidos nos Estados de São Paulo e Goiás. Em quatro desses experimentos as condições foram normais e favoráveis a altas produtividades e nos outros nove verificaram ocorrência de um ou mais dos seguintes parasitismos: murcha de Fusarium, nematóides, Ramulose e Viroses (mosaicos). A produtividade média dos ambientes variou de 1420 a $3700 \mathrm{Kg} / \mathrm{ha}$. O cultivar Deltapine Acala 90 mostrou-se o menos estável (menor média, maior coeficiente de regressão, o único estatisticamente diferente de 1,0 e os maiores desvios da regressão). Os demais genótipos tiveram, em relação à produtividade sem doenças, perdas, em média, de $29,6 \%$ enquanto o prejuízo verificado na Deltapine Acala 90 foi de 53,7\%.

Com respeito a correlações MILLER et alii (1958) relataram as observadas entre produção, componentes desta e algumas propriedades tecnológicas da fibra em três populações de linhagens de algodoeiro. Verificaram que a produção de fibras em todas as populações correlacionou positivamente com a porcentagem de fibra e $\circ$ número de capulhos/planta e negativamente com o índice de 
semente, peso de capulho, comprimento, resistência e finura da fibra.

SABINO et alii (1976b) estudaram as correlações entre a maturidade da fibra e outros caracteres agronômicos e tecnológicos da fibra e do fio, em cultivares paulistas e dois anos agrícolas e verificaram que o índice de maturidade correlacionou significativamente com a produção e com todas as demais características, com exceção da resistência do fio e da fibra. Observaram também grandes variações nos valores dos coeficientes de correlação, aparentemente aleatórios, tanto de ano para ano, considerando determinados cultivares, quanto de cultivar para cultivar dentro de um mesmo ano. O ano de condições piores para o algodoeiro conferiu valores mais altos aos coeficientes de correlação.

TURNER et alii (1976) estudando a interação entre local $x$ cultivar verificaram que os dois cultivares avaliados mostraram alta correlação positiva entre produção e resistência da fibra, o que os autores julgaram inesperado. A possível explicação para tal fato foi atribuída aos cultivares estudados, sendo um deles o cultivar Acala 1517-70, os quais são mais sensíveis às influências do ambiente do que outros cultivares. De fato, MILLER et alii (1958) citados anteriormente e CHENG e ZHAO (1991) observaram correlação negativa entre produção e resistência da Eibra.

DIMITROVA \& BOZHINOV (1988) estudaram a variabilidade das propriedades da fibra de três cultivares durante 5 anos em condições de irrigação e observaram que as 
características de fibra variaram nos diferentes anos e que o cultivar foi o maior fator de variabilidade. Com o aumento da irrigação, aumentou também o comprimento e decresceu a porcentagem da fibra. Embora a produção e as características da fibra tenham variado sob as diferentes condições ambientes, não correlacionaram negativamente entre si.

TOMAR e SINGH (1991) estudaram a correlação entre algumas características da planta em 83 genótipos em três ambientes e verificaram que a produção de algodão em caroço mostrou correlação positiva significativa com o número de capulhos, índice de sementes, porcentagem de fibra e índice de fibra em todos os locais.

LAZZARINI (1970) estudou as inter-relações das características tecnológicas da fibra e outras propriedades agronômicas com a produção e as características do fio obtido para 57 linhagens e cultivares paulistas de algodoeiro. O autor verificou que as variações da produção de algodão estiveram associadas às variações do comprimento da fibra, e também com as interações comprimento $x$ peso de capulho e comprimento $x$ Micronaire. Observou também que genótipos de alta produção e capulhos pesados apresentaram fibras mais curtas do que aqueles de alta produção, porém com capulhos mais leves. Com relação ao reflexo das características da fibra na performance do fio, observou que aumentando a resistência e/ou o comprimento houve aumento na resistência do fio. Esse aumento foi maior em algodões de Micronaire mais baixo. 


\section{MATERIAL E MÉTODO}

\subsection{Experimentos básicos}

Foram utilizados os dados gerados pela rede de Ensaios Nacionais de Cultivares de Algodoeiro de ciclo anual, conduzidos nas principais regiões algodoeiras (Meridional e Setentrional) do Brasil. Os experimentos considerados foram realizados em localidades situadas em 9 Estados e 33 Municípios, nos anos agrícolas de 1987/88 a 1989/90, perfazendo um total de 40 ambientes (tabela 1 ). Do total de ensaios conduzidos nos três anos agrícolas, foram aproveitados aqueles mais representativos dentro de cada região, procurando-se maior diversidade possível de ambientes. Algumas ocorrências foram identificadas nesses experimentos conforme relacionadas na tabela 2 .

Originalmente, os ensaios foram delineados em quadrado latino $7 \times 7$, entretanto, apenas quatro cultivares foram selecionados para os estudos. Os demais foram excluídos pela não coincidência em todos os anos ou pela similaridade quanto à origem e características agronômicas e tecnológicas da fibra.

As parcelas experimentais foram constituídas por quatro linhas de $5 \mathrm{~m}$ de comprimento, considerando-se úteis apenas as 
Tabela 1. Identificação dos ambientes, localidade de instalação dos experimentos selecionados e número de experimentos por ano.

Número Localidade
do
Ambiente

UF

Número de Ensaios

iente

$1987 / 88 \quad 1988 / 89 \quad 1989 / 90$

\begin{tabular}{|c|c|c|c|c|c|}
\hline 1 & Campinas & Sp & 1 & - & - \\
\hline 2 & Tietê & Sp? & 1 & - & - \\
\hline 3 & Tatuí & SP & 1 & - & - \\
\hline 4 & Mococa & $S P$ & 1 & - & - \\
\hline 5 & Votuporanga & SP? & 1 & - & - \\
\hline 6 & Pindorama & $S ?$ & 1 & - & - \\
\hline 7 & Tietê & $S P$ & - & 1 & - \\
\hline 8 & Ribeirão Preto & sp? & - & 1 & - \\
\hline 9 & Adamantina & $\mathrm{SP}$ & - & 1 & - \\
\hline 10 & Assis & $S P$ & - & 1 & - \\
\hline 11 & Ilha solteira & $S P$ & - & 1 & - \\
\hline 12 & Ituverava & $S P$ & - & 1 & - \\
\hline 13 & Tatuí & SP & - & - & 1 \\
\hline 14 & Ribeirão Preto & $S P$ & - & - & 1 \\
\hline 15 & Votuporanga & $S P$ & - & - & 1 \\
\hline 16 & Guaíra & $S P$ & - & - & 1 \\
\hline 17 & Jaú & SP & - & - & 1 \\
\hline 18 & Taciba & $S P$ & - & - & 1 \\
\hline 19 & Sta.Terezinha Itaipú & $\mathrm{PlR}$ & 1 & - & - \\
\hline 20 & Londrina & $\mathrm{PR}$ & - & 1 & - \\
\hline 21 & Cambará & PR & - & 1 & -. \\
\hline 22 & Campo Mourão & PR & - & - & 1 \\
\hline 23 & Naviraí & MS & 1 & - & - \\
\hline 24 & Ponta Porã & MS & 1 & - & - \\
\hline 25 & Ponta Porã & MS & - & 1 & - \\
\hline 26 & Edéia & GO & 1 & - & - \\
\hline 27 & Edéia & Go & - & - & 1 \\
\hline 28 & Campo Alegre de Goiás & GO & - & - & 1 \\
\hline 29 & Capinópolis & $\mathrm{MO}$ & 1 & - & - \\
\hline 30 & Porteirinha & MS & - & 1 & - \\
\hline 31 & Gorotuba & $M(3$ & - & - & 1 \\
\hline 32 & S.J. dos Quatro Marcos & $\mathrm{M}^{\prime} \mathrm{T}$ & 1 & - & - \\
\hline 33 & Diamantina & $\mathrm{M}^{\prime} \mathrm{T}$ & 1 & - & - \\
\hline 34 & Caruarú & $\mathrm{PE}$ & 1 & - & - \\
\hline 35 & Itaporanga & PE & 1 & - & - \\
\hline 36 & Surubim & $\mathrm{PE}$ & 1 & - & - \\
\hline 37 & Souza & $\mathrm{PB}$ & - & 1 & - \\
\hline 38 & Catolé do Rocha & $\mathrm{PB}$ & - & 1 & - \\
\hline 39 & Terra Seca & $\mathrm{RN}$ & - & 1 & - \\
\hline 40 & Catolé do Rocha & $\mathrm{PB}$ & - & - & 1 \\
\hline
\end{tabular}


Tabela 2. Ocorrências identificadas nos quarenta ambientes selecionados.

1

Nematóides, Bicudo

Alternária, Bicudo, chuvas na colheita, toxidez de omite Nematóides, Alternaria, Mancha angular

Alternaria, viroses (mosaicos)

Nada consta

Ácaro branco, viroses (mosaic:os)

Nematóides, Alternaria

Alternaria, Mancha angular, viroses (mosaicos)

Nada consta

Nada consta

Nada consta

Mancha angular, Alternaria, Nematóides, murcha de Fusarium Nematóides

Precipitação pluvial acima da média durante o ciclo.

Ácaro branco

Bicudo e ácaros

Nada consta

Mancha angular

Mancha angular, Alternaria, temperaturas altas

Nada consta

Mancha angular

Nada consta

Nada consta

Irrigação

Nada consta

Nada consta

Ramulose, Mancha angular

Encharcamento do solo

Nada consta

Nada consta

Nada consta

Nada consta

Nada consta

Baixa precipitação pluvial

Baixa precipitação pluvial

Baixa precipitação pluvial

Baixa precipitação pluvial

Baixa precipitação pluvial

Baixa precipitação pluvial

Baixa precipitação pluvial 
duas linhas centrais. Duas linhas marginais externas foram semeadas em cada lado e em toda a extensão do ensaio.

O espaçamento padrão foi de $1 \mathrm{~m}$ entre linhas. Dentro das linhas o espaçamento médio entre as plantas variou de 15 a $20 \mathrm{~cm}$, como resultado da uniformização do número de plantas, promovida por ocasião do desbaste.

A adubação padrão no plantio foi de 10-60-80kg/ha de N, P205 e K20 respectivamente, no caso de solos Latossolo Roxo e de 10-60-40 nos solos arenosos e em outros argilosos que não o mencionado. Em cobertura, cerca de 30 dias após a emergência, foram aplicados em ambos os casos $20 \mathrm{~kg} / \mathrm{ha}$ de $\mathrm{N}$. Todavia algumas modificações ocorreram nas adubações de alguns ensaios dependendo das análises químicas do solo e das recomendações específicas adotadas nas diversas regiões.

As épocas de semeadura variaram conforme as regiões. Nos Estados de Goiás, Mato Grosso do Sul, Minas Gerais, Paraná e São Paulo, os experimentos foram instalados no período de 7/10 a 28/11, com exceção dos ensaios de Gorotuba, MG, que foi semeado em 28/12 e o de Ilha Solteira, SP, em 04/01. Os dois experimentos no Estado de Mato Grosso foram semeados em 02/12 e 21/01. Nos ensaios do Nordeste, o período foi de 23/02 a 18/05.

$\mathrm{Na}$ semeadura foi utilizado sempre um excesso de sementes, realizando-se em torno de trinta dias após a germinação, um desbaste com o objetivo de deixar 30 plantas em cada linha das parcelas experimentais. Os tratos culturais e a aplicação de defensivos variaram conforme o ensaio, mas situaram-se em nível. equivalente ao das lavouras bem conduzidas das respectivas regiões. 
Com exceção do ensaio irrigado instalado em Ponta Porã, MS, no ano agrícola de 1987/88, os demais foram conduzidos em condições naturais de suprimento hídrico.

\subsection{Cultivares}

Foram utilizados para os estudos quatro cultivares, comuns a todos os locais e anos considerados: IAC 19, IAC 20, CNPA Precoce 1 e CNPA Acala 1.

O cultivar IAC 19 foi desenvolvido no Instituto Agronômico de Campinas-IAC e originou-se por seleção, da hibridação var. yucatanense Hutch. $x$ TNI-HOA x IAC RM3, na espécie Gossypium hirsutum L. Esse cultivar destaca-se pela produtividade, resistência à murcha de Fusarium e nematóides e pela qualidade da fibra e do fio (GRIDI-PAPP et alii, 1991). Lançado em 1980 permaneceu em cultivo até 1990, quando foi retirado das lavouras em virtude do advento do bicudo do algodoeiro Anthonomus grandis Boheman, por apresentar porte mais elevado e período de frutificação relativamente mais longo que os cultivares IAC 17 e IAC 20 .

O cultivar IAC 20 também desenvolvido pelo IAC, resultou de seleção no cultivar IAC 17 o qual foi selecionado no cultivar IAC RM3, descendente do cultivar norte americano Auburn 56. Destaca-se pela produtividade, ciclo mais determinado com relação ao cultivar anterior e pela resistência à murcha de Fusarium e nematóides (CIA et alii 1993). Lançado em 1983, 
atualmente é cultivado em mais de $80 \%$ da área de algodão na Região Meridional que representa $90 \%$ da cotonicultura brasileira.

Esses dois cultivares IAC apresentam também tolerância ou resistência média a outras doenças presentes em nosso meio, como mancha angular, murcha de Verticillium e ramulose.

O cultivar CNPA Precoce 1 foi desenvolvido pelo Centro Nacional de Pesquisa do Algodão - CNPA/EMBRAPA e lançado em 1985/86. Esse cultivar é resultado da aclimatação às condições do Nordeste brasileiro da linhagem norte-americana GH 11-9-75, derivada da linhagem TANCOT SP-37. Destaca-se pelo crescimento determinado e rápida frutificação (LUKEFAHR et alii, 1988) e apresenta baixo desempenho frente às principais doenças e nematóides do algodoeiro (CIA et alii, 1993).

O cultivar CNPA Acala 1 também desenvolvido pelo CNPA/EMBRAPA é um composto formado pela mistura de dez linhagens originadas a partir da seleção com testes de progênies em uma população do cultivar Acala del Cerro. Esse cultivar destaca-se pelas qualidades de fibra, principalmente o comprimento e resistência, sendo considerado de fibras longas (BARREIRO NETO et alii, 1986). Por outro lado, destaca-se também pela menor capacidade de produção relativa e pela maior susceptibilidade às principais doenças e nematóides do algodoeiro (CIA et alii, 1988). Os cultivares acima descritos foram escolhidos devido às diferentes origens, às diferenças marcantes quanto às características agronômicas e tecnológicas da fibra e às diferenças de comportamento face a doenças e nematóides. 


\subsection{Características estudadas}

Os estudos de laboratório foram realizados pela Seção de Algodão e Seção de Tecnologia de Fibras do Instituto Agronômico de Campinas, em amostras de 40 capulhos, colhidos no terço médio das plantas em cada parcela experimental.

O estudo completo os ensaios levou em consideração as seguintes características, determinadas em cada parcela experimental:

a) Produção: peso, em quilogramas, de algodão em caroço produzido nas linhas úteis de cada parcela experimental;

b) Peso de Capulho: peso médio, em gramas, do algodão em caroço de 1 capulho, determinado a partir do peso total da amostra estudada;

C) Peso das Sementes: peso em gramas, de 100 sementes, revelado em uma determinação feita na amostra;

d) Porcentagem de Fibra: peso relativo da fibra obtida após o beneficiamento das amostras, determinado por diferença, a partir do peso das sementes, e expresso em porcentagem;

e) Comprimento da fibra: valor médio, em milímetros, do comprimento "span 2,5\%", determinado no Fibrógrafo Mod. 430, e obtido a partir de cinco determinações feitas em cada amostra; 
f) Uniformidade: valor médio, expresso em porcentagem, da uniformidade do comprimento das fibras, baseado na relação dos valores de comprimento "span 50\%" e "span 2,5\%", fornecidos pelo Fibrógrafo Mod. 430. E obtido a partir de cinco determinações feitas em cada amostra;

g) Micronalre: Índice determinado no aparelho de nome Fibronaire, e que representa a finura da fibra, quando são iguais as condições de maturidade. Em nosso meio representa mais comumente - complexo finura + maturidade, quando ambas as propriedades variam. É obtido mediante duas determinações em cada amostra;

h) Tenacldade: índice médio referente à resistência à tração de uma mecha de fibras, expresso em g/Tex, determinado com espaçamento de $1 / 8$ de polegada entre as pinças do aparelho denominado Pressley. É obtido mediante quatro determinações em cada amostra;

i) Maturidade: valor médio referente à porcentagem de fibras maduras, determinado no Fibrógrafo mod. 430, conforme 0 método proposto por SABINO et alii. (1980). É obtido a partir de cinco determinações feitas na amostra;

j) Tenacldade do flo: valor médio, determinado no dinamômetro Dynamat II, da resistência do fio singelo, de título inglês $\mathrm{Ne} 22$, expresso em RKM e obtido mediante vinte arrebentamentos em cada amostra;

k) Elongação do fio: valor médio, em porcentagem, do alongamento do fio singelo de título inglês Ne 22 , até o momento da ruptura no dinamômetro Dynamat II. É obtido a partir de vinte determinações em cada amostra. 


\subsection{Estudos dos dados}

Obtidos os dados, foram realizados os estudos com os seguintes objetivos e procedimentos:

I - Verificar, para todas as características estudadas, o efeito do ambiente, do cultivar e da interação entre esses fatores. Para tanto, foram realizadas análises de variância para cada experimento e análise conjunta envolvendo todos os ensaios;

II - Dimensionar, para cada cultivar, a variação devida ao ambiente, em todas as características estudadas. Para cada uma delas foram calculados a média, os valores mínimos e máximos, a dispersão e o coeficiente de variação;

III - Averiguar se altos níveis de produtividade de algodão em caroço asseguram, automaticamente, fibra de boa qualidade. Para isso foram calculadas, para cada cultivar, as correlações simples entre os dados de produção e as demais características;

IV - Verificar, para avaliação do efeito ambiente, quais propriedades da fibra foram responsáveis pela qualidade do fio obtido. Para cada cultivar foram calculadas as correlações simples e a regressão múltipla, tanto da tenacidade como da elongação do fio, com as propriedades da fibra;

V - Em face da interação cultivar $x$ ambiente, verificar a possibilidade de que diferentes cultivares possam responder diversamente, para melhor ou para pior, à variação 
ambiente. Para isso foram efetuadas análises de estabilidade e adaptabilidade, baseadas em métodos de regressão.

As análises de variância individuais dos experimentos em cada ambiente, para todas as características estudadas, foram efetuadas segundo o modelo matemático:

\section{$Y i j=m+t i+b j+e i j$}

onde:

$$
\begin{aligned}
\text { Yif }= & \text { valor relativo do cultivar } i \\
& (i=1,2,3 \text { e } 4) \text { no bloco } j \\
& (j=1,2, \ldots, 7) ; \\
m= & \text { média geral } ; \\
t i= & \text { efeito do cultivar } i ; \\
b j= & \text { efeito do bloco } j ; \\
\text { eff }= & \text { efeito do erro experimental. }
\end{aligned}
$$

Na análise conjunta, devido a heterogeneidade das variâncias residuais, procedeu-se ao ajuste nos graus de liberdade correspondentes ao resíduo, conforme método proposto por PIMENTEL GOMES (1978). Tal procedimento foi adotado com o intuito de não eliminar ensaios representativos. Para a análise conjunta adotou-se o seguinte modelo matemático: 


\section{$Y 1 j k=m+t 1+a k+(t \times a) 1 k+b j k+e i j k$}

onde:

$$
\begin{array}{ll}
\text { Yijk = } & \text { observação média do cultivar } i, \text { na } \\
& \text { repetição } j \text { do ambiente } k ; \\
\mathbf{m}= & \text { média geral ; } \\
\mathbf{t}= & \text { efeito do cultivar } i ; \\
\mathbf{a k}= & \text { efeito do ambiente } \mathrm{K}(\mathrm{K}=1,2, \ldots, 40) ; \\
(\mathbf{t x a}) \mathbf{1 k}= & \text { efeito da interação do cultivar } \\
& \text { no ambiente } \mathrm{k} ; \\
\mathbf{b j k}= & \text { efeito da repetição } j \text { no ambiente } \mathrm{k} ; \\
\mathbf{e i j k}= & \text { erro experimental associado à média }
\end{array}
$$

Tanto nas análises individuais quanto na conjunta, nas comparações das variâncias e das médias, foram aplicados os testes F e de Duncan, respectivamente, ao nível de 5\% de probabilidade.

As determinações dos parâmetros de estabilidade e adaptabilidade dos cultivares foram efetuadas pelo método de regressão proposto por EBERHART \& RUSSELL (1966) que consiste em ajustar, para cada cultivar, um único segmento de reta para explicar o seu comportamento médio em diferentes ambientes, e pelo método de CRUZ et alii,(1989) que propõem dois segmentos de reta, um abrangendo os ambientes desfavoráveis e outro os ambientes favoráveis. Tendo em vista a significância dos valores do coeficiente de regressão $\left(b_{2}\right)$, a seguir definido, o que evidencia a existência de duas linhas de regressão, optou-se por este último método. 
O método de regressão adotado baseia-se no seguinte modelo matemático:

$$
Y i j=b_{0} i+b_{1} i I j+b_{2} i T(I j)+s i j+e i j
$$

onde :

$$
\begin{aligned}
\text { Yij }= & \text { média do cultivar } i(i=1,2, \ldots, n) \text { no } \\
& \text { ambiente } j(j=1,2, \ldots, m) ; \\
\mathbf{b}_{0} \mathbf{i}= & \text { média do cultivar } i \text { para todos } \\
& \text { os ambientes; } \\
\mathbf{b}_{1} \mathbf{i}= & \text { coeficiente de regressão linear que } \\
& \text { fornece a resposta do cultivar } i \text { aos } \\
& \text { ambientes desfavoráveis; } \\
\mathbf{I j}= & \text { índice do ambiente } j, \text { dado por: }
\end{aligned}
$$

$$
I J=(\Sigma Y i j / n)-\left(\Sigma_{i j} Y i j / m n\right),
$$

onde: $\quad \mathrm{n}=$ número de cultivares incluídos nos experimentos

$$
m \text { = número total de ambientes }
$$

ou seja, a média de todos os cultivares no ambiente, menos a media geral. 


$$
\begin{aligned}
& b_{2} \mathbf{i}=\text { coeficiente de regressão linear que } \\
& \text { fornece a diferença de resposta do } \\
& \text { cultivar i nos ambientes favoráveis } \\
& \text { e desfavoráveis, logo, } b_{1} i+b_{2} i \\
& \text { representa a resposta nos ambientes } \\
& \text { favoráveis; } \\
& T(I j)=T(I j)=0 \text { se } I j \leqslant 0 ; T(I j)=I j-\bar{I}+ \\
& \text { se } I j>0 \text {, sendo } \bar{I}+\text { a média dos } I j \\
& \text { positivos; } \\
& \text { sij = desvio da regressão do cultivar i no } \\
& \text { ambiente } j \text {; } \\
& \text { eij = erro experimental médio. }
\end{aligned}
$$

$\mathrm{Na}$ análise efetuada, os coeficientes de adaptabilidade $b_{1}, b_{2}$ e $\left(b_{1}+b_{2}\right)$ foram testados pelo teste $t$ e os desvios da regressão para cada cultivar pelo teste $F$, ao nível de 5\% de probabilidade.

o método se baseia, portanto, na regressão linear bi-segmentada e tem como parâmetro de adaptabilidade, para cada cultivar, a média $b_{0}$ e os coeficientes de regressão $b_{1}$ e $\left(b_{1}+b_{2}\right)$. A estabilidade é avaliada pela variância dos desvios da regressão $S^{2} d$.

Para interpretação dos resultados, se $b_{1}<1$ o cultivar tende a resistir à deterioração do ambiente e é tanto mais resistente quanto menor for esse coeficiente. Inversamente, se $b_{1}>1$ o cultivar é sensível a ambientes desfavoráveis e tanto mais, quanto maior esse parâmetro. Se $\left(b_{1}+b_{2}\right)>b_{1} \circ$ cultivar é responsivo 
à melhoria do ambiente, tanto mais quanto maior for o parâmetro. Ao contrário se $\left(b_{1}+b_{2}\right)<b_{1}, e$, portanto, $b_{2}$ é negativo, o cultivar não se beneficia com a melhoria das condições de cultivo.

Se $b_{1}$ e/ou $\left(b_{1}+b_{2}\right)$ forem iguais ou próximo de 1 , o cultivar não revela comportamento diferenciado nos ambientes respectivos e é caracterizado neste trabalho como apresentando adaptabilidade regular.

Por outro lado, o cultivar é mais estável - ou de comportamento previsível, segundo os ambientes - quanto menor a variância dos desvios da regressão. Com base nesses critérios, portanto, o cultivar adequado deve apresentar boa média, tanto geral como nos ambientes favoráveis e desfavoráveis, baixo valor de $b_{1}$, alto valor de $\left(b_{1}+b_{2}\right)$ e desvios da regressão mais baixo possíveis, preferencialmente nulos. 


\section{RESULTADO E DISCUSSÃO}

De acordo com as condições climáticas no transcorrer dos anos agrícolas de 1987/88, 1988/89 e 1989/90 nas diferentes regiões de cultivo do algodoeiro de ciclo anual, onde foram realizados os experimentos considerados neste estudo, verifica-se que não foram totalmente adequadas tanto para a produção quanto para a qualidade da fibra.

No ano agrícola de $1987 / 88$ as lavouras da região Meridional apresentaram bom desenvolvimento durante todo o ciclo da cultura, culminando com um bom nível de produtividade, porém o excesso de chuvas coincidindo com a colheita, principalmente nos Estados de São Paulo e Paraná, contribuiu para depreciar a qualidade da fibra. Na região setentrional, as condições climáticas foram normais promovendo aumento na produtividade das lavouras (FUNDAÇÃO GETÚLIO VARGAS, 1989 a). As safras de 1988/89 e 1989/90 na região Meridional foram marcadas pela escassez de chuvas na fase de implantação da cultura atrasando por aproximadamente um mês a semeadura. Esse atraso na semeadura, as estiagens verificadas no início de desenvolvimento das plantas e outras adversidades 
climáticas ocorridas durante o decorrer da cultura, contribuíram para baixar a produtividade das lavouras, principalmente nos Estados de São Paulo e Paraná. Por outro lado, devịdo ao atraso da semeadura e conseqüentemente, o deslocamento do ciclo da cultura, a colheita foi realizada em período menos chuvoso, contribuindo para a obtenção de algodão de boa qualidade. A região Nordeste foi marcada pela escassez de chuvas nesses dois anos, do que resultou menor produtividade das lavouras (FUNDAÇÃO GETÚLIO VARGAS, 1989b e INSTITUTO DE ECONOMIA AGRÍCOLA, 1990).

Os dados referentes às médias para os componentes da produção (algodão em caroço, peso de um capulho, peso de cem sementes e porcentagem de fibra); características tecnológicas da fibra (comprimento 2,5\%, uniformidade de comprimento, Micronaire, tenacidade e maturidade) e do fio (tenacidade e elongação) dos quatro cultivares em todos os ambientes considerados nesse estudo encontram-se no apêndice (tabelas 23 a 33). Os resultados das análises conjuntas encontram-se na tabela 3. São apresentadas as médias de cada cultivar, as amplitudes e as porcentagens de dispersão entre eles e as médias gerais para cada característica. Verifica-se que para todas as características foram altamente significativos os efeitos de cultivar, de ambiente e da interação cultivar $x$ ambiente. De especial interesse, são os dois últimos, principalmente para as características da fibra e do fio, objetivo maior deste estudo. 


\subsection{Efeito de cultivares}

Analisando-se as djferenças verificadas entre os cultivares, na média dos ambientes, para todas as características apresentadas na tabela 3, observa-se que os resultados confirmam os pressupostos da escolha desses cultivares, tendo em vista as diferentes particularidades de cada um.

Quanto à produção de algodão em caroço, embora diferiram significativamente entre si, as diferenças não são grandes quando se comparam os cultivares IAC 20, o mais produtivo, e IAC 19. Por outro lado, verificam-se as menores produções dos cultivares CNPA Precoce 1 e CNPA Acala 1, cerca de 10\% e 30,0\% mais baixas, respectivamente, do que a do IAC 20. Esses resultados confirmam aqueles já conhecidos na literatura de acordo com CIA et alii (1988), GRIDI-PAPP et (1991) e CIA et alii (1993), principalmente quanto à maior susceptibilidade desses dois cultivares às principais doenças e moléstias do algodoeiro em comparação com os cultivares IAC 19 e IAC 20.

Com relação aos componentes da produção, os cultivares diferiram substancialmente, confirmando também as principais características individuais tais como, o maior e menor peso de capulho verificados nos cultivares IAC 19 e CNPA Precoce 1 respectivamente. Do mesmo modo, o mais baixo peso de sementes do CNPA Precoce 1, e a menor porcentagem de fibras do CNPA Acala 1, 


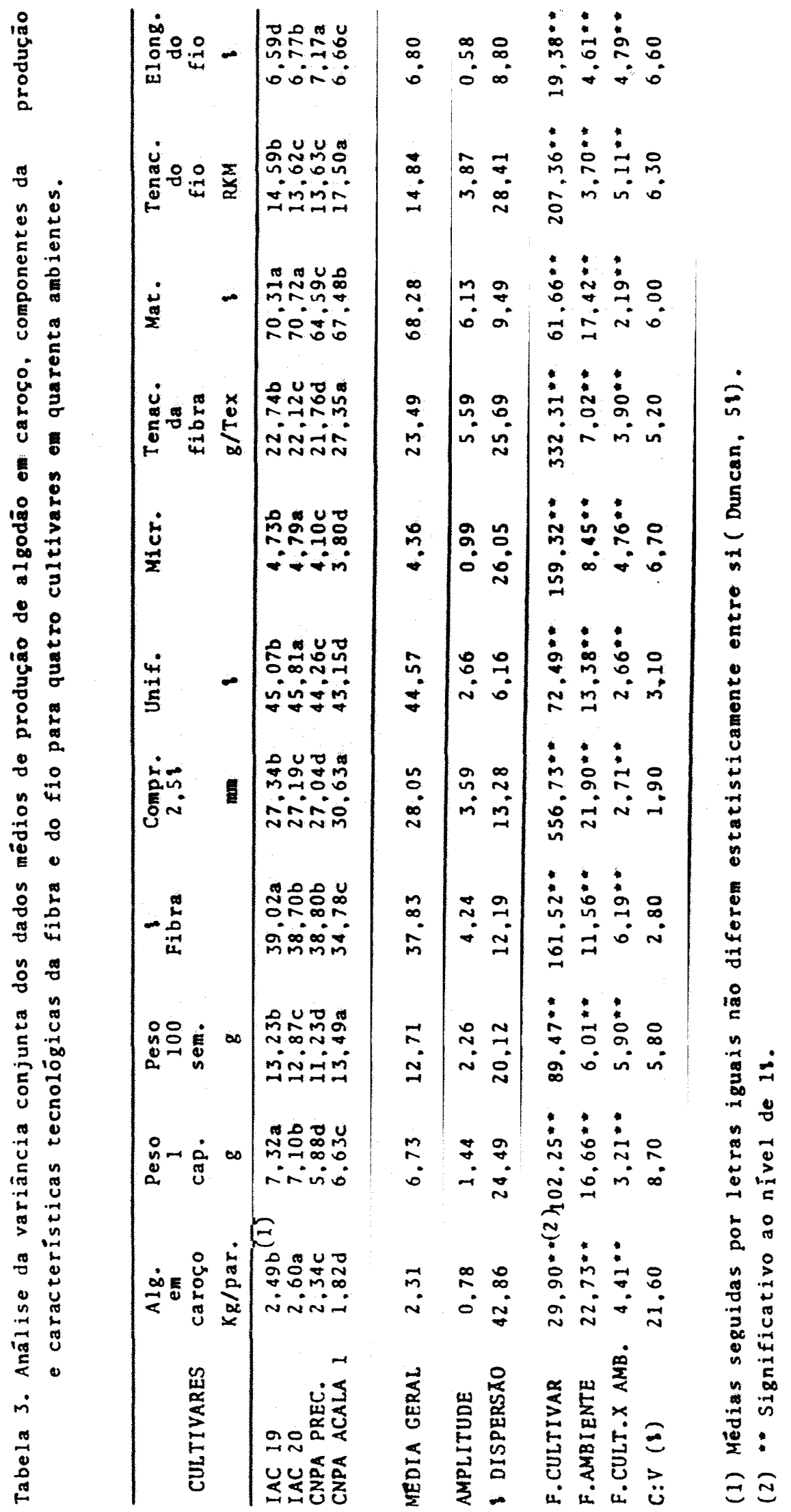


cerca de 4,0\% inferior em valor absoluto, à da média dos demais cultivares.

Diferenças substanciais foram verificadas também entre os cultivares quanto às características tecnológicas da fibra e do fio (tabela 3). O cultivar CNPA Acala 1 destaca-se positivamente dos demais quanto ao comprimento e tenacidade da fibra, além de Micronaire baixo. Esse comportamento confirma a particularidade desse material, tipicamente produtor de fibras longas. Esse cultivar confirmou, também, sua superioridade quanto à tenacidade do fio. Por outro lado, apresentou menor uniformidade de comprimento e baixa maturidade da fibra. Os demais cultivares podem ser comparados entre si, uma vez que se enquadram como produtores de fibra de comprimento médio. Desse modo, observa-se no conjunto das características, um nítido equilíbrio de comportamento entre IAC 19 e IAC 20, bem como a superioridade destes quando comparados com o CNPA Precoce 1 o qual se destacou apenas quanto à elongação do fio.

Analisando-se o efeito de cultivares nas características estudadas, pela amplitude de variação e pela porcentagem de dispersão apresentados na tabela 3, observa-se que os efeitos são variáveis conforme a característica. De todas as características estudadas, a produção de algodão em caroço mostrou ser a mais variável entre os cultivares com uma dispersão de $42,86 \%$. Dentre os componentes da produção, o peso de capulho mostrou-se o mais influenciado e a porcentagem de fibra o menos afetado. Quanto às características da fibra, o índice Micronaire e a tenacidade foram as mais afetadas, praticamente nos mesmos 
valores, e a maturidade mostrou a menor diferença. Com relação às características do fio, a tenacidade, pela dispersão apresentada $(28,48 \%)$ mostrou ser pelo menos três vezes mais afetada do que a elongação do fio $(8,80 \%)$.

\subsection{Efeito do ambiente}

Quanto aos efeitos do ambiente verificados nesse estudo (tabela 3) para os componentes da produção pode-se admitir que os resultados não se mostraram surpreendentes, conforme se verifica na literatura consultada. Da mesma maneira, são conhecidas as influências de fatores do ambiente durante os períodos de desenvolvimento e maturação das fibras e, conseqüentemente, nas suas características tecnológicas. Porém, o que se objetivou neste trabalho foi verificar, do ponto de vista prático, a ocorrência e magnitude do efeito de conjuntos indiscriminados e variáveis desses fatores, possíveis de ocorrer nos diferentes locais de cultivo do algodoeiro.

Nas tabelas 4,5 e 8 são apresentadas, para cada cultivar, nos 40 ambientes, a média, os valores máximos e mínimos, as amplitudes de variação, a porcentagem de dispersão e os coeficientes de variação, e os valores médios para os quatro cultivares, para os componentes da produção, características tecnológicas da fibra e características do fio, respectivamente. Analisando-se os dados, pelos valores médios quer dos coeficientes de variação quer da porcentagem de dispersão, 
verifica-se que as características foram afetadas diferentemente pelo ambiente.

\subsubsection{Efeito do ambiente em componentes da produção}

Analisando-se os dados apresentados na tabela 4 , verifica-se pelos altos valores médios da porcentagem de dispersão que todos os componentes da produção foram fortemente influenciados pelo ambiente. Esses valores, quando comparados com as dispersões apresentadas na tabela 3 , que se referem à influência de cultivar, indicam que a influência do ambiente foi muito superior à de cultivar. Nota-se, no caso da produção de algodão em caroço que a influência do ambiente chega a ser mais de dez vezes superior à de cultivar e pelo menos duas vezes maior para os demais componentes. Essa grande influência de ambientes na produção é esperada e explicada pela grande variação entre locais e anos quanto às condições edafoclimáticas regionais e a fatores adversos tais como pragas, doenças, nematóides, deficiências nutricionais, condições metereológicas e técnicas de cultivo.

Menos esperada, porém, é a dimensão do efeito nos demais componentes. De fato, a variação média aproximada de $68 \%$ no peso de capulho, de $37 \%$ no peso de cem sementes e de 25\% na porcentagem de fibra, levam a refletir sobre a validade de estabelecer padrões absolutos, ainda que médios, para essas características, com a finalidade de descrever cultivares. Basta 
Tabela 4. Valores dos componentes da produção obtidos para quatro cultivares em quarenta ambientes de cultivo do algodoeiro no Brasil, nos anos agrícolas de $1987 / 88$ a $1989 / 90$.

\section{Variável Cultivar Média v.Mín. V.Máx. Ampl. o Disp. CV \&}

$\begin{array}{llllllll}\text { Alg. } & \text { IAC } 19 & 2,49 \mathrm{~b} & 1,01 & 4,62 & 3,61 & 357,43 & 42,32 \\ \text { em } & \text { IAC 20 } & 2,60 \mathrm{a} & 0,82 & 4,88 & 4,06 & 495,12 & 40,77 \\ \text { caroçO } & \text { CNPA Pr.1 } & 2,34 \mathrm{C} & 0,95 & 4,63 & 3,68 & 387,37 & 41,14 \\ \text { (Kg/ } & \text { CNPA AC.1 } & 1,82 \mathrm{~d} & 0,48 & 3,63 & 3,15 & 656,25 & 46,56 \\ \text { parC.) } & & & & & & & \end{array}$

Média $\quad 2,31 \quad 0,82 \quad 4,44 \quad 3,63 \quad 474,04 \quad 42,70$

$\begin{array}{llllllll}\text { Peso } & \text { IAC } 19 & 7,32 \mathrm{a} & 5,55 & 8,92 & 3,37 & 60,72 & 11,54 \\ \text { de 1 } & \text { IAC 20 } & 7,10 \mathrm{~b} & 5,35 & 8,68 & 3,33 & 62,24 & 11,86 \\ \text { Cap. } & \text { CNPA Pr.1 } & 5,88 \mathrm{~d} & 4,71 & 7,27 & 2,56 & 54,35 & 11,90 \\ \text { (g) } & \text { CNPA AC.1 } & 6,63 \mathrm{C} & 4,28 & 8,41 & 4,13 & 96,50 & 15,53\end{array}$

\section{Média $\quad 6,73 \quad 4,97 \quad 8,32 \quad 3,35 \quad 68,45 \quad 12,71$}

$\begin{array}{lllrrrrr}\text { Peso } & \text { IAC } 19 & 13,23 \mathrm{~b} & 11,77 & 15,17 & 3,40 & 28,89 & 6,63 \\ \text { de } & \text { IAC 20 } & 12,87 \mathrm{c} & 10,92 & 14,15 & 3,23 & 29,76 & 6,47 \\ 100 & \text { CNPA Pr.1 } & 11,23 \mathrm{~d} & 9,60 & 12,57 & 2,97 & 30,94 & 6,92 \\ \text { sement. } & \text { CNPA Ac.1 } & 13,49 \mathrm{a} & 10,17 & 16,22 & 6,05 & 59,49 & 9,31\end{array}$
(g)

\section{Média $\quad 12,71 \quad 10,62 \quad 14,53 \quad 3,91 \quad 37,27 \quad 7,33$}

$\begin{array}{lllllllll} & \text { IAC } 19 & 39,02 \mathrm{a} & 35,72 & 43,12 & 7,40 & 20,72 & 4,25 \\ \% \text { de } & \text { IAC } 20 & 38,70 \mathrm{~b} & 35,18 & 42,85 & 7,67 & 21,80 & 4,27 \\ \text { Fibra } & \text { CNPA } & \text { Pr.1 } & 38,80 \mathrm{~b} & 34,40 & 43,91 & 9,51 & 27,65 & 5,62 \\ & \text { CNPA AC.1 } & 34,78 \mathrm{C} & 30,90 & 40,57 & 9,67 & 31,29 & 5,82\end{array}$
Média
37,83
34,05
42,62
8,56
25,37
4,99

Médias seguidas por letras iguais não diferem estatisticamente entre si (Duncan 5\%). 
assinalar que os resultados obtidos situam todos os cultivares estudados em todas as classes padrões sugeridas por FUZATTO et alii (1986), para essas características.

Dadas as diferentes porcentagens de dispersão entre os cultivares, pode-se verificar que foram diferentemente afetadas pelo ambiente. Pelas maiores dispersões em todas as características, o CNPA Acala 1 mostrou-se o mais influenciado e ao contrário, O IAC 19, com exceção do peso de capulho, foi o menos afetado. Os outros dois cultivares comportaram-se de maneira intermediária, alternando maior e menor influência conforme as características.

\subsubsection{Efeito do ambiente em caracteristicas da fibra}

Pelos dados apresentados na tabela 5 verifica-se, quer pela porcentagem de dispersão quer pelos coeficientes de variação, um grande efeito de ambiente nessas características e, a exemplo do que foi observado para os componentes da produção, esse efeito é bem maior do que o devido a cultivar, apresentado na tabela 3 . Dentre as características, o índice Micronaire e a maturidade, foram as que mais variaram sob a influência do ambiente. É importante ressaltar a incompatibilidade entre esse fato e o intuito, de setores ligados à indústria têxtil, de fixar e supervalorizar índices absolutos $(3,87)$ e mesmo faixas $(3,7-4,2)$ restritos para o índice Micronaire, como padrão de qualidade da fibra (DOCUMENTO SENAI/CETIQT, 1987). É interessante observar que embora o efeito do ambiente seja maior que o de cultivar, esse 
Tabela 5. Valores das características tecnológicas da fibra obtidos para quatro cultivares em quarenta ambientes de cultivo do algodoeiro no Brasil, nos agrícolas de $1987 / 88$ a $1989 / 90$.

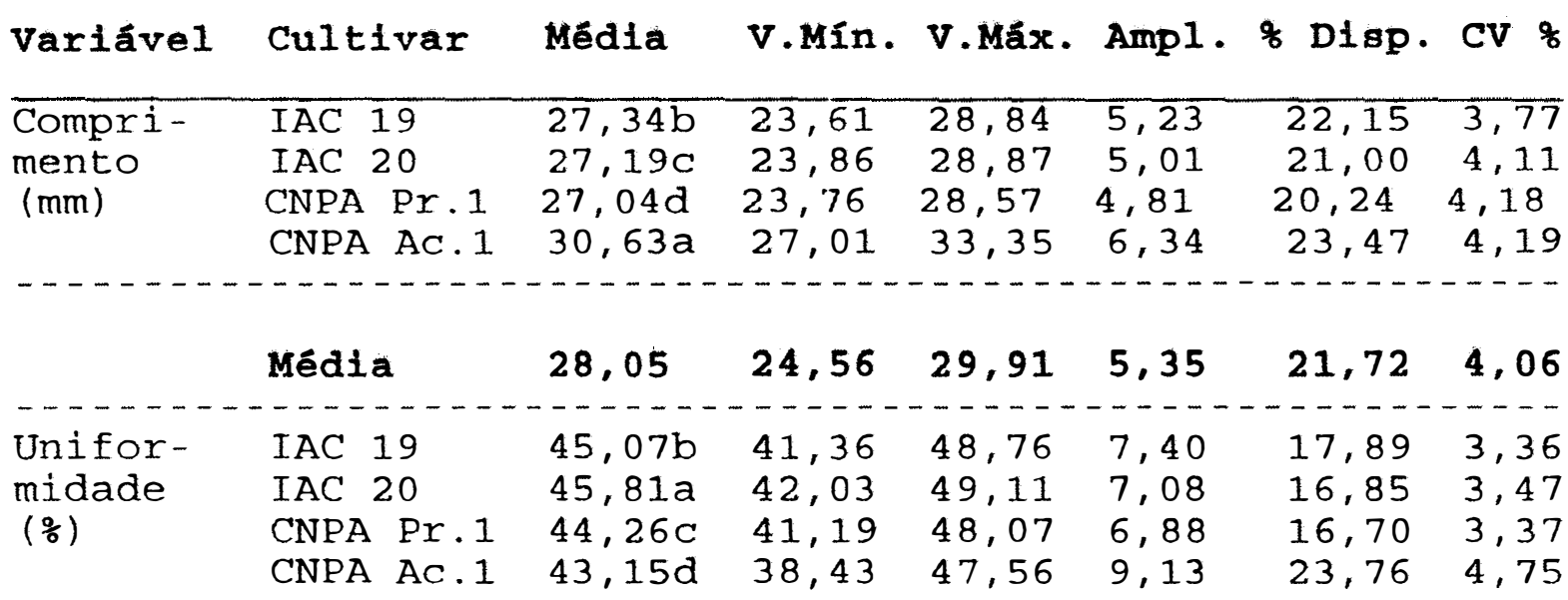

Médi $\quad 44,57 \quad 40,75 \quad 48,38 \quad 7,62 \quad 18,80 \quad 3,74$

\begin{tabular}{|c|c|c|c|c|c|c|c|}
\hline \multirow{4}{*}{$\begin{array}{l}\text { Micro- } \\
\text { naire }\end{array}$} & IAC 19 & $4,73 b$ & 3,93 & 5,49 & 1,56 & 39,69 & 8,70 \\
\hline & IAC 20 & $4,79 a$ & 3,94 & 5,51 & 1,57 & 39,85 & 8,56 \\
\hline & CNPA Pr. 1 & $4,10 \mathrm{C}$ & 3,19 & 4,94 & 1,75 & 54,86 & 10,47 \\
\hline & CNPA AC. 1 & $3,80 d$ & 2,99 & 4,56 & 1,57 & 52,51 & 8,6 \\
\hline
\end{tabular}

\begin{tabular}{llcccccc} 
& Média & $\mathbf{4}, 36$ & $\mathbf{3}, \mathbf{5 1}$ & $\mathbf{5 , 1 3}$ & $\mathbf{1 , 6 1}$ & $\mathbf{4 6 , 7 3}$ & $\mathbf{9}, 09$ \\
\hdashline Tenaci- & IAC 19 & $22,74 \mathrm{~b}$ & 21,07 & 24,93 & 3,86 & 18,32 & 4,77 \\
dade & IAC 20 & $22,12 \mathrm{C}$ & 19,46 & 25,16 & 5,70 & 29,29 & 5,18 \\
(g/tex) & CNPA Pr.1 & $21,76 \mathrm{~d}$ & 19,43 & 24,97 & 5,54 & 28,51 & 15,53 \\
& CNPA AC.1 & $27,35 \mathrm{a}$ & 24,27 & 32,60 & 8,33 & 34,32 & 7,35
\end{tabular}

Média $\quad 23,49 \quad 21,06 \quad 26,92 \quad 5,86 \quad 27,61 \quad 5,71$

\begin{tabular}{|c|c|c|c|c|c|c|c|}
\hline $\begin{array}{l}\text { Maturi- } \\
\text { dade } \\
(\%)\end{array}$ & $\begin{array}{l}\text { IAC } 19 \\
\text { IAC } 20 \\
\text { CNPA Pr. } 1 \\
\text { CNPA AC. } 1\end{array}$ & $\begin{array}{l}70,31 a \\
70,72 a \\
64,59 c \\
67,48 b\end{array}$ & $\begin{array}{l}57,87 \\
59,64 \\
52,62 \\
53,75\end{array}$ & $\begin{array}{l}77,81 \\
78,87 \\
74,40 \\
76,07\end{array}$ & $\begin{array}{l}19,94 \\
19,23 \\
21,78 \\
22,32\end{array}$ & $\begin{array}{l}34,46 \\
32,24 \\
41,39 \\
41,53\end{array}$ & $\begin{array}{l}7,03 \\
6,28 \\
8,05 \\
8,63\end{array}$ \\
\hline & Média & 68,28 & 55,97 & 76,79 & 20,82 & 37,41 & 7,50 \\
\hline
\end{tabular}

Médias seguidas por letras iguais não diferem estatisticamente entre si (Duncan 5\%). 
fato não ocorre similarmente para todos as características. Exemplo disso é a maturidade da fibra que foi relativamente pouco variável entre os cultivares e mostrou-se altamente influenciada pelo ambiente. Por outro lado, o índice Micronaire mostrou-se o mais variável tanto devido aos cultivares quanto às variações do ambiente.

O que é importante salientar nos dados da tabela 5 é a grande variação devida a ambiente, independentemente de cultivar, para todas as características. A tal ponto de o algodão produzido por um cultivar como o CNPA Acala 1, esperadamente de alta qualidade, apresentar-se - principalmente quanto ao comprimento e tenacidade - em níveis totalmente impróprios para as finalidades a que se destina. Da mesma maneira, para os outros cultivares podem ser obtidas matérias primas com características aquém das exigências mínimas para funcionamento e resultados adequados no processo de fiação. É interessante, também, observar que, dependendo do ambiente onde foram produzidas, a qualidade das fibras pode se igualar e até mesmo inverter, em relação ao que se espera de cultivares tão distintos como o CNPA Acala 1, de um lado, e os de fibra média, de outro.

\subsubsection{Reflexos do efeito do ambiente na qualidade do fio}

A qualidade do fio é função das características da matéria prima e das condições de processamento. Como estas últimas foram presumivelmente uniformes, o efeito do ambiente sobre o fio pode ser atribuído apenas à ação que ele exerce nas 
propriedades da fibra. Para isso faz-se necessário verificar quais destas, e em que medida, foram responsáveis pelas características do fio produzido. As tabelas 6 e 7 contêm os resultados das análises de correlação simples e de regressão múltipla que associam a tenacidade e a elongação do fio, respectivamente, com as características da fibra (na regressão múltipla adotou-se a exigência do nível de 5\% de significância estatística para inclusão da variável independente na equação).

Com relação à tenacidade do fio (tabela 6) verifica-se que, na média dos cultivares, cerca de $60 \%$ da sua variação deveu-se à variação das características da fibra. Esse número variou de $55 \%$, na CNPA Acala 1, á 65\% para O IAC 20. O comprimento, a uniformidade e a tenacidade da fibra foram as características mais importantes para essa qualidade do fio. O micronaire contribuiu também, no caso da IAC 20, ao passo que o comprimento não teve influência significativa no caso da CNPA Acala 1.

Com respeito à elongação do fio (tabela 7), excluído - cultivar CNPA Acala 1, cerca de $65 \%$ da variação pode ser atribuída à fibra (69\% no caso da IAC 19). As características mais importantes, nesse caso, foram o comprimento, a uniformidade e o micronaire. No caso da CNPA Acala 1, além do baixo nível de associação (12\%), apenas a uniformidade da fibra afetou a elongação do fio. É possível que a elongação da fibra, característica não determinada neste trabalho, pudesse contribuir para explicar melhor a variação dessa propriedade do fio. 


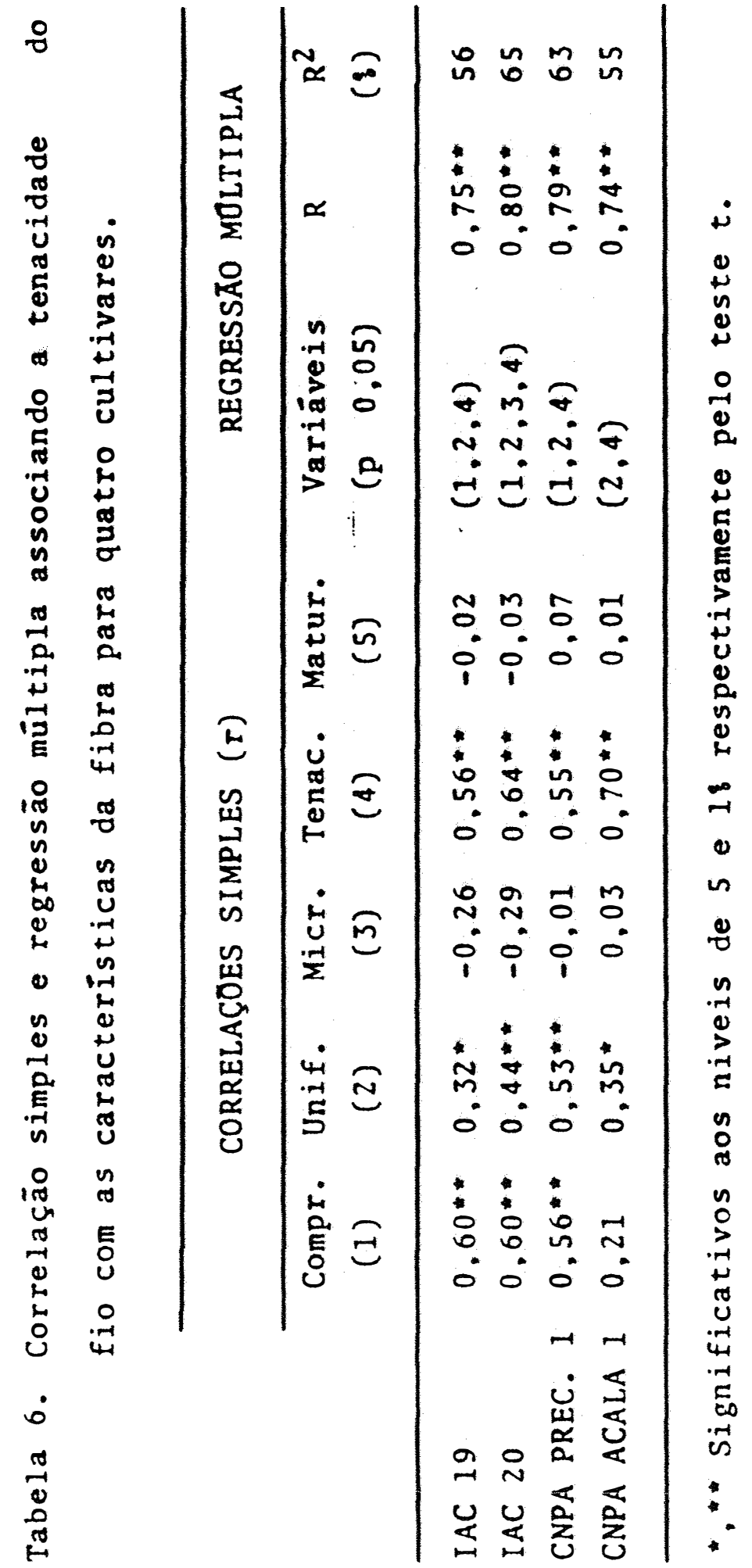




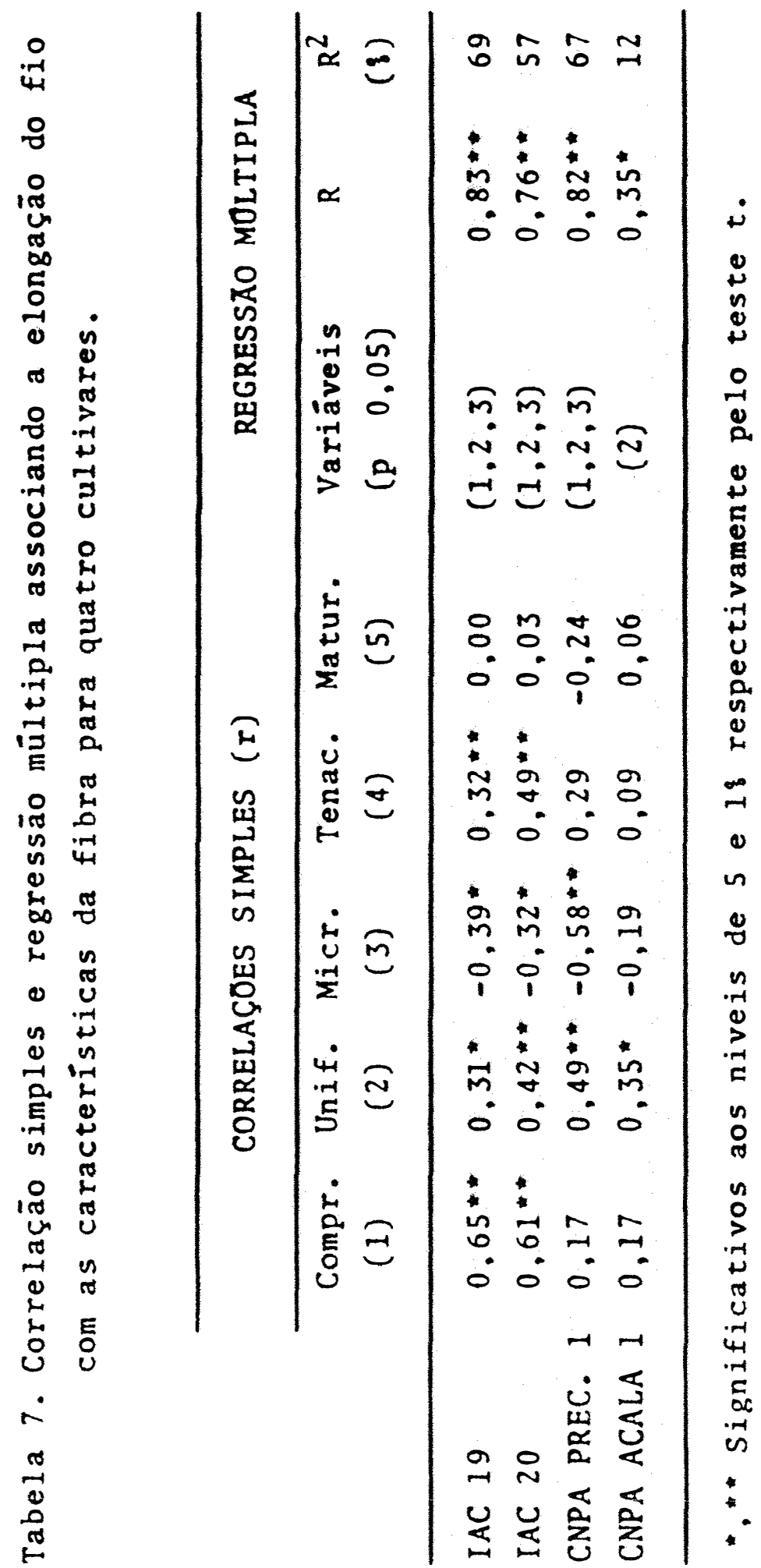


Tendo em vista o exposto verifica-se pela tabela 8 que a tenacidade do fio variou de 12,71 a 16,78 , na média dos cultivares, sendo que $O$ CNPA Precoce 1 foi $O$ mais afetado, apresentando cerca de $41 \%$ de dispersão contra aproximadamente $27 \%$ verificado no CNPA Acala 1 e $29 \%$ e $33,5 \%$ no IAC 19 e IAC 20 respectivamente.

Do mesmo modo, a elongação do fio (tabela 8) variou de 5,78 a 7,92, na média dos cultivares, sendo novamente o CNPA Precoce 1 o mais variável, com cerca de 45\% de dispersão contra aproximadamente $29 \%, 36 \%$ e $38 \%$ de dispersão verificado nos cultivares CNPA Acala 1, IAC 20 e IAC 19 respectivamente.

A exemplo do que foi observado no caso da fibra, pode-se verificar que, dependendo do ambiente onde foi produzida a matéria prima, a qualidade do fio pode estar invertida ao que seria de esperar segundo os cultivares. O fato é particularmente importante no caso da produção de fios finos, para os quais se exigem fibras longas, finas e resistentes. As quais, em ambientes desfavoráveis, mesmo um cultivar com aptidão genética, não conseguirá produzir.

\subsection{Correlações entre produção de algodão em caroço e demais caracteristicas}

Para verificar se altas produtividades garantiriam a obtenção de boa qualidade na fibra efetuou-se o cálculo das correlações entre a produção de algodão em caroço e as demais características estudadas. Os dados encontram-se na tabela 9. 
Tabela 8. Valores das características do fio de algodão obtidos a partir de fibras produzidas por quatro cultivares em quarenta ambientes de cultivo no Brasil, nos anos agrícolas de 1987/88 a 1989/90.

Variável Cultivar Média V.Mín. V.Máx. Ampl. o Disp. CV

$\begin{array}{llllllll}\text { Tenaci- } & \text { IAC } 19 & 14,59 \mathrm{~b} & 12,77 & 16,44 & 3,67 & 28,74 & 5,63 \\ \text { dade } & \text { IAC 20 } & 13,62 \mathrm{C} & 11,64 & 15,54 & 3,90 & 33,51 & 6,72 \\ \text { (RKM) } & \text { CNPA Pr.1 } & 13,63 \mathrm{C} & 11,02 & 15,54 & 4,52 & 41,02 & 6,47 \\ & \text { CNPA AC.1 } & 17,50 \mathrm{a} & 15,42 & 19,58 & 4,16 & 26,98 & 5,30\end{array}$

Média $\quad 14,84 \quad 12,71 \quad 16,78 \quad 4,06 \quad 32,56 \quad 6,03$

$\begin{array}{llllllll}\text { Elonga- } & \text { IAC } 19 & 6,59 \mathrm{~d} & 5,48 & 7,55 & 2,07 & 37,77 & 6,31 \\ \text { Ção } & \text { IAC 20 } & 6,77 \mathrm{~b} & 5,78 & 7,85 & 2,07 & 35,81 & 6,52 \\ (\%) & \text { CNPA Pr.1 } & 7,17 \mathrm{a} & 5,92 & 8,58 & 2,66 & 44,93 & 8,26 \\ & \text { CNPA AC.1 } & 6,66 \mathrm{C} & 5,94 & 7,68 & 1,74 & 29,29 & 5,17\end{array}$

$\begin{array}{lllllll}\text { Média } & 6,80 & 5,78 & 7,92 & 2,14 & 36,95 & 6,57\end{array}$

Médias seguidas por letras iguais não diferem estatisticamente entre si (Duncan 5\%). 
Analisando-se os dados referentes aos 40 ambientes, verificou-se que apesar de haver significância estatística de alguns valores dos coeficientes de correlação $(r)$, para algumas características, no geral estes valores são baixos. Considerando os coeficientes de determinação $\left(R^{2}\right)$ para esses valores, observa-se pouca dependência das características quanto à produção. Como era esperado, a dependência manifesta-se para os componentes de produção, especificamente $O$ peso de capulho ( $r$ médio $=0,61)$ e peso de sementes (r médio $=0,34$ ) em todos os cultivares.

Com relação às características da fibra, a única que se mostrou dependente para todos os cultivares foi o comprimento da fibra., Cabe ressaltar, porém, que o cultivar CNPA Acala 1, que se destaca pelas qualidades da fibra e pela maior susceptibilidade a doenças e nematóides, comportou-se diferentemente dos demais, ou seja, todas as características da fibra mostraram-se correlacionadas com a produção. Estes dados evidenciam que, no caso deste cultivar, a melhor adequação de fatores para incremento da produtividade ou seja, a melhoria do ambiente, deve refletir positivamente na qualidade de suas fibras.

A existência ou não de correlações das características da fibra, quer entre si ou com a produção, é extremamente dependente das condições ambientes e da maior ou menor interação com cultivares. Vários autores citados na revisão de literatura apresentam resultados conflitantes os quais são atribuídos às condições do ambiente. Em geral aparecem com certa constância, correlações entre a produção e o comprimento, podendo ser positiva ou negativa e com a resistência, freqüentemente 


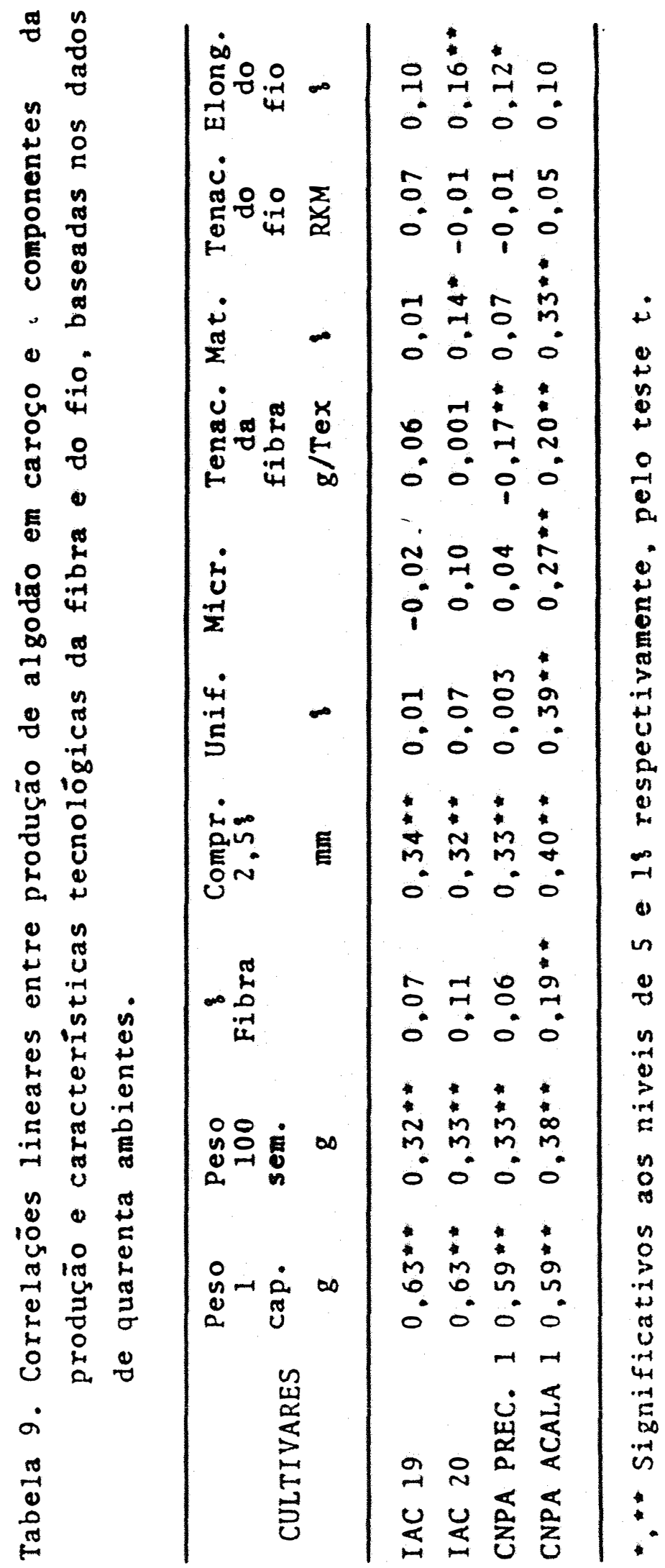


negativa. TURNER et alii.(1976) trabalhando com o cultivar Acala 1517-70, constataram a existência de correlação positiva entre a produção e a resistência da fibra. Os autores julgaram inesperado esse comportamento e atribuíram o fato à maior sensibilidade desse cultivar às influências do ambiente. No caso presente, pode-se observar o mesmo comportamento para o cultivar CNPA Acala 1 que também é muito sensível às variações ambientes no nosso meio. Para o cultivar CNPA Precoce 1 verificou-se correlação negativa, embora baixa, entre esses dois fatores e inexistência de correlação para os demais cultivares.

Evidências da influênciia do ambiente nos cultivares foram confirmadas quando os ambientes foram agrupados por região. $\mathrm{Na}$ tabela 10 encontram-se os ambientes localizados na região Meridional de cultivo de algodão e na tabela 11 aqueles da região Setentrional. Os resultados observados na tabela 10 não são muito diferentes quando comparados com a tabela 11. Na região Meridional onde se presume haver melhores condições climáticas para a produção e menos favoráveis para as qualidades da fibra, se observa maior variabilidade entre os locais tais como: incidências de doenças e nematóides e condições metereológicas como apresentado na tabela 2 . Conseqüentemente, os cultivares mais sensíveis ou seja, aqueles selecionados originalmente sob outras condições mostraram maior dependência das condições de produção para a qualidade da fibra. Por outro lado, quando se considera apenas o agrupamento de locais conduzidos na região setentrional, onde se presume haver condições mais favoráveis para as características da fibra, a dependência da produção é menor para os cultivares 


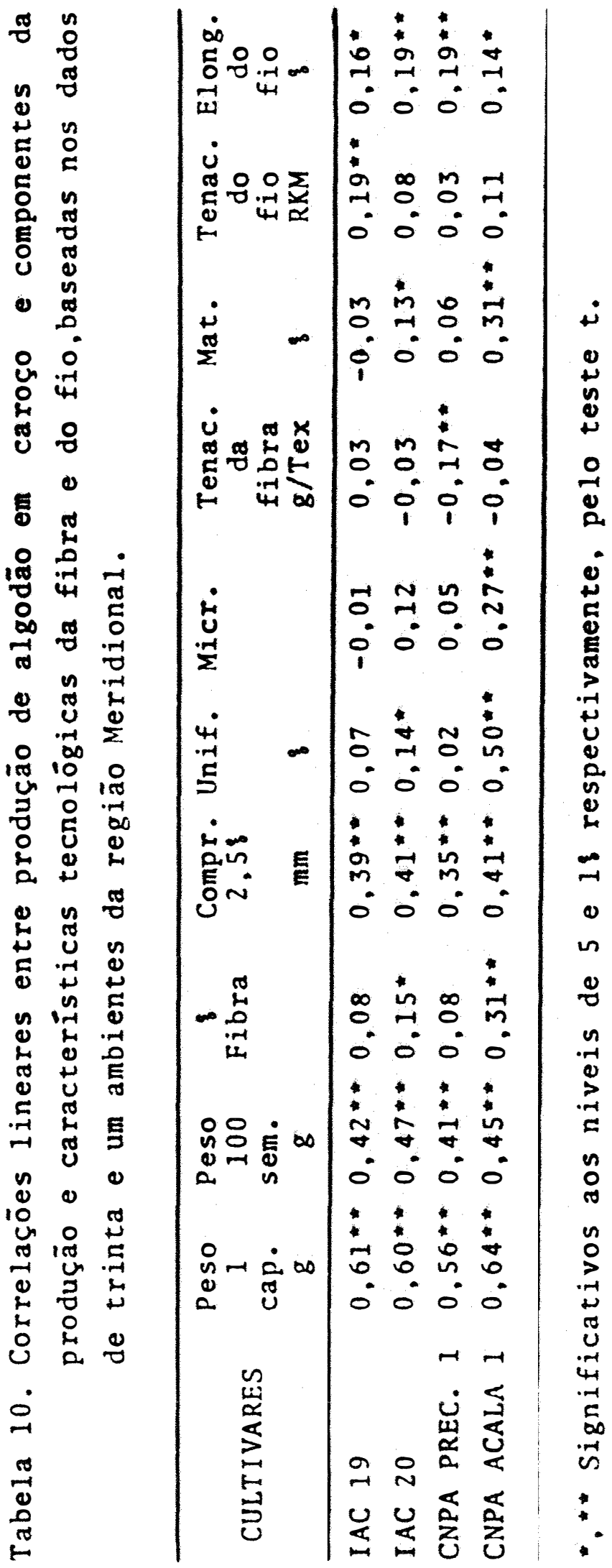


62.

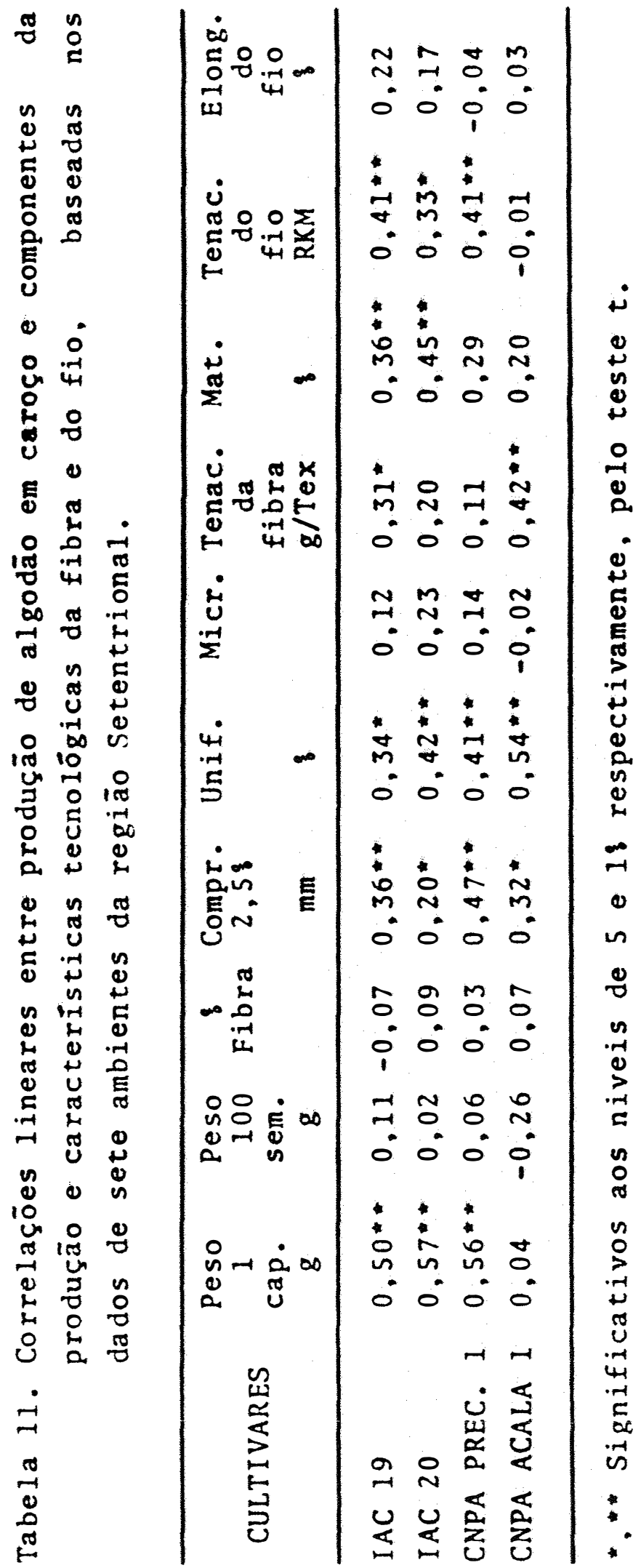


selecionados nessas condições, notadamente o cultivar CNPA Acala 1. O contrário se verifica para os cultivares IAC 19 e IAC 20 selecionados na região Meridional. Em síntese, por esses dados o que se observa é, além de baixos valores, o comportamento errático dos cultivares no que se refere à correlação das características da fibra com a produção. O comprimento da fibra aparece como a única característica que mostrou dependência mais consistente. Estes resultados estão de acordo com aqueles apresentados por MILLER et alii. (1958), LAZZARINI (1970), TURNER et alii. (1976), DIMITROVA \& BOZHINOV (1988) e TOMAR \& SINGH (1.991).

Procurou-se identificar os ambientes desfavoráveis para cada característica e verificar possíveis consistências entre locais ou regiões e valores baixos ou altos para essas características ou para um grupo de características. Para tanto consideraram-se os quartis superiores e inferiores dos dados para cada característica, identificando-se dessa maneira os ambientes favoráveis e os desfavoráveis. Desse modo, pode-se verificar que não houve coincidência de locais favoráveis ou desfavoráveis, quer considerados individualmente quer em grupos regionais, com a qualidade dessas características. Uma provável explicação para o local não ser sistematicamente desfavorável é a atuação de fatores imprevisíveis do ambiente, para cada característica, em dado momento do ciclo da planta. Estes resultados confirmam a hipótese levantada por GRIDI-PAPP et alii, (1994) os quais sugerem que eventuais destaques positivos ou principalmente os negativos, para certas características, parecem ser devidos a fatores circunstanciais locais, compreendendo tanto adversidades climáticas 
e fitossanitárias quanto deficiências tecnológicas na condução da cultura.

\subsection{Interação cultivar $\mathrm{x}$ ambiente}

Como se verificou na análise conjunta dos dados (tabela 3), o efeito da interação entre cultivares e ambientes foi altamente significativo para todas as características estudadas. Como se observa na literatura, diversos pesquisadores tem demonstrado o comportamento diferencial entre cultivares, com respeito à adaptabilidade e/ou estabilidade da produção de algodão. Todavia, não foram encontrados estudos dessa natureza para outras características. Desse modo, procurou-se estudar através dos parâmetros de estabilidade/adaptabilidade, a interação cultivar X ambiente enfatizando principalmente as características tecnológicas da fibra e do fio.

Nas tabelas de 12 a 22 são apresentados para cada característica os parâmetros de adaptabilidade e estabilidade. As figuras 1 a 11 mostram, graficamente, o comportamento de cada cultivar.

Analisando-se a tabela 12 e a figura 1, verifica-se a ocorrência de resposta diferencial dos cultivares às variações do ambiente. Os cultivares IAC 19 e IAC 20 destacaram-se por apresentar maior estabilidade da produção de algodão em caroço uma vez que os quadrados médios dos desvios não diferiram estatisticamente de zero. Embora com uma certa sensibilidade à 
Tabela 12. Estimativas dos parâmetros de estabilidade e adaptabilidade de quatro cultivares para produção de algodão em caroço, segundo a metodologia de CRUZ et alii (1989).

CULTIVAR

$\mathrm{B}_{0} \quad \mathrm{~B}_{1}$

$\mathrm{B}_{2}$

$\mathrm{B}_{1}+\mathrm{B}_{2}$

QM DES

$R^{2}(z)$

\section{IAC 19}

$2,49 \mathrm{~b}$

$1,076^{*}$

$2,60 a$

1,083 *

0,138

$1,215 *$ *

0,276

96,65

IAC 20

$2,34 \mathrm{C}$

0,960

0,111

1,194 *

0,265

96,79

CNPA PREC. 1

$1,82 \mathrm{~d}$

0,880 ** $-0,271$ **

0,983

0,696 **

89,78

CNPA ACALA 1

$1,82 d$

0,609 **

0,664 **

87,55

Médias seguidas por letras iguais não diferem estatisticamente entre si (Duncan 5\%).

*, ** Significativas aos níveis de 5 e $1 \%$ respectivamente pelo teste $t$.

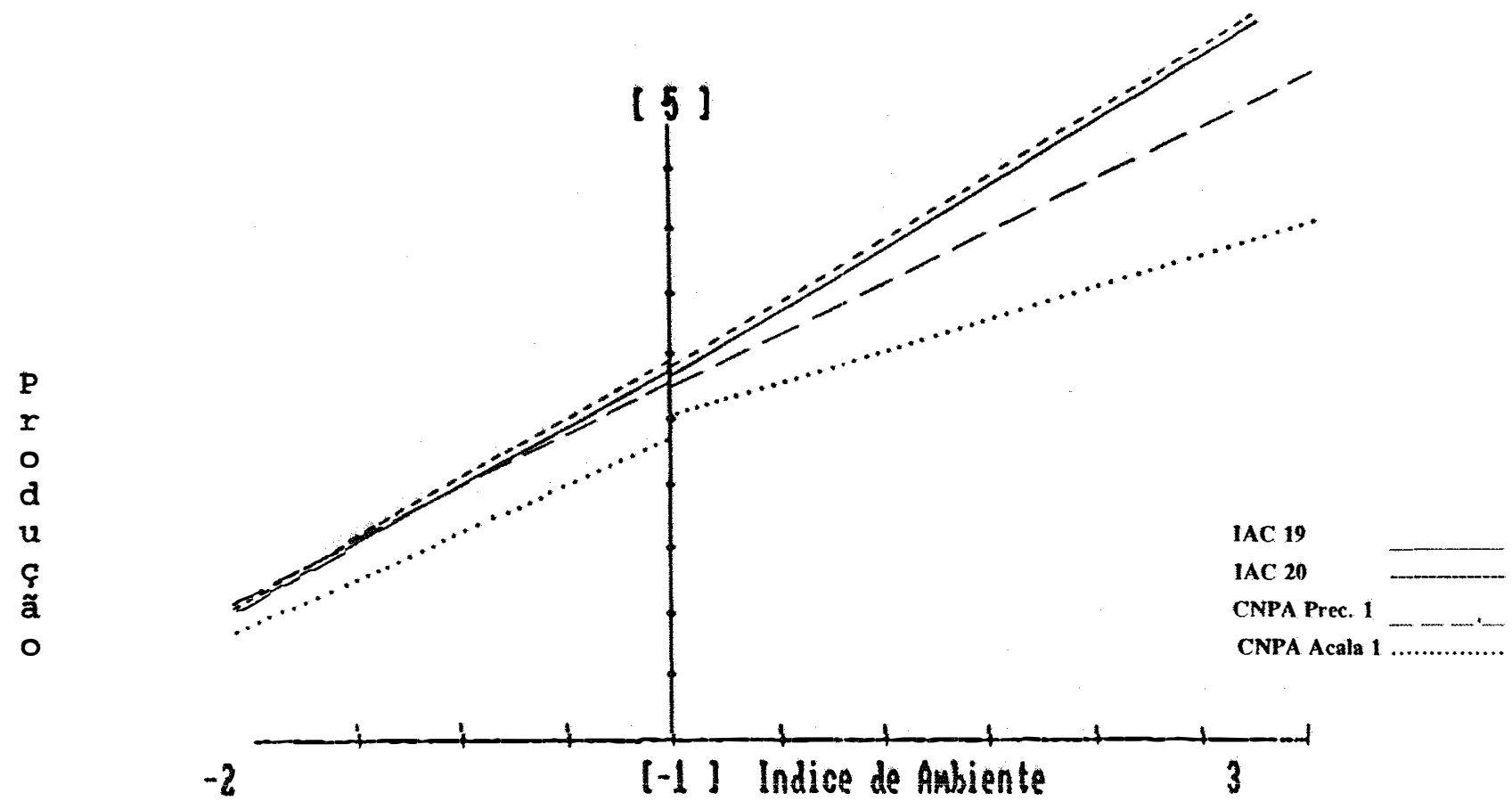

Figura 1. Representação gráfica da produção de algodão em caroço dos quatro cultivares segundo a variação do ambiente. 
degradação do ambiente, apresentaram as maiores médias de produção, e responderam positivamente às melhorias do ambiente.

Os cultivares CNPA Precoce 1 e CNPA Acala 1 mostraram-se menos estáveis e de comportamento menos previsível às variações do ambiente. Com uma capacidade de produção mais baixa, notadamente o segundo, ambos mostraram-se mais adaptados aos ambientes desfavoráveis porém não aproveitaram bem quando as condições melhoraram. A explicação provável para as diferenças de comportamento entre os dois grupos distintos de cultivares, provavelmente tem a ver com as condições nas quais foram desenvolvidos. Os cultivares paulistas IAC 19 e IAC 20 foram selecionados e avaliados em condições favoráveis e desfavoráveis do ambiente enquanto que os outros em condições aparentemente apenas desfavoráveis.

Quanto aos demais componentes da produção, cujos resultados são apresentados nas tabelas 13,14 e 15 e figuras 2,3 e 4 podemos observar, a exemplo da produção, a ocorrência de resposta diferencial dos cultivares às variações do ambiente. Analisando-se os componentes conjuntamente, destaca-se a semelhança de comportamento dos cultivares IAC 19 e IAC 20, em comparação com os outros dois cultivares CNPA Precoce 1 e CNPA Acala 1, que para certos parâmetros apresentaram a mesma reação, diferindo entretanțo em outros parâmetros entre si e dos demais. Os cultivares IAC 19 e IAC 20 mostraram boa estabilidade de comportamento para todas essas características, com exceção da IAC 19 que mostrou certa instabilidade para a porcentagem da fibra (tabela 15 e figura 4). Por outro lado, os outros dois cultivares mostraram-se menos 
estáveis para todas estas características. Para o peso de capulho (tabela 13 e figura 2), os cultivares IAC 19 e IAC 20 apresentaram as maiores médias e adaptabilidade regular nos diferentes ambientes ou seja $B_{1}$ e $B_{1}+B_{2}$ próximos de 1,0. O cultivar CNPA Precoce 1, com a menor média para essa característjca mostrou-se mais resistente a degradação do ambiente do que os anteriores, porém não respondeu bem nos ambientes favoráveis. Contrariamente, o cultivar CNPA Acala 1 mostrou maior sensibilidade aos ambientes desfavoráveis e do mesmo modo que os anteriores não foi responsivo à melhoria do ambiente. Para o peso das sementes (tabela 14 e figura 3) com exceção das variações verificadas nas médias, sendo a maior delas obtida pelo cultivar CNPA Acala 1, todos os cultivares tiveram o mesmo comportamento observado para o peso de capulho (tabela 13 e figura 2) com exceção do CNPA Acala 1 que se mostrou mais sensível aos ambientes desfavoráveis. Quanto à porcentagem da fibra ltabela 15 e figura 4), O IAC 20, apesar de mostrar a média um pouco inferior ao do IAC 19 que teve a maior média, apresentou adaptabilidade mais regular. Já, o IAC 19 mostrou-se não responsivo à melhoria do ambiente. Comportando-se de maneira inversa, o cultivar CNPA Acala 1 apresentou a mais baixa porcentagem de fibra porém foi altamente responsivo à melhoria do ambiente. Para essa mesma característica, o CNPA Precoce 1 foi o único que se mostrou sensível aos ambientes desfavoráveis.

Da mesma forma como observado para os componentes da produção pode-se verificar também para todas as características tecnológicas da fibra (tabela 16 a 20 e figuras 5 a 9), a consistente estabilidade dos cultivares IAC 19 e IAC 20, com 
Tabela 13. Estimativas dos parâmetros de estabilidade e adaptabilidade de quatro cultivares de algodão para o peso de um capulho, segundo a metodologia de CRUZ et alii (1989).

CULTIVAR

$\mathrm{B}_{0} \quad \mathrm{~B}_{1}$

$\mathbf{B}_{2}$

$\mathrm{B}_{1}+\mathrm{B}_{2} \quad \mathrm{QM}$ DES.

$\mathbf{R}^{2}(8)$

IAC 19

IAC 20

CNPA PREC. 1

CNPA ACALA 1

$7,32 a$

$7,10 \mathrm{~b}$

0,999

$5,88 \mathrm{~d}$

1,021

$6,63 \mathrm{C}$
$0,786 * *$

$1,194 *$

0,073
$-0,081$
0,013
$-0,005$

1,072

0,940

0,799

1,189
0,296

0,253

$0,574 *$ *

$0,891 * \star$
94,37

95,16

84,07

88,63

Médias seguidas por letras iguais não diferem estatisticamente entre si (Duncan 5\%).

*, * Significativas aos níveis de $5 \%$ e $1 \%$ respectivamente pelo teste $t$.

p
e
s
o
C
$\mathbf{a}$
p
u
1
h
o

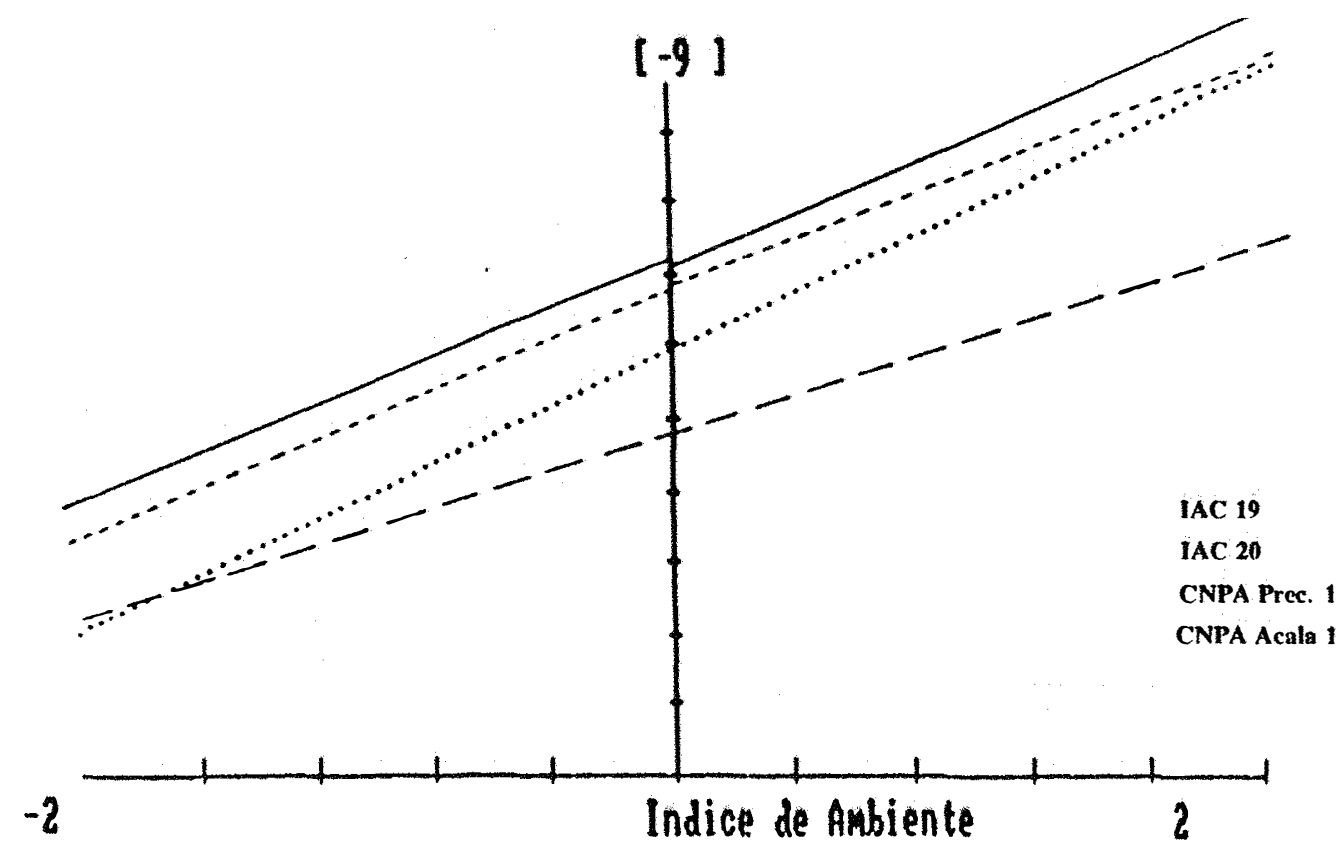

Figura 2. Representação gráfica do peso de um capulho dos quatro cultivares segundo a variação do ambiente. 
Tabela 14. Estimativas dos parâmetros de estabilidade e adaptabilidade de quatro cultivares de algodão para o peso de cem sementes, segundo a metodologia de CRUZ et alii (1989).

\begin{tabular}{|c|c|c|c|c|c|c|}
\hline CULTIVAR & $\mathrm{B}_{0}$ & $\mathrm{~B}_{1}$ & $\mathrm{~B}_{2}$ & $\mathrm{~B}_{1}+\mathrm{B}_{2}$ & QM DES. & $R^{2}(8)$ \\
\hline IAC 19 & $13,23 b$ & 0,987 & 0,067 & 1,055 & 0,656 & 80,54 \\
\hline IAC 20 & $12,87 \mathrm{c}$ & 0,986 & $-0,163$ & 0,822 & 0,504 & 90,31 \\
\hline CNPA PREC. 1 & $11,23 d$ & $0,720 * \star$ & 0,211 & 0,931 & $1,485 * \star$ & 66,2 \\
\hline CNPA ACALA 1 & $13,49 a$ & $1,307 * *$ & $-0,115$ & 1,192 & $3,122 * *$ & 73,02 \\
\hline
\end{tabular}

Médias seguidas por letras iguais não diferem estatisticamente entre si (Duncan 5\%).

*, * significativas aos níveis de 5 e $1 \%$ respectivamente pelo teste $t$.

1
0
0
s
e
m
e
n
t
e
s

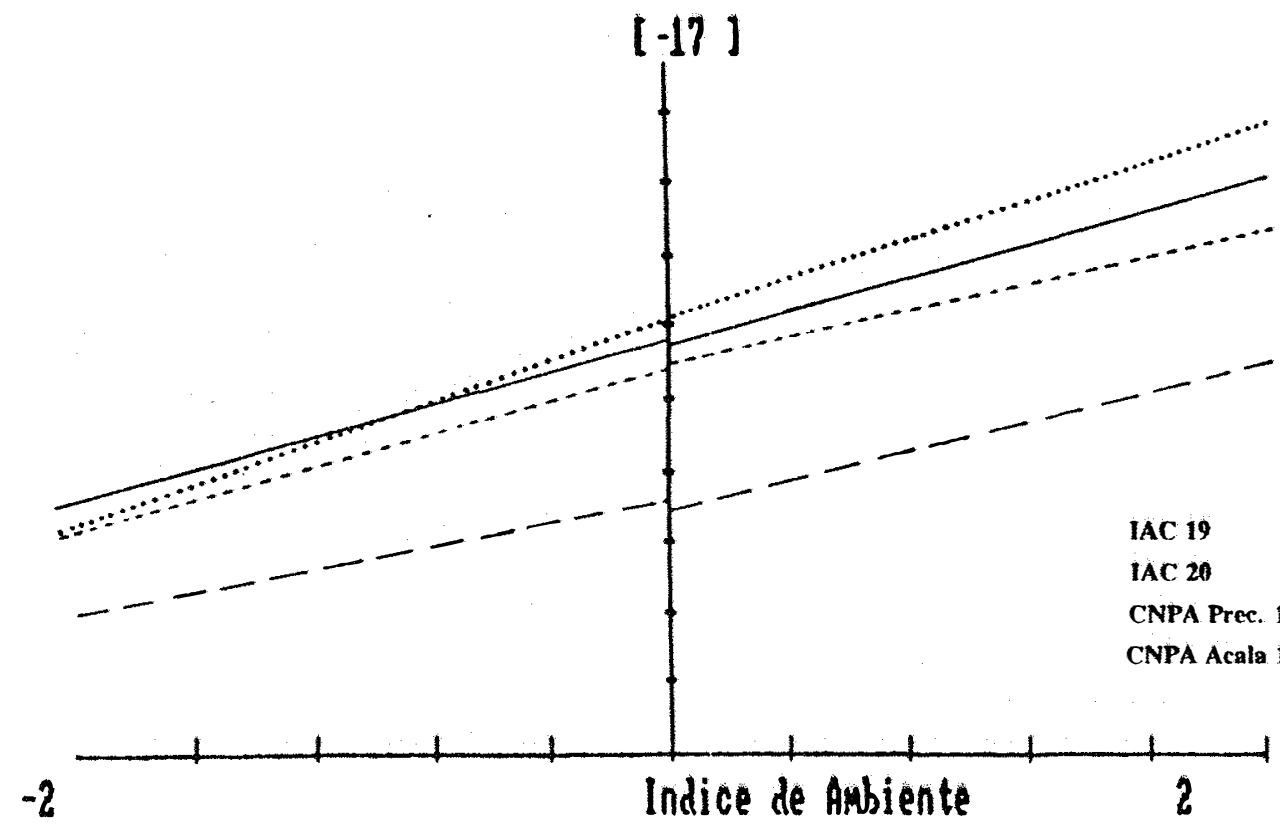

Figura 3. Representação gráfica do peso de cem sementes dos quatro cultivares segundo a variação do ambiente. 
Tabela 15. Estimativas dos parâmetros de estabilidade e adaptabilidade de quatro cultivares de algodão para porcentagem de fibras, segundo a metodologia de CRUZ et alii (1989).

\begin{tabular}{|c|c|c|c|c|c|c|}
\hline CULTIVAR & $\mathrm{B}_{0}$ & $B_{1}$ & $\mathrm{~B}_{2}$ & $B_{1}+B_{2}$ & QM DES. & $R^{2}(z)$ \\
\hline IAC 19 & $39,02 a$ & 0,949 & $-0,143$ & $0,806 *$ & 1,820 * & 91,08 \\
\hline IAC 20 & $38,70 \mathrm{~b}$ & 0,949 & $-0,103$ & 0,846 & 1.587 & 92,25 \\
\hline CNPA PREC. 1 & $38,80 \mathrm{~b}$ & $1,178 * \star$ & $-0,202 *$ & 0,976 & $6,658 * \star$ & 80,99 \\
\hline CNPA ACALA 1 & $34,78 \mathrm{c}$ & 0,925 & $0,447 * *$ & $1,372 * \star$ & $6,217 \star \star$ & 79,45 \\
\hline
\end{tabular}

Médias seguidas por letras iguais não diferem estatisticamente entre si (Duncan $5 \%$ ).

*, ** Significativas aos níveis de 5 e $1 \%$ respectivamente pelo teste $t$.

$q$
$F$
1
$b$
$x$
$a$

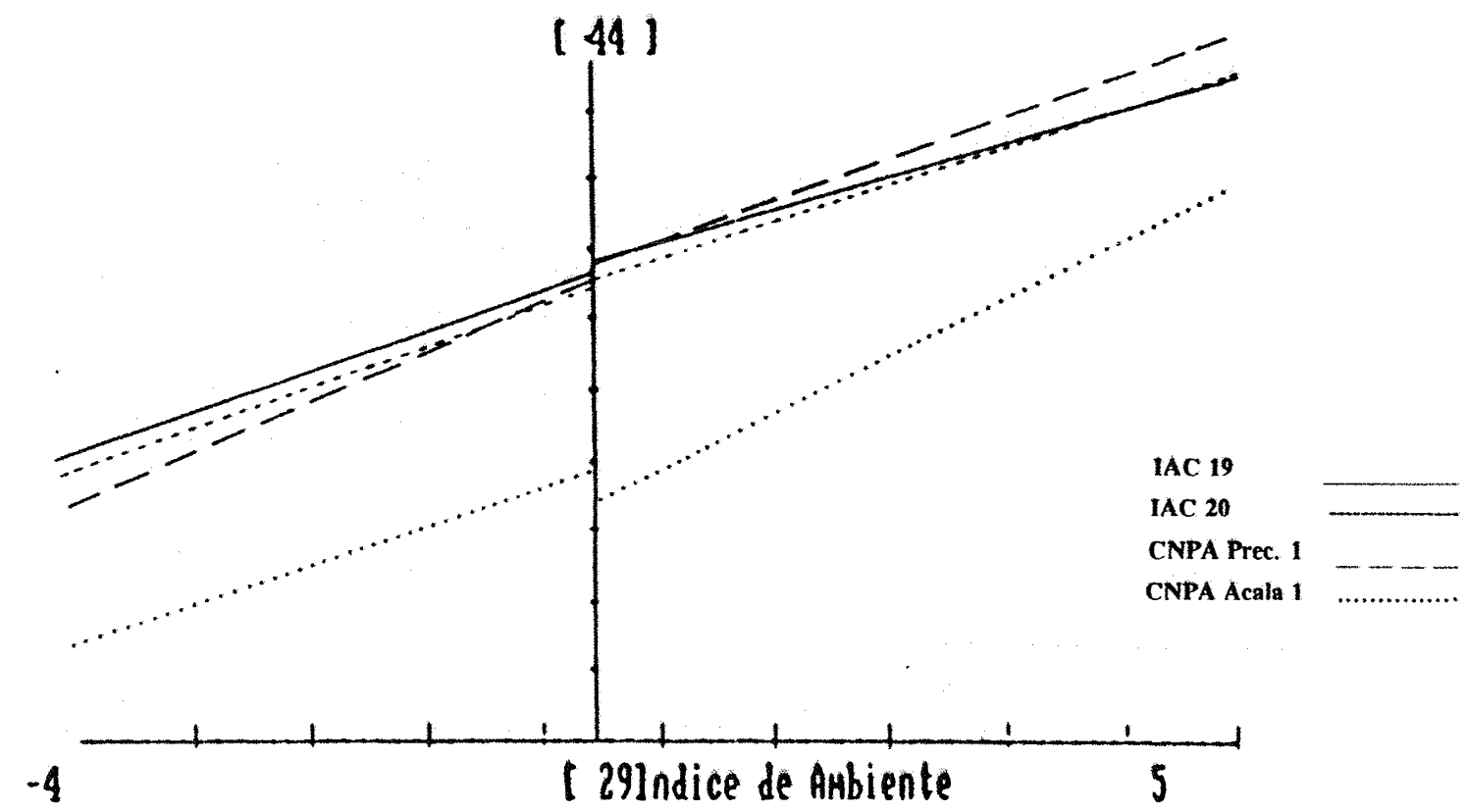

Figura 4. Representação gráfica da porcentagem de fibra dos quatro cultivares segundo a variação do ambiente. 
exceção apenas do índice Micronaire (tabela 19 e figura 8) no caso do IAC 19. Por outro lado, pode-se verificar também a consistente instabilidade geral dos cultivares CNPA Acala 1 e CNPA Precoce 1. Analisando-se o comportamento diferencial dos cultivares pode-se tecer algumas considerações gerais quando se trata de todas as características da fibra conjuntamente: nenhum dos cultivares considerados neste estudo mostrou-se responsivo à melhoria das condições do ambiente para qualquer característica, enquanto que se verifica comportamento diferencial dos cultivares em condições desfavoráveis. Notadamente o cultivar CNPA Acala 1 mostrou-se sensível à deterioração do ambiente para todas as características da fibra com exceção do índice Micronaire. Para os demais, algumas diferenças de comportamento foram observados nos ambientes desfavoráveis.

Quanto ao comprimento da fibra (tabela 16 e figura 5), observa-se pela média, que o cultivar CNPA Acala 1 produz o maior comprimento, porém, foi o único que se mostrou sensível quando o ambiente não é favorável para esta característica. Quanto aos demais cultivares, tipicamente produtores de fibras de comprimento médio, mostraram uma adaptabilidade regular.

Analisando-se os parâmetros obtidos para a uniformidade do comprimento (tabela 17 e figura 6), verifica-se que os cultivares IAC 19 e IAC 20 os quais fornecem as maiores médias, apresentaram uma adaptabilidade regular. O cultivar CNPA Precoce 1 foi resistente às más condições do ambiente enquanto que o CNPA Acala 1 apresentou a menor média e mostrou-se sensível a fatores negativos do ambiente. 
Tabela 16. Estimativas dos parâmetros de estabilidade e adaptabilidade de quatro cultivares de algodão para o comprimento de fibra, segundo a metodologia de CRUz et alii (1989).

CULTIVAR

$B_{0} \quad B_{1}$

$B_{2} \quad B_{1}+B_{2}$

QM DES. $R^{2}(\gamma)$

IAC 19

IAC 20

CNPA PREC. 1

CNPA ACALA 1
$27,34 \mathrm{~b}$

$27,19 \mathrm{c}$

$27,04 d$

$30,63 a$
0,931

0,998

0,966

1,106 *
$-0,058$

0,026

$-0,042$

0,074
0,872

1,024

0,924

1,180
0,528

0,510

$1,538 *$

$1,521 * *$
93,31

94,41

83,80

87,51

Médias seguidas por letras iguais não diferem estatisticamente entre si (Duncan 5\%).

*, ** Significativas aos níveis de 5 e $1 \%$ respectivamente pelo teste $t$.

$c$
$o$
$m$
$p$
$r$
1
$m$
$e$
$n$
$t$
$o$

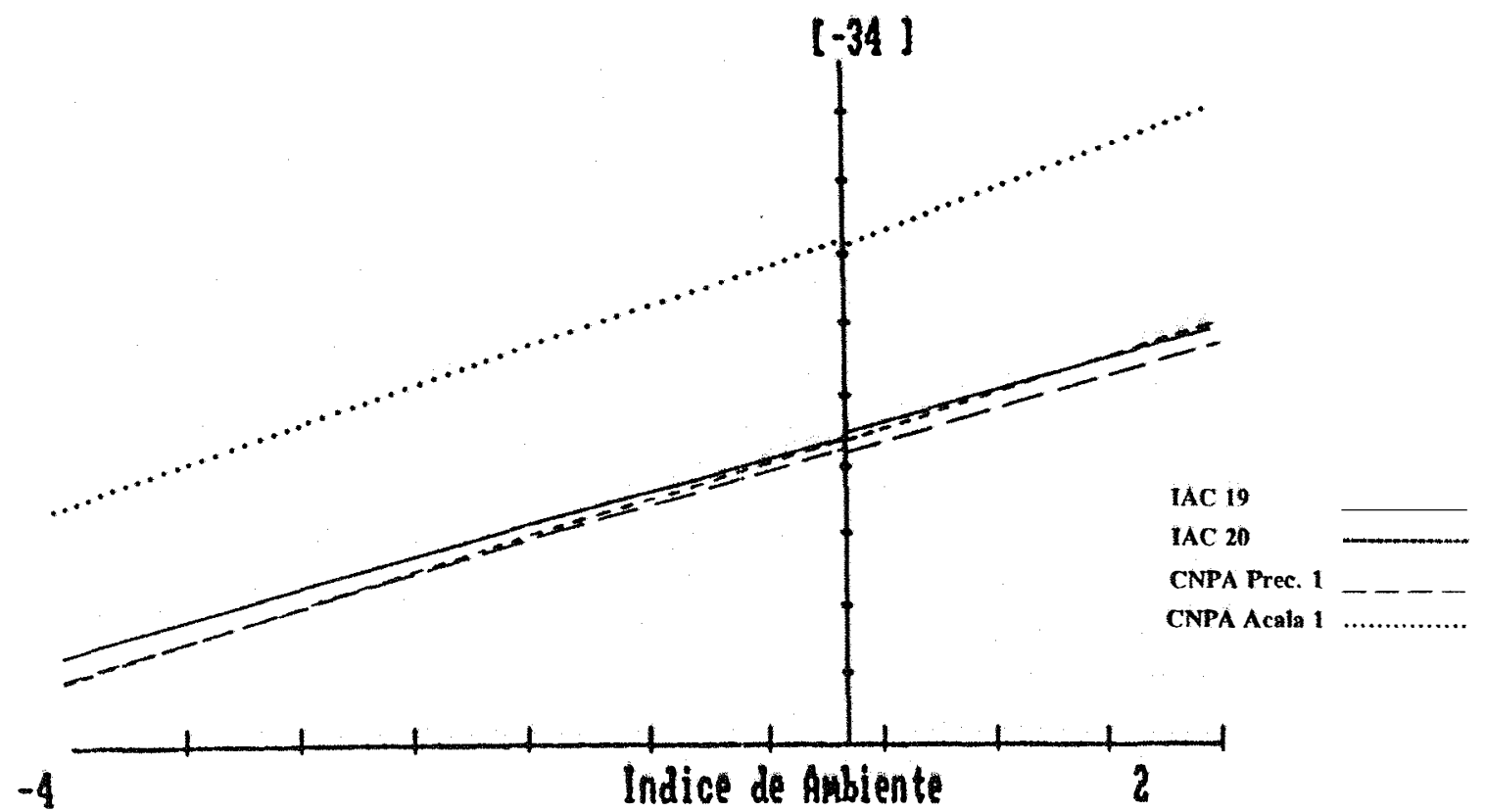

Figura 5. Representação gráfica do comprimento de fibra dos quatro cultivares segundo a variação do ambiente. 
Tabela 17. Estimativas dos parâmetros de estabilidade e adaptabilidade de quatro cultivares de algodão para uniformidade de comprimento, segundo a metodologia de CRUz et alii (1989).

\begin{tabular}{|c|c|c|c|c|c|c|}
\hline CULTIVAR & $\mathrm{B}_{0}$ & $\mathrm{~B}_{1}$ & $\mathrm{~B}_{2}$ & $B_{1}+B_{2}$ & QM DES. & $R^{2}(z)$ \\
\hline IAC 19 & $45,07 \mathrm{~b}$ & 0,920 & 0,088 & 1,009 & 1,565 & 90,86 \\
\hline IAC 20 & $45,81 a$ & 0,986 & $-0,031$ & 0,955 & 1,540 & 91,73 \\
\hline CNPA PREC. 1 & $44,26 c$ & 0,835 * & 0,120 & 0,955 & $3,336 * \star$ & 79,60 \\
\hline CNPA ACALA 1 & $43,15 d$ & $1,259 * *$ & $-0,177$ & 1,082 & $4,468 * \star$ & 85,73 \\
\hline
\end{tabular}

Médias seguidas por letras iguais não diferem estatisticamente entre si (Duncan 5\%).

*, ** Significativas aos níveis de 5 e $1 \%$ respectivamente pelo teste $t$.

U
n
i
f
$o$
$r$
m
$i$
$d$
$a$
$d$
$e$

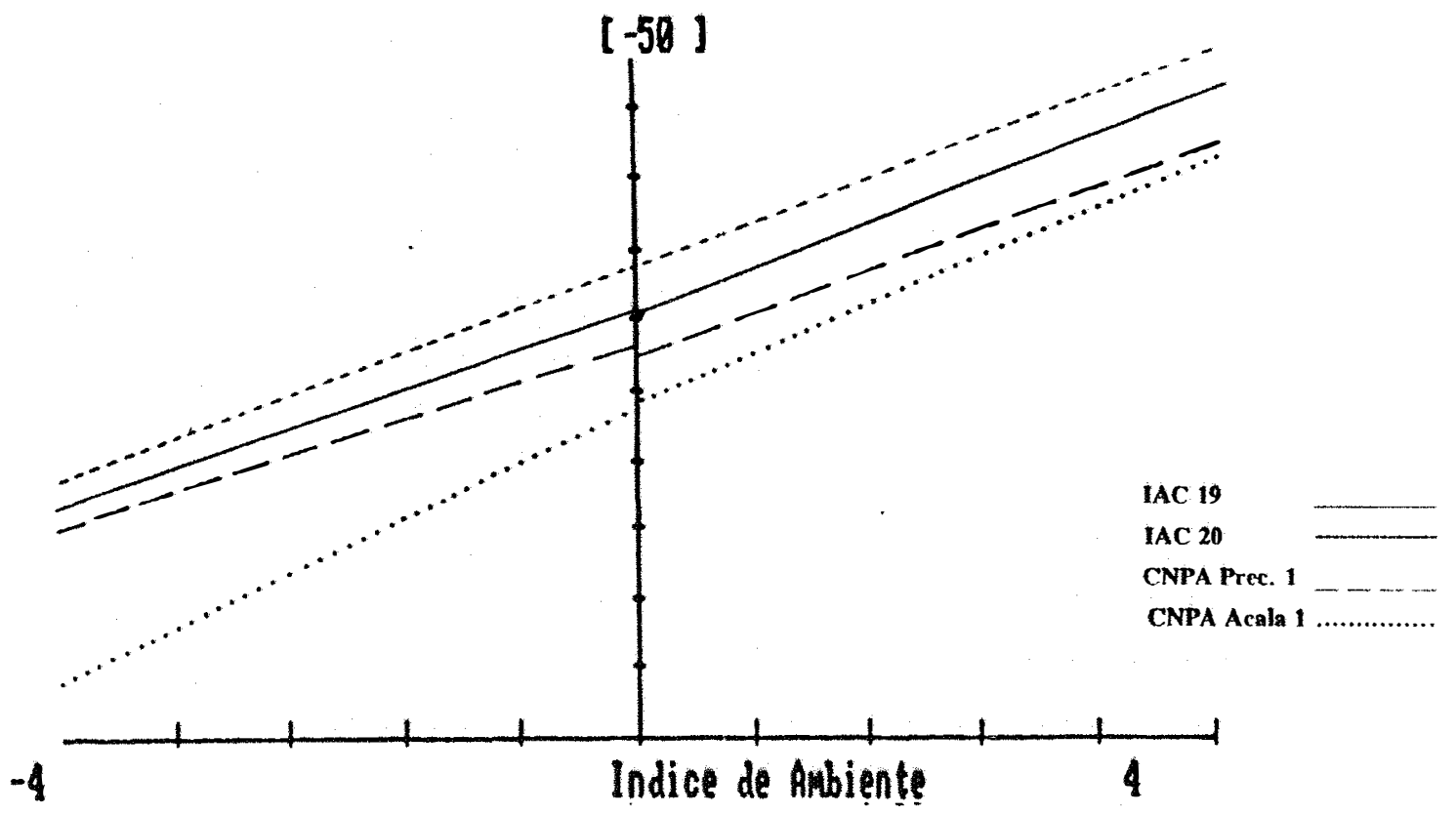

Figura 6. Representação gráfica da uniformidade de fibra dos quaquatro cultivares segundo a variação do ambiente. 
Considerando a tenacidade da fibra (tabela 18 e figura 7), observa-se a ampla superioridade do cultivar CNPA Acala,1 quando se comparam as médias. Porém, como vem sendo observado para as outras características, esse cultivar mostrou-se altamente sensível aos ambientes inferiores. Quanto aos demais cultivares, todos mostraram-se igualmente resistentes à deterioração do ambiente. Porém, destaca-se nesta característica, como produtor de fibras medias, O cultivar IAC 19 por apresentar fibras mais resistentes.

Quanto ao índice Micronaire (tabela 19 e figura 8), verifica-se um comportamento antagônico entre os cultivares CNPA Acala 1 e IAC 20. O primeiro apresentou o menor índice e mostrou-se resistente à deterioração do ambiente, enquanto O IAC 20 comportou-se de maneira inversa. Os outros dois cultivares, apresentando valores intermediários quanto à média, mostraram adaptabilidade regular.

Quando se analisam os parâmetros obtidos para a maturidade da fibra (tabela 20 e figura 9), considerando-se os mesmos cultivares, CNPA Acala 1 e IAC 20 o antagonismo se dá de maneira inversa: O IAC 20 apresenta maior média e resistência a condições desfavoráveis e o CNPA Acala 1 comporta-se de maneira inversa. O cultivar IAC 19 mostra pelo conjunto de seus parâmetros, uma adaptabilidade regular, enquanto que o cultivar CNPA Precoce 1 , apresenta a média mais baixa. Considerando que o índice Micronaire pode representar a finura da fibra, para as mesmas condições de maturidade, os cultivares CNPA Precoce 1 e CNPA Acala 1 poderiam ser tidos como produtores de fibra fina. Porém, se considerarmos 
Tabela 18. Estimativas dos parâmetros de estabilidade e adaptabilidade de quatro cultivares de algodão para a tenacidade da fibra, segundo a metodologia de CRUz et alii (1989).

\begin{tabular}{lccrcrr}
\hline CULTIVAR & $\mathbf{B}_{\mathbf{0}}$ & $\mathbf{B}_{\mathbf{1}}$ & $\mathbf{B}_{\mathbf{2}}$ & $\mathbf{B}_{\mathbf{1}}+\mathbf{B}_{\mathbf{2}}$ & QM DES. & $\mathbf{R}^{\mathbf{2}(\boldsymbol{8})}$ \\
& & & & & & \\
\hline IAC 19 & $22,74 \mathrm{~b}$ & $0,837 *$ & $-0,154$ & 0,683 & 1,630 & 81,25 \\
IAC 20 & $22,12 \mathrm{C}$ & $0,841 *$ & 0,134 & 0,975 & 1,969 & 79,73 \\
CNPA PREC.1 & $21,76 \mathrm{~d}$ & $0,866^{*}$ & 0,115 & 0,981 & $4,991 *$ & 62,04 \\
CNPA ACALA 1 & $27,35 \mathrm{a}$ & $1,456 * *$ & $-0,095$ & 1,361 & $7,868 * *$ & 73,60
\end{tabular}

Médias seguidas por letras iguais não diferem estatisticamente entre si (Duncan 5\%).

*, * Significativas aos níveis de 5 e $1 \%$ respectivamente pelo teste $t$.

I
n
d
I
c
e
P
r
e
s
s
I
e
y

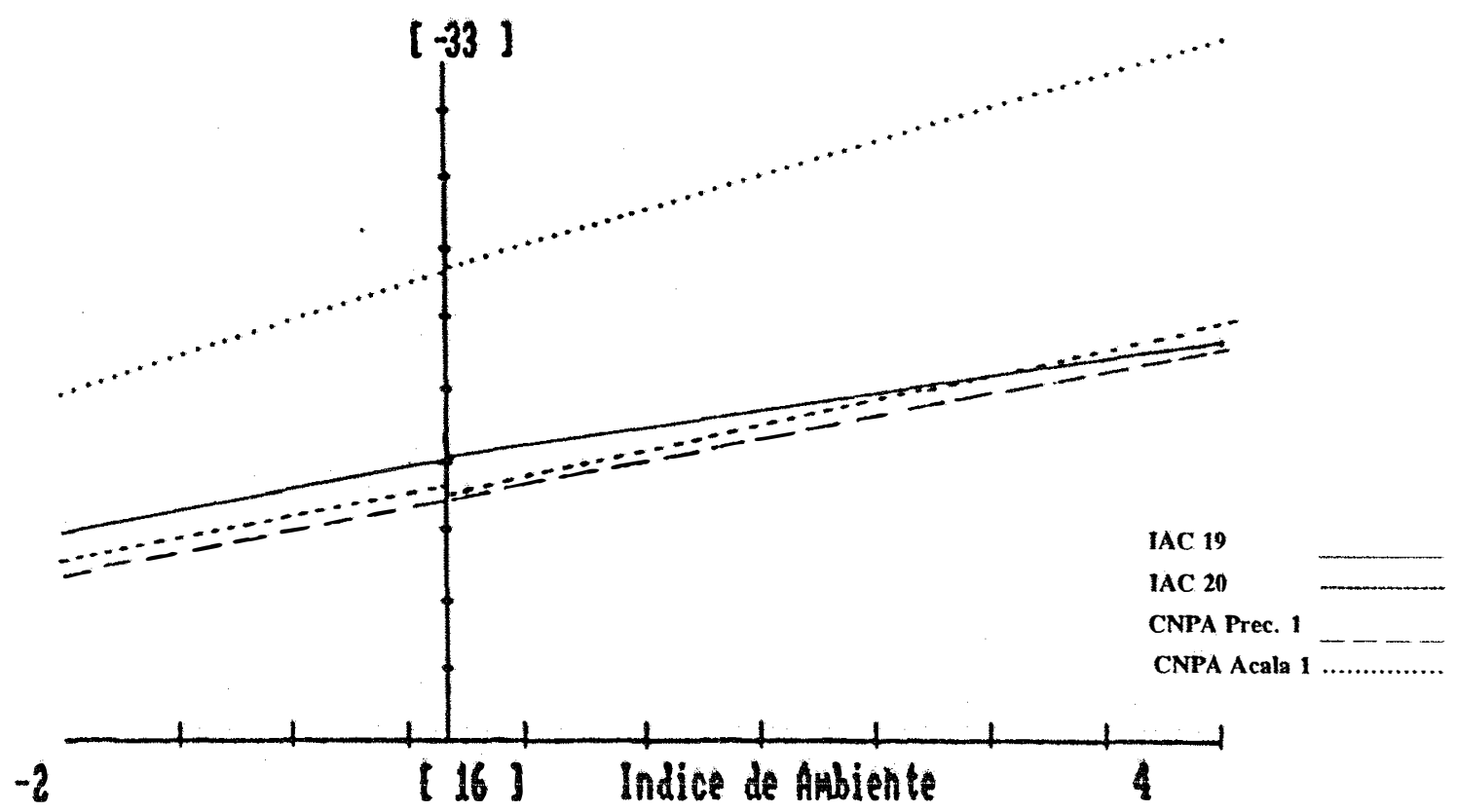

Figura 7. Representação gráfica da tenacidade da fibra dos quatro cultivares segundo a variação do ambiente. 
Tabela 19. Estimativas dos parâmetros de estabilidade e adaptabilidade de quatro cultivares de algodão para o índice Micronaire, segundo a metodologia de CRUZ et alii (1989).

CULTIVAR

$\begin{array}{llllll}B_{0} & B_{1} & B_{2} & B_{1}+B_{2} & \text { QM DES. } & R^{2}(\%)\end{array}$

IAC 19

IAC 20

$4,73 \mathrm{~b}$

1,094

0,028

1,122

0,140 *

88,97

CNPA PREC. 1

$4,79 a$

1,120 *

0,017

1,138

0,102

91,99

CNPA ACALA 1

$4,10 \mathrm{C}$

1,030

$-0,044$

0,986

$0,384 * *$

71,80

$3,80 \mathrm{~d}$

$0,755 * *-0,001$

0,754

$0,306 * *$

63,50

Médias seguidas por letras iguais não diferem estatisticamente entre si (Duncan 5\%).

*, ** Significativas aos níveis de 5 e $1 \%$ respectivamente pelo teste $t$.

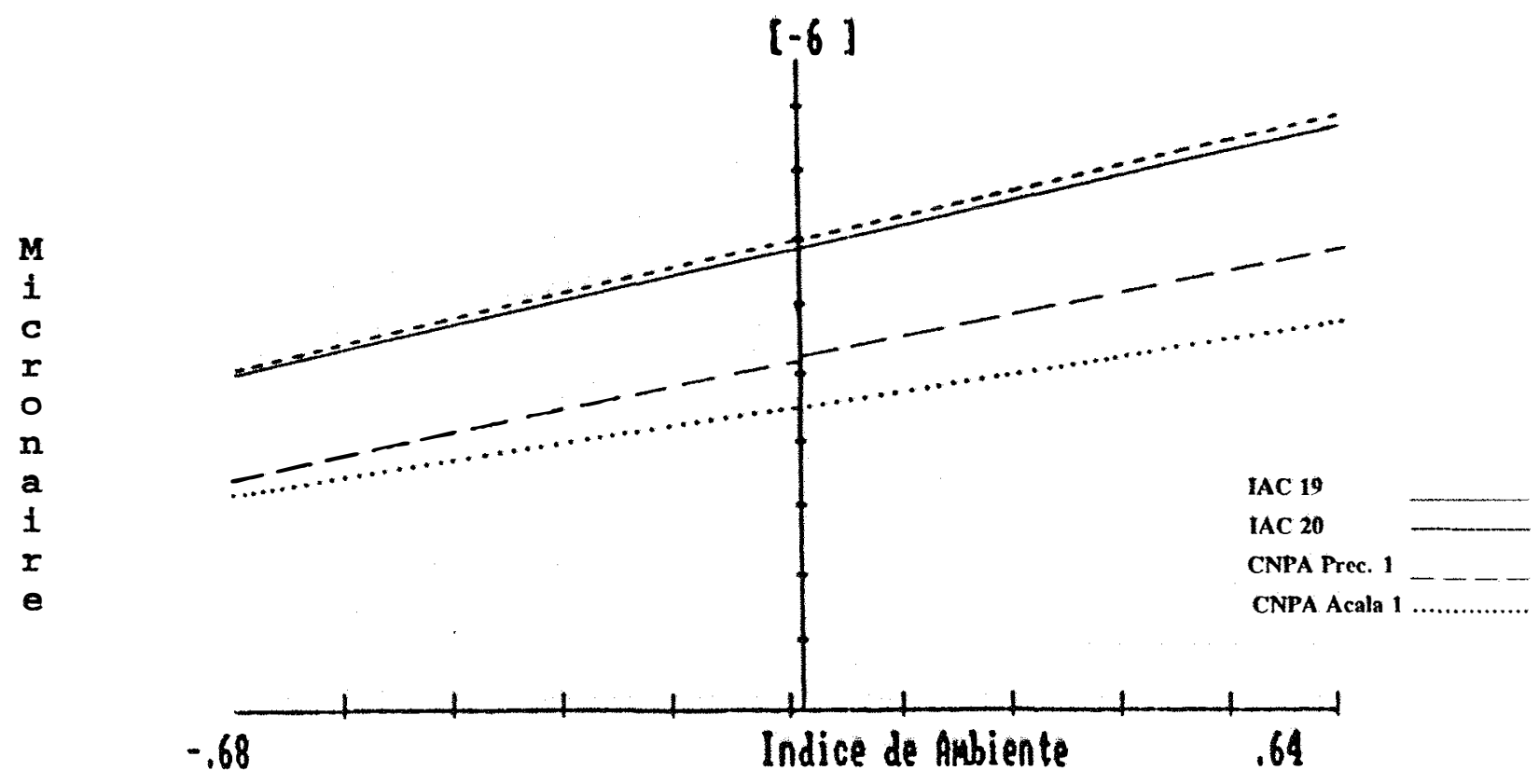

Figura 8. Representação gráfica do índice Micronaire dos quatro cultivares segundo a variação do ambiente. 
Tabela 20. Estimativas dos parâmetros de estabilidade e adaptabilidade de quatro cultivares de algodão para a maturidade de fibra, segundo a metodologia de CRUz et alii (1989).

CULTIVAR

$\mathrm{B}_{0}$

$\mathbf{B}_{1}$

$\mathrm{B}_{2}$

$\mathrm{B}_{1}+\mathrm{B}_{2} \quad \mathrm{QM}$ DES.

$R^{2}(z)$

IAC 19

$70,31 a$

0,980

0,081

1,061

14,441

91,97

IAC 20

$70,72 a$

0,865 *

0,096

0,961

15,590

89,29

CNPA PREC. 1

$64,59 \mathrm{c}$

0,998

$-0,056$

0,942

33,995 * *

83,01

CNPA ACALA 1

$67,48 b$

$1,157 * \star-0,121$

1,036

29,276 **

88,31

Médias seguidas por letras iguais não diferem estatisticamente entre si (Duncan 5\%).

*, ** Significativas aos níveis de 5 e $1 \%$ respectivamente pelo teste $t$.

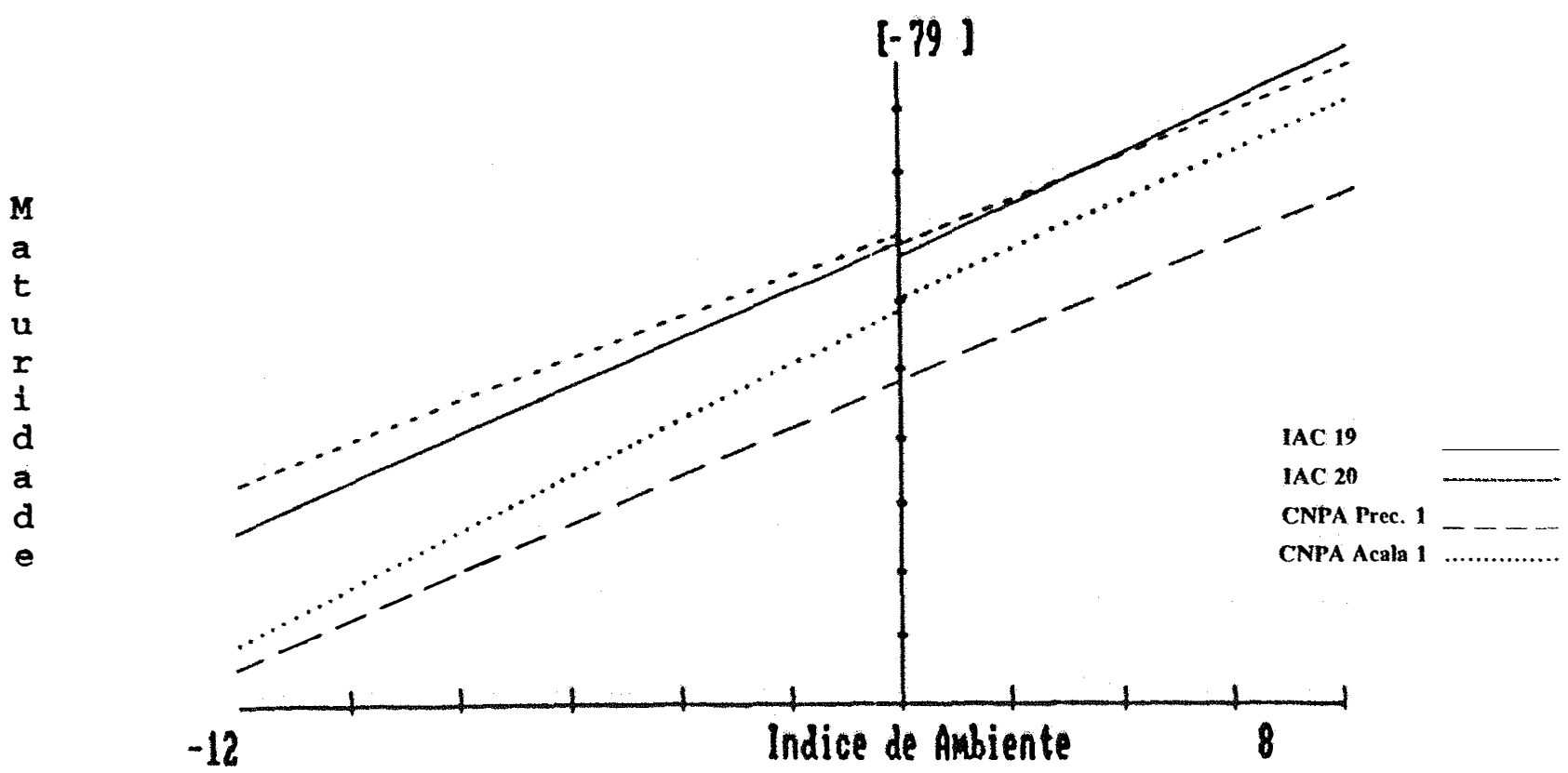

Figura 9. Representação gráfica da maturidade da fibra dos quatro cultivares segundo a variação do ambiente. 
o seu comportamento, qual seja, baixos índices Micronaire e baixas maturidades da fibra, estes dados sugerem que as fibras destes cultivares foram de fato imaturas e não propriamente finas. No caso dos cultivares IAC 19 e IAC 20, os quais apresentaram valores mais altos do índice Micronaire e da maturidade da fibra, pode-se considerar que apresentam uma adaptabilidade regular para a finura da fibra.

Tendo em vista a diferença de comportamento observada entre os cultivares com relaçăo ao ambiente, para as características tecnológicas da fibra, procurou-se verificar os reflexos do conjunto dessas características na qualidade do fio. Analisando-se a tenacidade do fio (tabela 21 e figura 10), verifica-se que o algodão produzido pelos cultivares CNPA Precoce 1 e CNPA Acala 1, nos diversos ambientes, deu origem a fios cuja tenacidade, além de menos estáveis, são também menos previsíveis, a julgar pelos baixos coeficientes de determinação $\left(R^{2}\right)$. Por outro lado, os cultivares IAC 19 e IAC 20 demonstraram produzir fibra que possibilita maior previsibilidade para essa característica do fio. Uma possível explicação para isso é a também maior estabilidade e previsibilidade desses últimos cultivares com respeito às características da fibra que determinam a tenacidade do fio, principalmente o comprimento, a uniformidade e a tenacidade. Analisando-se os outros parâmetros, verifica-se que para esta característica todos os cultivares apresentam uma adaptabilidade regular às variações ambientes. Quanto à elongação do fio (tabela 22 e figura 11), o cultivar CNPA Precoce 1 mostrou-se o menos estável, refletindo a menor estabilidade para as características da 
Tabela 21. Estimativas dos parâmetros de estabilidade e adaptabilidade de quatro cultivares de algodão para a tenacidade do fio, segundo a metodologia de CRUZ et alii (1989).

\begin{tabular}{|c|c|c|c|c|c|c|}
\hline CULTIVAR & $\mathrm{B}_{0}$ & $\mathrm{~B}_{1}$ & $\mathrm{~B}_{2}$ & $B_{1}+B_{2}$ & QM DES. & $R^{2}(z)$ \\
\hline IAC 19 & $14,59 \mathrm{~b}$ & 0,971 & $-0,009$ & 0,962 & 0,997 & 80,11 \\
\hline IAC 20 & $13,62 \mathrm{c}$ & 1,153 & $-0,151$ & 1,002 & 0,800 & 87,00 \\
\hline CNPA PREC. 1 & $13,63 \mathrm{C}$ & 0,909 & 0,067 & 0,976 & $2,168 * \star$ & 62,78 \\
\hline CNPA ACALA 1 & $17,50 a$ & 0,967 & 0,093 & 1,060 & $2,299 \star \star$ & 64,55 \\
\hline
\end{tabular}

Médias seguidas por letras iguais não diferem estatisticamente entre si (Duncan 5\%).

*, * Significativas aos níveis de 5 e $1 \%$ respectivamente pelo teste $t$.

$\mathrm{T}$
e
$\mathrm{n}$
$\mathrm{a}$
$\mathrm{c}$
$\mathrm{i}$
$\mathrm{d}$
$\mathrm{a}$
$\mathrm{d}$
$\mathrm{e}$

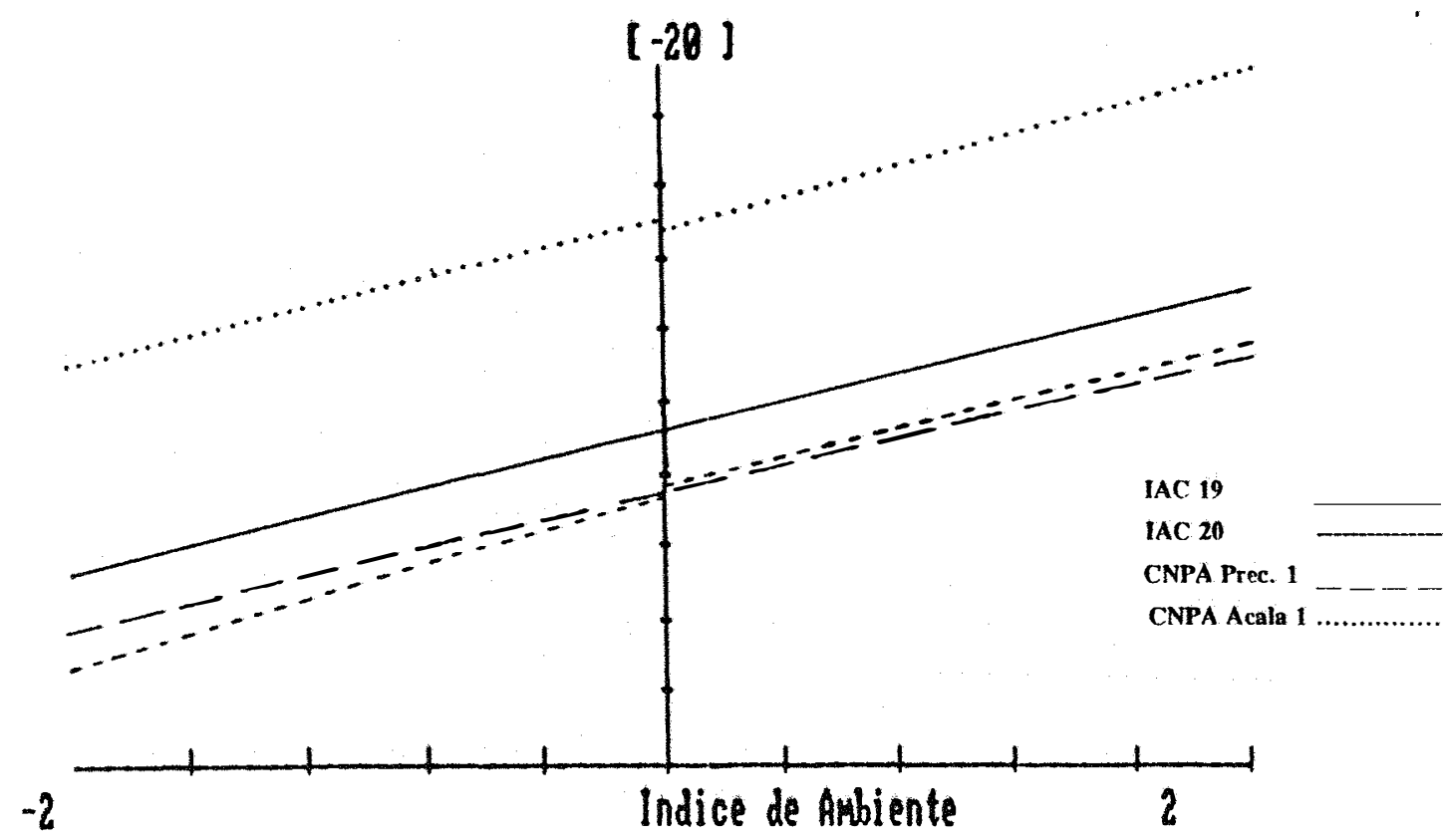

Figura 10. Representação gráfica da tenacidade do fio dos quatro cultivares segundo a variação do ambiente. 
fibra responsáveis por essa propriedade do fio, principalmente o comprimento, a uniformidade e o Micronaire. O cultivar CNPA Acala 1, embora mais estável do que essse último, apresentou menor previsibilidade para a elongação do fí. É de se notar, entretanto, que nesse caso a elongação do fio dependeu apenas da uniformidade da fibra e a variação explicada foi de apenas 12\% (tabela 7).

Por outro lado O IAC 19 e O IAC 20 ainda quanto a elongação do fio produzido (tabela 22 e figura 11) mostraram-se não apenas mais estáveis como de comportamento mais previsível, e revelaram adaptabilidade regular. Já, o cultivar CNPA Precoce 1 mostrou-se altamente sensível aos ambientes desfavoráveis e pouco responsivo nos bons ambientes, enquanto que $\bigcirc$ CNPA Acala 1 , inversamente, mostrou-se resistente às condições desfavoráveis e reagiu bem com a melhoria do ambiente. Esse comportamento não coincide com o que foi observado para as características da fibra responsáveis pela elongação do fio. 'Todavia, como já se ressaltou, além de pouco explicada a variação dessa propriedade, no caso do CNPA Acala 1, é provável que a não determinação da elongação da fibra - supostamente fator de importância na elongação do fio tenha contribuído para obtenção desses resultados pouco coerentes. Outra possível explicação é que por se tratar de fio médio (Título $22 \mathrm{NE})$, O CNPA Acala 1 não mostrou as correlações e comportamento que poderiam ser obtidos com fios finos e extra-finos, para os quais se destina seu algodão. 
Tabela 22. Estimativas dos parâmetros de estabilidade e adaptabilidade de quatro cultivares de algodão para a elongaÇão do fio, segundo a metodologia de CRUZ et alii (1989).

\begin{tabular}{lcccccc}
\hline CULTIVAR & $\mathbf{B}_{\mathbf{0}}$ & $\mathbf{B}_{\mathbf{1}}$ & $\mathbf{B}_{\mathbf{2}}$ & $\mathbf{B}_{\mathbf{1}}+\mathbf{B}_{\mathbf{2}}$ & QM DES . & $\mathbf{R}^{\mathbf{2}(8)}$ \\
\hline IAC 19 & $6,59 \mathrm{~d}$ & 0,952 & $-0,072$ & 0,879 & 0,226 & 82,66 \\
IAC 20 & $6,77 \mathrm{~b}$ & 1,036 & $-0,119$ & 0,917 & 0,175 & 87,82 \\
CNPA PREC.1 & $7,17 \mathrm{a}$ & $1,346 * \star$ & $-0,108$ & 1,238 & $0,474 * \star$ & 81,96 \\
CNPA ACALA 1 & $6,66 \mathrm{C}$ & $0,666 * \star$ & 0,299 & 0,965 & 0,255 & 72,07
\end{tabular}

Médias seguidas por letras iguais não diferem estatisticamente entre si (Duncan 5\%).

*, ** Significativas aos níveis de 5 e $1 \%$ respectivamente pelo teste $t$.

$\mathbf{E}$
I
o
n
g
$\mathbf{a}$
$\mathbf{c}$
$\mathbf{a}$
o

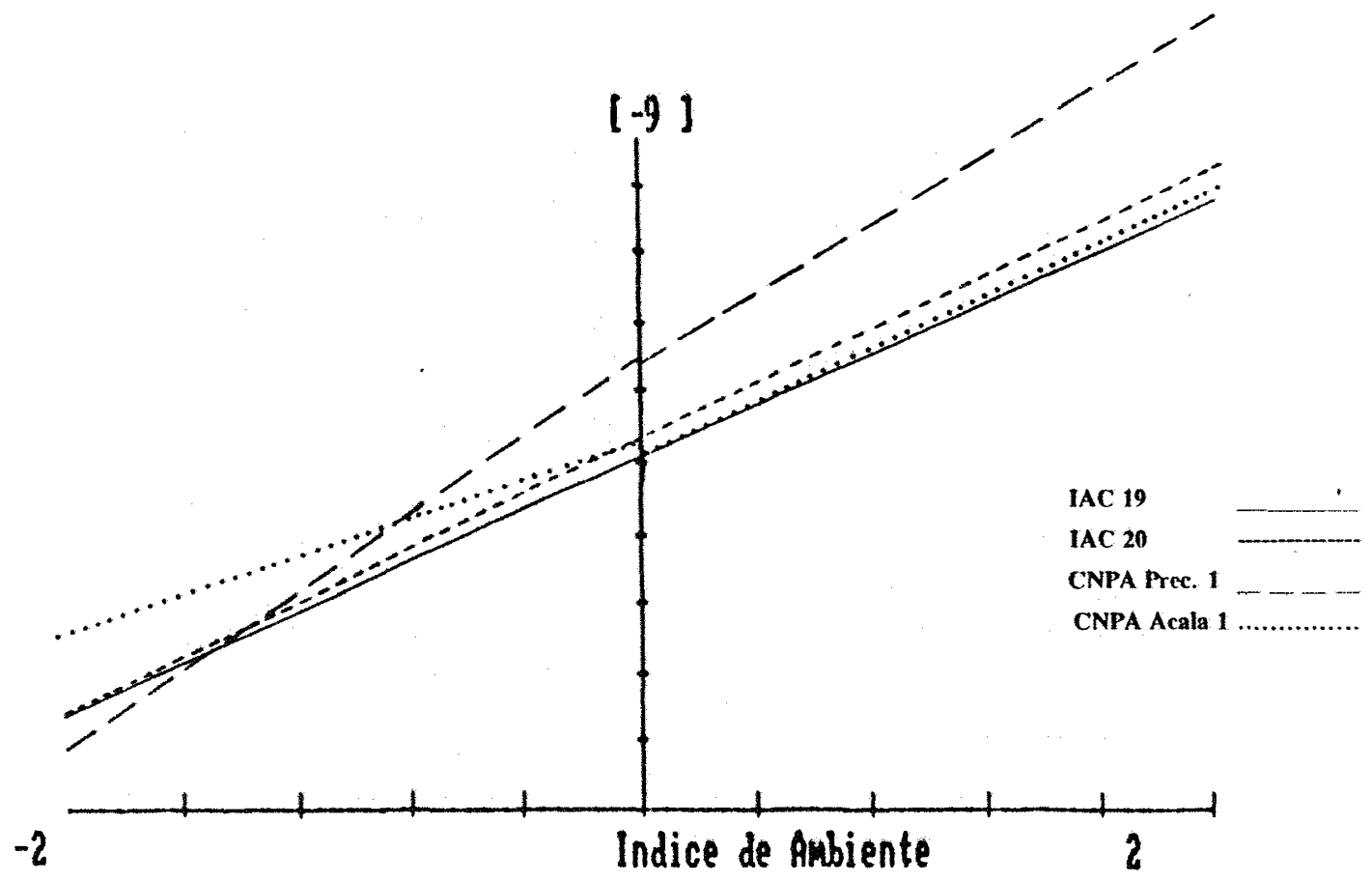

Figura 11. Representação gráfica da elongação do fio dos quatro cultivares segundo a variação do ambiente. 


\section{CONCLUSÃo}

Os resultados obtidos no presente estudo permitem concluir:

1. Embora, idealmente, devessem atender de igual forma todos os segmentos envolvidos, cultivares de algodoeiro podem favorecer setores ou sistemas de produção específicos. Do comportamento dos cultivares estudados nesse trabalho pode-se depreender:

a) destacando-se pela maior produtividade, O IAC 20 beneficia o produtor que comercializa algodão em caroço, dada a impraticabilidade de remunerar a qualidade intrínseca da fibra, nesse tipo de transação;

b) embora menos produtivo (4\%), O IAC 19, pela melhor qualidade e maior porcentagem de fibra, pode favorecer o produtor que beneficia seu próprio algodão e comercializa a fibra diretamente com o industrial;

c) 0 CNPA Acala 1, pela alta qualidade da fibra, atende essencialmente ao interesse do industrial, uma vez que suas produções de algodão em caroço e de fibra são cerca de $29 \%$ e $36 \%$, respectivamente, inferiores a dos cultivares mais produtivos IAC 19 
e IAC 20. Sua utilização, portanto, exige remuneração superior equivalente para o produto, em cada caso, e seria mais segura se realizada mediante contrato prévio com o interessado nessa fibra.

2. A influência do ambiente nas características estudadas foi em geral, maior à de cultivar. Consequentemente, torna-se imprevisível a pré-determinação de valores das características, notadamente as da fibra, conforme requerido pela indústria têxtil, que demanda uma maior padronização dentro e entre as características.

3. Dada a dispersão média de $46,73 \%$ e em valores absolutos médios de 3,51 a 5,13 para o índice Micronaire, é discutível a tendência de se fixar e supervalorizar índices absolutos 3,87 e mesmo faixas $(3,7-4,2)$ restritos para essa característica, como padrão de qualidade da fibra em geral, por parte de setores ligados à indústria têxtil. De fato, considerando que este índice está associado também com a maturidade, pode-se impedir que ele caia abaixo dos limites inferiores mediante técnicas adequadas, porém, é questjonável a possibilidade de se impedir que ele se situe acima do limite superior de 4,2.

4. Melhorias do ambiente exclusivamente para a produção de algodão, não resultam n€əcessariamente em melhorias na qualidade da fibra e do fio. 
5. A melhoria do ambiente garante a capacidade genética dos cultivares para a qualidade da fibra porém, alguns cultivares mostram-se mais sensíveis a condições desfavoráveis.

6. O cultivar CNPA Acala 1, típico produtor de fibra longa e alta qualidade geral das demais características da fibra e do fio, apresenta, em certas condições, comportamento igual ou inferior ao que pode ser obtido com cultivares de fibra média, dada a sua maior sensibilidade aos ambientes desfavoráveis. Verifica-se, pois, que apenas o cultivar não é garantia de boa qualidade geral das características estudadas.

7. A interação cultivar $x$ ambiente pode estar na dependência de fatores imprevisíveis do ambiente para cada característica. A constatação principalmente da ocorrência de doenças e nematóides como fatores desfavoráveis do ambiente, tanto para a produção de algodão como para a qualidade da fibra, reforça a importância da utilização de cultivares com resistência múltipla a essas adversidades, como garantia de preservação do potencial genético para obtenção das características desejadas.

8. O comportamento diferenciado observado entre os cultivares frente às variações do ambiente, evidencia a possibilidade de obtenção de cultivares mais estáveis e mais adaptados a determinadas condições, para as características estudadas. 
9. Dada a importância do comprimento, uniformidade e tenacidade da fibra na tenacidade do fio, e do comprimento, uniformidade e índice Micronaire na elongação do fio, melhorias do ambiente que favoreçam principalmente estas características da fibra refletem positivamente na qualidade do fio.

10. Como reflexão final deve-se atentar como objetivo permanente nos programas de melhoramento genético e condição indispensável no caso da introdução de cultivares, a avaliação da estabilidade e adaptabilidade dos cultivares para todas as características agronômicas e propriedades tecnológicas da fibra.e do fio. São importantes ainda, técnicas de cultivo que garantam não apenas a produtividade mas também a qualidade da fibra. 


\section{REFERÊNCIAS BIBLIOGRÁFICAS}

ABDALLA, F.H.; SHALABY, E.M.; EISSA, A.M. \& ABDEL-MALAK, K.K.I. Effect of planting systems, planting dates, distance between hills on seed and fiber properties and net return of cotton. Assiut Journal of Agricultural Sciences, Assiut, 20(2):267-278, 1989. Apud Cotton and Tropical Fibres, Wallingford, 3(1): 22, 1992.

ABOU-EL-FITTOUH, H.A.; RAWLINGS, J.O. \& MILLER, P.A. Genotype by environment interactions in cotton- Their nature and related environmental variables. Crop Science, Madison, 9: 377-381, 1969 .

ABRAHÃO, J.T.M. Influência da energia solar sobre a fase reprodutiva do algodão (Gossypium hirsutum L.).Piracicaba, ESALQ/USP, 146 p., 1979 (Tese de Livre-Docente).

ALABI, S.O. \& ECHEKWU, C.A. Genotype $x$ environment interactions in cotton and their implications for future variety testing in the northern cotton-growing zone of Nigeria. Samary Journal of Agricultural Research Zaria, 6: 44-49, 1989. Apud Cotton and Tropical Fibres, Wallingford, 2: 14, 1991. 
BARREIRO NETO, M.; NEVES, F.P.; COSTA, J.N.\& SOBRINHO, R. B. CNPA Acala 1: Nova cultivar de algodão para a região amazônica. In: REUNIÃO NACIONAL DO ALGODÃO, 4., Belém, 1986. Anais. Campinas Grande, EMBRAPA-CNPA/ SAGRI, 1986 p. 39.

BENEDICT, C.R. Physiology. In: KOHEL, R.J. \& LEWIS, C.F., ed. Cotton Madison, American Society of Agronomy Inc., Crop Science Society of America, Inc., Soil Science Society of America, Inc., 1984. p. 151-200.

BILBRO, J.D. \& RAY,L.L. Effect of planting date on the yield and fibre properties of three cotton cultivars. Agronomy Journal, Madison, 65: 606-609,1973.

BILBRO, J.D. \& RAY, L.L. Environmental stability and adaptation of several cotton cultivars. Crop Science, Madison, 16: 821-824, 1976.

BRIDGE, R.R.; MEREDITH Jr. W.R. \& CHISM, J.F. Variety $x$ Environment interactions in cotton variety testes in the delta of Mississippi. Crop Science, Madison, 9: 837-838, 1969.

BUGBEE, W.M. \& SAPPENFIELD, W.P. Effect of Verticillium wilt on cotton yield, fiber properties, and seed quality. Crop science, Madison, 10: 649-652, 1970 . 
CABANGBANG, R.P.\& MANGUIAT. P.H. Cotton cultivar responses to high rainfall and low solar radiation environment. Phillippine Journal of Crop Science, Los Baños, 14(2): 55-59, 1989. Apud Cotton and Tropical Fibres, wallingford, 3(1): 17, 1992.

CAMPINAS. Ensaios regionais de variedades paulista de algodoeiro, V. 1975/76 - 1976/77. Campinas, Instituto Agronômico, 1980. 86 p. (IAC Boletim técnico, 65).

CANUTO, N.N. Influência da época de colheita sobre as características tecnológicas da fibra do algodoeiro anual (Gossypium hirsutum L.). Fortaleza, UFC, 55p.1978 (Dissertação de Mestrado).

CARVALHO, L.H. Aplicação de boro na cultura do algodoeiro (Gossypium hirsutum L. var. latifolium Hutch). Piracicaba ESALQ/USP, 76 p., 1988 (Tese de Doutorado).

CARVAlHO, L.H.; CIA. E.; CHIAVEGATO, E.J.; KONDO, J.I.; SABINO, J.C.; PETINELLI Jr, A.; BORTOLETTO, N.; GALLO, P.B. \& SILVEIRA, J.C.O. Efeito de fitorreguladores de crescimento e da capação na cultura algodoeira. In: REUNIÃO NACIONAL DO ALGODÃO, 4., Belém, 1986. Anais. Campina Grande, EMBRAPA-CNPA/SAGRI, 1986, p.55. 
CARVALHO, F.I.F.; FEDERIZZI, L.C.; NODARI, R.O. \& STORCK, L. Comparison among stability models in evaluating genotypes. Revista Brasileira de Genética, Ribeirão Preto, 6: 667-691, 1983.

CARVAI,HO, L.P. \& LIMA, E.F. Influência da ramulose nas características de produção e fibra do algodoeiro G. hirsutum L. In: REUNIÃO NACIONAL DO ALGODÃO, 2., Salvador, 1982. Anais. Campina Grande, EMBRAPA/CNPA, 1982, P. 233.

CHAHAL, G.S.; SINGH, T.H.\& SHARMA, S.R. Use of replicate-block mean as an environmental index for stability stabilty analysis in upland cotton. Crop Improvement, Punjab, $17(2):$ 166-169, 1990. Apud Cotton and Tropical Fibres, Wallingford, 3: 20, 1992.

CHENG, B.J. \& ZHAO, L.Y. Multiple correlation analysis of yield, fibre quality and plant characteristies in upland Cotton. Acta Agriculturae Shanghai, Hefei, $7(3): 29-35,1991$. Apud Cotton and Tropical Fibres, Wallingford, 3:17, 1992.

CIA, E.; FUZATTO, M.G.; GRIDI-PAPP, I.L.; CHIAVEGATO, E.J.; DUdienAs, C.; CAMARGo, A.P.; CAMPANA, M.P.; LÉlis, L.G. L.; BORTOLETTO, N.; PAULO, E.M. \& KASAI, F.S. Comportamento de materiais genéticos estudados nos ensaios nacional e regional paulista de variedades em 1987/88, em face de doenças e nematóides. In: REUNIÃO NACIONAL DO ALGODÃO, 5. , Campina Grande, 1988. Anais. Campina Grande, EMBRAPA-CNPA, 1988 p. 28. 
CIA E.; FUZATTO, M.g.; GRIDI-PAPP, I.L.; CHIAVEGATO, E.J.;PIZZINATO, M.A.; CAMARGO; A.P.; CAMPANA, M.P.; KASAI, F.S.; PAULO, E.M. \& PETTINELLI Jr, A. Comportamento de materiais genéticos de algodoeiro estudados nos ensaios nacional e regional de variedades em 1992/93, em face de doenças e nematóides. In: REUNIÃO NACIONAL DO ALGODÃO, 7., Cuiabá, 1993. Anais. Campinas Grande, EMPAER-MT/ EMBRAPA/CNPA 1993, p.31.

COOK, C.G. \& NAMKEN, L.N. Effect of reniform nematodes on growth, lint yield and fiber quality of 15 cotton cultivars. In: BELTWIDE COTTON PRODUCTION RESEARCH CONFERENCES, 52., Proceedings, Memphis, National Cotton Council, 1992. Apud the ICAC Record, Technical information, Washington, 10 (3): 10, 1992.

CRUZ, C.D. \& REGAZZI, A.J. Modelos biométricos aplicados ao melhoramento genético. Viçosa, U.F.V., 1994. 390 p.

CRUZ, C.D.; TORRES, R.A. de A. \& VENCOVSKY, R.An alternative approach to the stability analysis proposed by silva and Barreto. Revista Brasileira de Genética, Ribeirão Preto 12 : $567-580,1989$. 
DIMITROVA, L. \& BOZHINOV, M. Variability of technological properties of cotton fibre under the influence of cultivar and some environmental factors. Rasteniev "dni Nauki, Chirpam, 25(9): 27-34, 1988. Apud Cotton and Tropical Fibres Abstracts, $14(11): 118,1989$

DOCUMENTO SENAI/CETIQT, Diretrizes e recomendações para a formulação de uma política de incentivo à produção e à melhoria da qualidade do algodão brasileiro. Comitê permanente de acompanhamento da qualidade do algodão brasileiro. $1987.27 p$.

DUARTE, J.B. \& ZIMMERMANN, M.J.O. Adaptabilidade e estabilidade de rendimento de genótipos de feijoeiro comum. Pesquisa Agropecuária Brasileira, Brasília, 29: 25-32, 1994.

EBERHART, S.A. \& RUSSELL, W.A. Stability parameters for comparing varieties. Crop Science, Madison, 6:36-40,1966.
EL-SABBAGH,
A.N. ;
AHMED,
N. I .
$\&$
ABDEL-HAFEEZ,
A. A.

Fiberfine-structure and yarn mechanical properties of some Egyptian and upland cotton varieties treated by some insecticides. Assiut Journal of Agricultural Sciences, Cairo, 20 (4) : 267-282, 1989. Apud Cotton and Tropical Fibres, 3 (1): 86, 1992 . 
EL-ZIK, K.M.; NAMKEN, N.L. \& THAXTON, P.M. Effect of weather on cotton seedlings survival and its association with lint yield and fiber quality. In: BELTwIDE COTTON PRODUCTION RESEARCH CONFERENCES, $50 \ldots$ Las Vegas. Proceedings. Memphis, National Cotton Council, 1990. p. 9-14.

EMBRAPA. Ensaio Nacional de variedades de algodoeiro herbáceo, I : 1977/78. Campina Grande, Centro Nacional de Pesquisa do Algodão, 1981. 63 p. (EMBRAPA. Boletim de Pesquisa, 2).

EMBRAPA. Ensaio Nacional de variedades de algodoeiro herbáceo II. 1978/79 Campina Grande, Centro Nacional de Pesquisa do Algodão, 1982, 63 p. (EMBRAPA. Boletim de Pesquisa, 9).

EVENSON, J.P. Sersonal variation in commercial cotton quality in the ord valley north western Australia. Cotton Growing Review, London . 46: 189-196, 1969.

FERRAZ, C.A.M.; CIA, E.; SABINO, N.P.; GROSSI, J.M.M.; VEIGA, A.A. \& YOSHIDA, H. Efeitos da densidade de plantio e da aplicação de CCC, em algodoeiro. Bragantia, Campinas, 36 : $239-251,1977$. 
FERRAZ, C.A.M.; LAZZARINI, J.F. \& FUZATTO, M.G. Possibilidade de melhoria das características tecnológicas da fibra de algodão através de práticas agrícolas complementares ao uso de sementes selecionadas. Campinas, Instituto Agronômico. Mimeografado, 1968. 4 p.

FERREIRA, I.C. Séries históricas do algodão-Período: 1980 a 1994. Bolsa de Mercadorias \& Futuros, Gerência de Classificação, são Paulo. Mimeografado, 1994. 23 p.

FINLAY, K.W. \& WILKINSON, G.N. The analysis of adaptation in a plant - breeding programme. Australian Journal of Agricultural Reserche, Melbourne, 14: 742-754, 1963.

FREIRE, E.C.; SANTOS, J.W. dos; ANDRADE, F.P. de; NETO, F.C. V.; LIRA, M.A. \& RIBEIRO, J.L. Adaptabilidade e estabilidade de cultivares de gergelim. Pesquisa Agropecuária Brasileira, Brasília, 29: 891-900, 1994.

FUNDAÇÃo GETÚlio VARGAs. Agroanalysis. Rio de Janeiro, FGC/IBE, $13: 16-18,1989 a$.

FUNDAÇÃO GETÚLIO VARGAS. Retrospectiva da agropecuaria-anos 80 . Rio de Janeiro, FFV/IBE, 1989b, p. 22-27. 
FUZATTO, M.G. Objetivos e resultados obtidos nos trabalhos de pesquisa conduzidos no Instituto Agronômico de Campinas com respeito à qualidade da fibra de algodão. In: CONFERÊNCIA NACIONAL DE TECNOLOGIA TÊXTIL, 4, Rio de Janeiro, CETICT/SENAi, 1987. 28p.

FUZATtO, M.G.; ChIAVEGATO, E.J. \& GRIDI-PAPP, I.L. Classes padroões para algumas características do algodão produzido por variedades anuais (Gossypium hirsutum L.) no Brasil In: REUNIÃO NACIONAL DO ALGODÃO, 4, Belém, 1986. Anais. Campina Grande, EMBRAPA- CNPA, 1986. p. 26.

FUZATTO, M.G.; CIA, E. \& CHIAVEGAto, E.J. Estabilidade da produção de variedades e linhagens de algodoeiro em face da ocorrência de doenças e nematóides. 1993. In: REUNIÃO NACIONAL DO ALGODÃO 7. Cuiabá, 1993. Anais. Campina Grande, EMPAER-MT/EMBRAPA/CNPA. 1993. p. 33 .

FUZATTO, M.G.; SILVA, N.M. da \& CORRÊA, F.A.O efeito das fertilizações nas características do produto do algodoeiro. In: REUNIÃO ANUAL DA SBPC, 8., Belo Horizonte, 1965. Anais. São Paulo, SBPC, 1965. p. 198-199.

GIPSON, J.R. \& JOHAM, H.E. Influence of night temperature on growth and development of cotton (Gossypium hirsutum L.) I. Fruiting and boll development. Agronomy Journal, Madison, 60: 292-295, $1968 a$. 
GIPSON, J.R. \& JOHAM, H.E. Influence of night temperature on growth and development of cotton (Gossypium hirsutum L.) II. Fibre properties. Agronomy Journal, Madison, 60:296-298, 1968b.

GIPSON, J.R. \& RAY, L.L. Fiber elongation rates in five varieties of cotton (Gossypium hirsutum L.) as influenced by night temperature. Crop Science, Madison, 9: 339-341, 1969.

GONZALEZ, L.M.A.R. Estudo da interação genótipos $x$ ambientes para a cultura do algodão (Gossypium sp.) na região oriental do Paraguai. Piracicaba, ESALQ/USP, 91 p., 1988 ( Dissertação de Mestrado)

GRIDI-PAPP, I.L. Botânica e Genética. In: Cultura e Adubação do Algodoeiro. São Paulo, Instituto Brasileiro de Potassa, 1965 p. 117-160.

GRIDI-PAPP, I.L.; CIA, E.; FUZATTO, M.G.; CAVALERI, P.A.; CHIAVEGATO, E.J. ; SILVA, N.M. da; CARVALHO, L.H. ; SABINO, N.P. ; KONDO, J.I.; SUGIMORI, M.H.; SOAVE, J. \& FERRAZ, C. A.M. Melhoramento do algodoeiro no Estado de são Paulo: obtenção da variedade IAC 19. Bragantia, Campinas, 50: 181-194, 1991.

GRIDI-PAPP, I.L.; FUZATTO, M.G. ; CIA, E. ; CHIAVEGATO. E.J.; SABINO, N.P. ; KONDO, J.I.; CAVALERI, P.A.; SILVA, N.M. da; CARVALHO, L.H.; RODRIQUES FO.. F.S.O.; WIESEL, J.B.C.; MARTINS, A.L.M. ;PETTINELli. Jr., A.; SORDI, G.de; SABINO, J.C.; PEREIRA, 
J.A.V.N.A.; CAMPANA, M.P.; BORTOLETTO, N. ; GALLO, P.B. Ensaios regionais de variedades paulistas de algodoeiro. VII. 1979/80 1980/81. Campinas, Instituto Agronômico,1993.60 p. (IAC Boletim Científico, 27)

GRIDI-PAPP, I.L. ; FUZATTO, M.G. ; CIA, E.; CHIAVEGATO, E.J. ; SABINO, N.P.; KONDO, J.I.; SILVA, N.M. da; CARVALHO, L. H.; MARTINS, A.L.M.; PETTINELLI Jr., A.; SORDI, G. de, SABINO, J.C.; PEREIRA, J.C.V.N.A.; CAMPANA, M.P.; BORTOLETTO, N. \& GALLO, P.B. Ensaios regionais de variedades paulistas de algodoeiro. VI. 1977/78. Campinas, Instituto Agronômico, 1985. 87 p. (IAC Boletim Científico, 04).

GUTKNECHT, J. Effect of environment and cultural pratices on cotton technological characteristics. Montpellier, I.R.C.T., Division de Technologie. Mimeografado, 1984. $24 \mathrm{p}$.

HAN, H.J. The effects of climatic-ecological factors on cotton yield and fibre quality. Scientia Agricultura Sinica, Zhengzhon, 24 (5): 23-29, 1991. Apud Cotton and Tropical Fibres, Wallingford, 3(1): 6, 1992.

HELMS, T.C. Selection for yield and stability among oat lines. Crop Science, Madison, 33: 423-426, 1993. 
HESKETH, J.D. \& IJOW. A. Effect of temperature on components of yield and fibre quality of cotton varieties of diverse origin. Cotton Growing Review, London, 45: 243-257,1968.

INSTITUTO DE ECONOMIA AGRÍCOLA, São Paulo, IEA, 20: 92-94, 1990.

JALALUDDIN, Md. \& HARRISON, S.A. Repeatability of stability estimators for grain yield in wheat.Crop science, Madison, 33 : $720-725,1993$.

KALSY, H.S. \& SINGH, T.H. Phenotypic stability in Upland cotton. Cotton Growing Review, London, 51: 210-212, 1974 .

LAZZARINI, J.F. Inter-relações das características tecnológicas da fibra e outras propriedades do algodão com as características do fio e com a produção.Bragantia, Campinas, 29: 309-328, 1970.

LUKEFAHR, M.J.; CARVALHO, L.P.de; MOREIRA, J.A.N.; SANTANA, J.C.F. \& SOARES, J.J. Lançamento do cultivar CNPA Precoce 1. Relatório Técnico Anual do Centro Nacional de Pesquisa do Algodão 1985/1986, Campina Grande, EMBRAPA-CNPA, 1988. p. 280-281.

MALUF, W.R., CORDEIRO, C.M.T., MIRANDA, J.E.C.; COUTO, F.A. A. \& Boock, O. Yield stability of potato (Solanum tuberosum L.) cultivars. Revista Brasileira de Genética, Ribeirão Preto, 6 : $29-41,1983$. 
MAUNEY, J.R. Anatomy and Morphology of Cultivated Cottons.In: KOHEL, R.J. \& LEWIS, C.F. Cotton. Madison, American Society of Agronomy Inc.,Crop Science Society of America, Inc., Soil Science Society of America, Inc., 1984. p. 59-80.

MILLER, P.A.; ROBINSON, H.F. \& POPE, O.A. Cotton variety testing: Additional informations on variety $\mathrm{x}$ environment interactions. Crop Science, Madison, 2: 349-352, 1962 .

MILLER, P.A.; WILLIAMS, J.C. \& ROBINSON, H.F. Variety x Environment interactions in cotton variety testes and their implications on testing methods. Agronomy Journal, Madison, 51: 132-134,1959.

MILLER, P.A.; WIliliamS, J.C.; ROBINSON, H.F. \& COMSTOCK, R.E Estimates of genotypic and environmental variances and covariances in Upland cotton and their implications in selection.Agronomy Journal, Madison, 50: 126-131, 1958 .

MURRAY, J.C. \& VERHALEN, L.M. Genotype by environment interaction study of cotton in Oklahoma. Crop Science, Madison, 10: 197-199, 1970 .

NIZAMA, J.R.; SHROFF, V.N.; PATEL, V.G. \& DABHOLKAR, A.R. Phenotypic stability of single and three way hybrids of cotton with respect to their yield and yield components. Journal of the Indian Society for Cotton Improvement, Maktampur, 13 (2): 
118-123, 1988. Apud Cotton and Tropical Fibres, Wallingford, $3(1): 16,1992$.

OMRAN, A.O.; MUSTAFA, S. \& ABED, S.M. Genotype-environment interactions and stability of yield performance in the southern cotton growing zone of Nigeria. Cotton et Fibres Tropicales, Montpellier, 38: 217-220, 1983 .

oOsterom, E.J.van; KLEIJN, D.; CECCARELLI, S. \& NACHIT, M.M.Genotype-by-environment interactions of barley in the mediterranean region. Crop Sclence, Madison. 33: 669-674, 1993.

PIMENTEL GOMES, F. Curso de estatística experimental. 8 ed.Piracicaba, 1978. 430 p.

QUIÑNES, V. Estabilidad del rendimento en variedades de algodon (Gossypium hirsutum L.) en Venezuela. Revista Latinoamericana de Ciênclas Agrícolas, Cidade do México, 15: 113-129, 1980.

QUISENBERRY, J.E. \& GIPSON, J.R. Growth and productivity of cotton grown from seed produced under four night temperatures. Crop Sclence, Madison, 14: 300-302, 1974 .

RAO, H.K.H.; RAJASEKARAN, S. \& BASU, A.K. Evoluation of eli-te varieties of cotton (G. hirsutum L.) of different cotton growing zones for their adaptability across the zones. Samary Journal of 
Agricultural Research, Zaria, 6:44-49, 1989. Cotton andTropical Fibres, Wallingford, 2 : 15, 1991 .

SABINO, N.P.; GRIDI-PAPP, I.L. \& GROSSI, J.M.M. Correlações entre a maturidade da fibra e outros caractéres econômicos do algodoeiro. Bragantia, Campinas, 35:375-380, 1976b.

SABINO, N.P.; GRIDI-PAPP, I .L.; KONDO, J . I . \& CARNEIRO, J.B. Maturidade da fibra de algodão determinada pelo fibrógrafo modelo 430 . Bragantia, Campinas, 39:69-77, 1980 .

SABINO, N.P.; KONDO, J.I.; SILVA, N.M.da \& IGUET, T. Efeitos da calagem e da adubação potássica sobre as características agronômicas e propriedades tecnológicas da fibra do algodoeiro. Bragantia, Campinas, 1994b. (no prelo).

SABINO, N.P.; SILVA, N.M. da \& KONDO, J.I. Efeito da adubação em superfosfato simples em características agronômicas e propriedades tecnológicas da fibra das variedades de algodoeiro IAC 13-1, IAC 16 e IAC 17. Bragantia, Campinas, 50: 129-137, 1991.

SABINO, N.P.; SILVA, N.M. da; KONDO, J.I. \& IGUE, T. Efeitos da aplicação de uréia e de sulfato de amônio nas características agronômicas e proporiedades tecnológicas da fibra do algodoeiro. Bragantia, Campinas, 1994a. (no prelo). 
SABINO, N.P.; SILVA. N.M. da \& RODRIQUES FILHO, F.S. de O. Efeito da aplicação de nitrogênio e potássio, na qualidade da fibra do algodoeiro cultivado em latossolos roxos do Estado de São Paulo. Bragantia, Campinas, 35: 381-388, 1976a.

SANTANA, J.C.F. de; CAVALCANTI, F.B. \&e SANTOS, E.O. dos. Parâmetros de estabilidade na comparação de cultivares de algodoeiro herbáceo. Pesquisa Agropecuária Brasileira, Brasília, 18 : $261-267,1983$

SHUBERT, A.M.; BENEDICT, C.R.; BERLIN,J.D. \& KOHEL, R.J. Cotton fibre development-kinetics of cell elongation and secondary wall thickening. Crop science, Madison, 13: 704-709, 1973 .

SIlva, N.M. da; CARVAlHo, L.H.; CHIAVEGATO. E.J.; SABINO,N. P. \& HIROCE, R. Efejto de doses de boro aplicadas no sulco de plantio do algodoeiro, em solo deficiente. Bragantia, Campinas, 41: $181-191,1982$.

SILVA, N.M. da; FUZATTO, M.G. \& SABINO, N.P. Adubação do algodoeiro em latossolos roxos altamente deficientes em potássio. Campinas, Instituto Agronômico. Projeto BNDE/ANDA/CIA-Publicação, 6, 1971 . $15 \mathrm{p}$. 
SILVA, M.J.da; HOLANDA, A.F.da; SAUNDERS, L.C.V.\& CAVALCANTI, F.B. Fatores que afetam a produtividade do algodoeiro. In: REUNIÃO NACIONAL DO ALGODÃO, 3.; Recife, 1984.Anais.Campina Grande, EMBRAPA/CNPA, 1984. p. 177.

SILVEIRA. E.P. \& VENCOVSKY, R. Estabilidade da produção de grãos de sequeiro (Oriza sativa L.) no Estado de São Paulo. Ciência e Cultura, São Paulo, 35: 971-973, 1982.

SING, S.V.; GUPTA, P.K. \& SHARMA, K.P. Phenotypic stability for tuber yield in potato (Solanum tuberosum L.) Indian Journal of Genetics and Plant Breeding, New Delhi, 48: 9-12, 1988 .

SMITH, R.G.; WEECH, J.A. \& GANNAWAY, J.R.The effect of Meloidogyne incognita on cotton development and fiber quality of the Texas High Plains. In: BELTWIDE COTTON PRODUCTION RESEARCH CONFERENCES, 51., Proceedings. Memphis, National Cotton Council, 1991, Apud the ICAC Record, Techical information section, Washington, 10 (3): 10, 1992.

SOUZA, N.A.de \& HOLANDA, J.S.de. Adaptabilidade ambiental de cultivares de a] godoeiro mocó. Pesquisa Agropecuária Brasileira, Brasilia, 28: 797-801, 1993.

SOUZA, F.R.S.de; RAMALHO, M.A.P.; OLIVEIRA, A.C.de \& SANS, Estabilidade de cultivares de milho em diferentes épocas e 
locais de plantio em Minas Gerais. Pesquisa Agropecuária Brasileira, Brasília, 26: 885-892, 1991.

STORCK, L. \& VENCOVSKY, R. Novo modelo para avaliação da estabilidade de cultivares. Pesquisa Agropecuária Brasileira, Brasília, 27: 1201-1211,1992.

TELLYAEV, R. \& YAKUBOV, B. Inter-row cultivations on wilt-infected fields. Scientific-Production Associations "Soyuzkhlopok", Botanika, Tashkent, 3: 19-20, 1991. Apud Cotton and Tropical Fibres, wallingford, 3(1):24, 1992.

TOMAR, S.K. \& SINGH, S.P. Genetic variability and association of characters in tree cotton (Gossypium arboreum). Indian Journal of Agricultural Sciences, New Delhi, 61: 255-258, 1991.

TONDEUR, R.; VERSCHRAEGE, L. \& DEMOL, J. Contribution à l'étude de l'influence de divers facteurs climatiques sur la production et la qualité des fibres chez Gossypium hirsutum L. Coton et Fibres Tropicales, Montpellier, 44: 5-20, 1989

TURNER, J.H.; RAMEY Jr., H.H. \& WORLEY Jr.; S. Rellationship of yield, seed quality, and fiber properties in upland cotton. Crop Science, Madison, 16: 578-580, 1976.

VENCOVSKY, R. \& BARRIGA, P. Genética biométrica no fitomelhoramento. Revista Brasileira de Genética, 1992, 496 p. 
104.

A P Ê N D I C E 
Tabela 23. Valores médios da produção de algodão em caroço de quatro cultivares, avaliados em quarenta ambientes; médias gerais de ambientes $(Y j)$ e de cultivares (Yi); quadrados médios residuais (QMR) e coeficientes de variação (CV\&).

\begin{tabular}{|c|c|c|c|c|c|c|c|}
\hline \multirow{2}{*}{ AMB IENTE } & \multicolumn{4}{|c|}{ CULTIVARES } & \multirow[b]{2}{*}{ TOTAL } & & \\
\hline & IAC 19 & IAC 20 & $\begin{array}{c}\text { CNPA } \\
\text { Prec } 1\end{array}$ & $\begin{array}{l}\text { CNPA } \\
\text { AC. } 1\end{array}$ & & $\begin{array}{c}\text { MÉDIA } \\
Y j\end{array}$ & $\begin{array}{r}\mathrm{CV} \\
\frac{8}{8}\end{array}$ \\
\hline
\end{tabular}

\begin{tabular}{|c|c|c|c|c|c|c|c|c|}
\hline 1 & 1,55 & 1,65 & 1,08 & 0,74 & 5,03 & 1,25 & 25,59 & 0,103 \\
\hline 2 & 2,75 & 3,08 & 2,38 & 1,89 & 10,12 & 2,53 & 10,73 & 0,073 \\
\hline 3 & 2,55 & 2,51 & 2,32 & 1,52 & 8,91 & 2,22 & 27,49 & 0,375 \\
\hline 4 & 2,91 & 3,31 & 3,00 & 2,78 & 12,01 & 3,00 & 8,58 & 0,066 \\
\hline 5 & 2,37 & 2,50 & 2,53 & 1,49 & 8,90 & 2,22 & 10,26 & 0,052 \\
\hline 6 & 4,50 & 4,88 & 4,50 & 3,63 & 17,52 & 4,38 & 8,19 & 0,128 \\
\hline 7 & 3,90 & 3,71 & 2,86 & 2,57 & 13,05 & 3,26 & 17,77 & 0,336 \\
\hline 8 & 4,19 & 4,17 & 3,54 & 2,60 & 14,51 & 3,62 & 19,63 & 0,507 \\
\hline 9 & 3,74 & 3,88 & 3,64 & 2,76 & 14,04 & 3,51 & 9,66 & 0,115 \\
\hline 10 & 1,38 & 1,15 & 1,17 & 1,14 & 4,85 & 1,21 & 29,20 & 0,125 \\
\hline 11 & 1,12 & 1,30 & 1,25 & 0,48 & 4,16 & 1,04 & 19,13 & 0,039 \\
\hline 12 & 4,04 & 3,95 & 2,59 & 2,42 & 13,01 & 3,25 & 12,06 & 0,154 \\
\hline 13 & 1,68 & 2,06 & 1,34 & 1,39 & 6,48 & 1,62 & 32,87 & 0,284 \\
\hline 14 & 4,62 & 4,72 & 4,63 & 2,50 & 16,48 & 4,12 & 14,95 & 0,380 \\
\hline 15 & 2,93 & 3,09 & 2,76 & 2,00 & 10,78 & 2,69 & 12,01 & 0,105 \\
\hline 16 & 1,29 & 1,50 & 0,95 & 0,76 & 4,51 & 1,12 & 21,87 & 0,061 \\
\hline 17 & 1,71 & 1,55 & 2,10 & 0,62 & 5,99 & 1,49 & 19,66 & 0,086 \\
\hline 18 & 3,20 & 3,06 & 2,53 & 2,91 & 11,71 & 2,92 & 11,48 & 0,113 \\
\hline 19 & 3,18 & 3,22 & 3,31 & 2,46 & 12,19 & 3,04 & 11,31 & 0,118 \\
\hline 20 & 4,15 & 3,98 & 3,70 & 3,32 & 15,16 & 3,79 & 9,68 & 0,134 \\
\hline 21 & 3,40 & 3,46 & 2,59 & 2,08 & 11,54 & 2,88 & 11,04 & 0,101 \\
\hline 22 & 1,90 & 2,00 & 1,66 & 1,34 & 6,92 & 1,73 & 18,32 & 0,100 \\
\hline 23 & 1,84 & 2,17 & 1,89 & 1,43 & 7,35 & 1,83 & 28,81 & 0,280 \\
\hline 24 & 1,64 & 1,74 & 2,48 & 0,98 & 6,85 & 1,71 & 19,36 & 0,110 \\
\hline 25 & 2,96 & 3,29 & 3,21 & 2,17 & 11,64 & 2,91 & 15,03 & 0,191 \\
\hline 26 & 1,93 & 2,33 & 1,87 & 1,51 & 7,65 & 1,91 & 28,73 & 0,302 \\
\hline 27 & 2,76 & 3,14 & 2,88 & 2,08 & 10,88 & 2,72 & 12,87 & 0,122 \\
\hline 28 & 3,51 & 3,62 & 2,56 & 3,32 & 13,03 & 3,25 & 20,14 & 0,431 \\
\hline 29 & 2,12 & 2,15 & 1,46 & 0,66 & 6,40 & 1,60 & 21,31 & 0,116 \\
\hline 30 & 1,12 & 1,28 & 1,09 & 1,02 & 4,51 & 1,12 & 18,44 & 0,043 \\
\hline 31 & 3,60 & 3,58 & 3,62 & 2,84 & 13,64 & 3,41 & 12,39 & 0,178 \\
\hline 32 & 1,73 & 2,06 & 1,91 & 1,48 & 7,19 & 1,79 & 14,25 & 0,065 \\
\hline 33 & 2,28 & 2,37 & 1,85 & 2,22 & 8,74 & 2,18 & 12,03 & 0,069 \\
\hline 34 & 1,01 & 0,82 & 1,21 & 0,88 & 3,94 & 0,98 & 24,08 & 0,056 \\
\hline 35 & 1,28 & 1,49 & 1,48 & 0,96 & 5,22 & 1,30 & 33,66 & 0,193 \\
\hline 36 & 1,50 & 1,49 & 1,13 & 1,23 & 5,36 & 1,34 & 21,60 & 0,083 \\
\hline 37 & 2,01 & 1,87 & 1,86 & 1,35 & 7,10 & 1,77 & 23,75 & 0,178 \\
\hline 38 & 1,01 & 1,01 & 1,10 & 0,76 & 3,89 & 0,97 & 17,59 & 0,029 \\
\hline 39 & 2,05 & 2,20 & 2,89 & 2,45 & 9,61 & 2,40 & 25,07 & 0,362 \\
\hline 40 & 2,32 & 2,47 & 2,58 & 2,14 & 9,52 & 2,38 & 14,78 & 0,123 \\
\hline $\begin{array}{l}\text { TOTAL } \\
\text { MÉDIA }\end{array}$ & 99,47 & 103,89 & 93,51 & 72,86 & 369,73 & & & \\
\hline$Y i$ & 2,49 & 2,60 & 2,34 & 1,82 & & & & \\
\hline
\end{tabular}


Tabela 24. Valores médios do peso de um capulho de quatro cultivares, avaliados em quarenta ambientes; médias gerais de ambientes

$(\mathrm{Yj})$ e de cultivares (Yi); quadrados médios residuais (QMR) e coeficientes de variação (CVơ).

\begin{tabular}{|c|c|c|c|c|c|c|c|}
\hline AMB IENTE & & CULT: & ARES & & & & \\
\hline & IAC 19 & IAC 20 & $\begin{array}{c}\text { CNPA } \\
\text { Prec. } 1\end{array}$ & $\begin{array}{l}\text { CNPA } \\
\text { AC. } 1\end{array}$ & TOTAL & $\begin{array}{c}\text { MEDIA } \\
Y j\end{array}$ & $\begin{array}{l}\mathrm{CV} \\
\text { g }\end{array}$ \\
\hline
\end{tabular}

\begin{tabular}{|c|c|c|c|c|c|c|c|c|}
\hline 1 & 8,02 & 8,02 & 6,27 & 7,45 & 29,78 & 7,44 & 6,20 & 0,213 \\
\hline 2 & 8,68 & 8,68 & 7,27 & 8,41 & 33,04 & 8,26 & 3,79 & 0,098 \\
\hline 3 & 7,74 & 7,62 & 6,50 & 7,71 & 29,58 & 7,39 & 9,74 & 0,519 \\
\hline 4 & 8,54 & 8,35 & 7,15 & 7,82 & 31,88 & 7,97 & 7,93 & 0,399 \\
\hline 5 & 6,38 & 6,25 & 5,31 & 5,91 & 23,87 & 5,96 & 5,29 & 0,099 \\
\hline 6 & 8,92 & 8,00 & 6,42 & 8,35 & 31,71 & 7,92 & 6,51 & 0.266 \\
\hline 7 & 8,15 & 8,04 & 6,25 & 7,37 & 29,82 & 7,45 & 3,01 & 0,050 \\
\hline 8 & 8,12 & 7,98 & 6,38 & 7,77 & 30,27 & 7,56 & 6,33 & 0,229 \\
\hline 9 & 7,90 & 7,70 & 6,37 & 7,07 & 29,04 & 7,26 & 5,14 & 0,139 \\
\hline 10 & 6,38 & 6,08 & 5,02 & 5,80 & 23,30 & 5,82 & 9,12 & 0,282 \\
\hline 11 & 5,94 & 5,58 & 4,78 & 4,28 & 20,60 & 5,15 & 11,23 & 0,334 \\
\hline 12 & 8,22 & 7,88 & 6,04 & 7,47 & 29,62 & 7,40 & 4,73 & 0.122 \\
\hline 13. & 7,10 & 7,54 & 5,95 & 6,35 & 26,95 & 6,73 & 9,61 & 0,420 \\
\hline 14 & 8,37 & 8,15 & 7,00 & 7,55 & 31,08 & 7,77 & 2,55 & 0,039 \\
\hline 15 & 8,11 & 7,51 & 6,12 & 6,94 & 28,70 & 7,17 & 4,02 & 0,083 \\
\hline 16 & 5,91 & 5,90 & 4,82 & 5,00 & 21,64 & 5,41 & 8,52 & 0,212 \\
\hline 17 & 7,04 & 7,24 & 6,32 & 6,30 & 26,91 & 6,72 & 7,69 & 0,268 \\
\hline 18 & 7,38 & 7,11 & 5,82 & 6,71 & 27,04 & 6,76 & 4,98 & 0,113 \\
\hline 19 & 7,37 & 7,05 & 6,17 & 6,90 & 27,50 & 6,87 & 4,31 & 0,087 \\
\hline 20 & 7,28 & 7,42 & 6,05 & 7,05 & 27,82 & 6,95 & 2,85 & 0,039 \\
\hline 21 & 7,28 & 7,17 & 5,50 & 6,65 & 26,61 & 6,65 & 3,70 & 0,060 \\
\hline 22 & 6,48 & 6,22 & 4,95 & 6,20 & 23,87 & 5,96 & 7,03 & 0,176 \\
\hline 23 & 7,54 & 7,10 & 6,70 & 7,20 & 28,54 & 7,13 & 10,60 & 0,572 \\
\hline 24 & 7,25 & 6,40 & 5,61 & 5,97 & 25,24 & 6,31 & 7,03 & 0,196 \\
\hline 25 & 7,72 & 7,41 & 6,42 & 6,65 & 28,22 & 7,05 & 9,12 & 0,414 \\
\hline 26 & 7,85 & 7,42 & 6,24 & 7,47 & 29,00 & 7,25 & 7,35 & 0,284 \\
\hline 27 & 8,40 & 7,81 & 6,47 & 7,71 & 30,40 & 7,60 & 5,01 & 0,145 \\
\hline 28 & 7,37 & 8,02 & 5,77 & 8,31 & 29,48 & 7,37 & 7,46 & 0,303 \\
\hline 29 & 6,28 & 6,27 & 4,81 & 5,74 & 23,11 & 5,77 & 10,58 & 0,374 \\
\hline 30 & 6,12 & 5,91 & 4,71 & 5,35 & 22,11 & 5,52 & 4,93 & 0,074 \\
\hline 31 & 7,98 & 7,41 & 6,85 & 7,20 & 29,45 & 7,36 & 4,09 & 0,090 \\
\hline 32 & 7,04 & 6,91 & 5,38 & 6,50 & 25,84 & 6,46 & 7,45 & 0,232 \\
\hline 33 & 6,58 & 6,21 & 4,88 & 6,47 & 24,15 & 6,03 & 12,00 & 0,525 \\
\hline 34 & 5,55 & 5,35 & 4,95 & 5,52 & 21,40 & 5,35 & 7,60 & 0,165 \\
\hline 35 & 5,97 & 5,47 & 5,01 & 4,60 & 21,05 & 5,26 & 16,19 & 0,726 \\
\hline 36 & 7,52 & 7,21 & 5,62 & 6,78 & 27,15 & 6,78 & 7,33 & 0,248 \\
\hline 37 & 7,05 & 6,68 & 5,60 & 5,72 & 25,07 & 6,26 & 7,87 & 0,243 \\
\hline 38 & 7,05 & 6,90 & 5,74 & 5,94 & 25,64 & 6,41 & 5,31 & 0,116 \\
\hline 39 & 6,91 & 6,77 & 5,94 & 4,78 & 24,41 & 6,10 & 10,26 & 0,392 \\
\hline 40 & 7,31 & 7,07 & 5,94 & 6,42 & 26,75 & 6,68 & 5,12 & 0,117 \\
\hline $\begin{array}{l}\text { TOTAL } \\
\text { MÉDIA }\end{array}$ & 292,84 & 283,98 & 235,25 & 265,35 & 1077,42 & & & \\
\hline$Y i$ & 7,32 & 7,10 & 5,88 & 6,63 & & & & \\
\hline
\end{tabular}


Tabela 25. Valores médios do peso de cem sementes de quatro cultivares, avaliados em quarenta ambientes; médias gerais de ambientes ( $Y j)$ e de cultivares (Yi); quadrados médios residuais (QMR) e coeficientes de variação (CVo).

\begin{tabular}{|c|c|c|c|c|c|c|c|}
\hline \multirow[t]{2}{*}{ AMBIENTE } & \multicolumn{4}{|c|}{ CULTIVARES } & \multirow[b]{2}{*}{ TOTAL } & & \\
\hline & IAC 19 & IAC 20 & $\begin{array}{c}\text { CNPA } \\
\text { Prec. } 1\end{array}$ & $\begin{array}{l}\text { CNPA } \\
\text { AC. } 1\end{array}$ & & $\begin{array}{c}\text { MÉDIA } \\
Y j\end{array}$ & $\begin{array}{l}\text { CV } \\
\%\end{array}$ \\
\hline
\end{tabular}

\begin{tabular}{|c|c|c|c|c|c|c|c|c|}
\hline 1 & 14,42 & 13,97 & 12,22 & 15,42 & 56,05 & 14,01 & 2,91 & 0,166 \\
\hline 2 & 14,97 & 14,15 & 12,57 & 16,22 & 57,92 & 14,48 & 2,74 & 0,158 \\
\hline 3 & 13,74 & 13,41 & 11,84 & 14,45 & 53,45 & 13,36 & 3,91 & 0,273 \\
\hline 4 & 13,11 & 12,41 & 11,90 & 13,11 & 50,54 & 12,63 & 3,10 & 0,154 \\
\hline 5 & 12,00 & 11,22 & 10,05 & 11,50 & 44,78 & 11,19 & 4,33 & 0,235 \\
\hline 6 & 15,17 & 14,15 & 12,30 & 14,44 & 56,07 & 14,01 & 3,55 & 0,248 \\
\hline 7 & 13,45 & 13,15 & 11,45 & 14,41 & 52,48 & 13,12 & 3,16 & 0,172 \\
\hline 8 & 12,61 & 12,97 & 11,32 & 14,27 & 51,18 & 12,79 & 4,32 & 0,305 \\
\hline 9 & 13,85 & 13,42 & 12,00 & 13,82 & 53,11 & 13,27 & 4,03 & 0,286 \\
\hline 10 & 12,17 & 11,87 & 10,67 & 13,01 & 47,72 & 11,93 & 6,62 & 0,625 \\
\hline 11 & 11,77 & 11,41 & 10,60 & 11,25 & 45,04 & 11,26 & 3,37 & 0,144 \\
\hline 12 & 14,55 & 13,74 & 11,90 & 14,34 & 54,54 & 13,63 & 4,01 & 0,300 \\
\hline 13 & 13,01 & 13,01 & 10,32 & 14,10 & 50,45 & 12,61 & 5,60 & 0,500 \\
\hline 14 & 13,65 & 13,35 & 10,94 & 14,28 & 52,24 & 13,06 & 2,18 & 0,081 \\
\hline 15 & 14,12 & 13,58 & 11,15 & 14,68 & 53,55 & 13,38 & 4,09 & 0,300 \\
\hline 16 & 12,27 & 12,31 & 10,02 & 12,15 & 46,77 & 11,69 & 2,75 & 0,103 \\
\hline 17 & 13,05 & 13,07 & 10,77 & 13,70 & 50,60 & 12,65 & 2,33 & 0,087 \\
\hline 18 & 12,74 & 12,47 & 11,14 & 13,04 & 49,40 & 12,35 & 3,69 & 0,208 \\
\hline 19 & 12,55 & 12,28 & 10,88 & 13,50 & 49,22 & 12,30 & 3,75 & 0,213 \\
\hline 20 & 13,98 & 13,85 & 12,44 & 15,57 & 55,85 & 13,96 & 3,39 & 0,224 \\
\hline 21 & 13,74 & 13,25 & 10,98 & 14,05 & 52,04 & 13,01 & 2,50 & $0,1.06$ \\
\hline 22 & 12,01 & 12,14 & 10,04 & 12,97 & 47,17 & 11,79 & 4,96 & 0,342 \\
\hline 23 & 12,64 & 12,02 & 11,25 & 12,61 & 48,54 & 12,13 & 3,53 & 0,184 \\
\hline 24 & 14,00 & 13,27 & 11,68 & 13,14 & 52,10 & 13,02 & 4,80 & 0,392 \\
\hline 25 & 13,57 & 13,21 & 12,04 & 14,37 & 53,20 & 13,30 & 5,52 & 0,540 \\
\hline 26 & 12,85 & 12,77 & 11,37 & 13,05 & 50,05 & 12,51 & 5,59 & 0,489 \\
\hline 27 & 13,48 & 13,12 & 11,70 & 13,97 & 52,28 & 13,07 & 3,44 & $0,2.02$ \\
\hline 28 & 12,22 & 12,25 & 10,05 & 14,37 & 48,91 & 12,22 & 7,24 & 0,784 \\
\hline 29 & 11,98 & 11,28 & 9,60 & 12,25 & 45,12 & 11,28 & 3,25 & 0,134 \\
\hline 30 & 11,92 & 12,18 & 10,28 & 11,72 & 46,12 & 11,53 & 6,57 & 0,575 \\
\hline 31 & 13,48 & 13,32 & 12,00 & 13,42 & 52,24 & 13,06 & 3,23 & 0,178 \\
\hline 32 & 13,94 & 13,21 & 11,57 & 13,40 & 52,12 & 13,03 & 7,21 & 0,883 \\
\hline 33 & 13,38 & 12,27 & 10,54 & 14,91 & 51,11 & 12,77 & 8,47 & 1,172 \\
\hline 34 & 13,42 & 13,38 & 10,95 & 14,10 & 51,87 & 12,96 & 4,11 & 0,284 \\
\hline 35 & 11,84 & 10,92 & 10,95 & 10,17 & 43,90 & 10,97 & 9,94 & 1,190 \\
\hline 36 & 13,45 & 13,20 & 11,12 & 13,67 & 51,45 & 12,86 & 4,40 & 0,321 \\
\hline 37 & 13,84 & 14,12 & 12,42 & 13,22 & 53,62 & 13,40 & 4,88 & 0,429 \\
\hline 38 & 13,74 & 13,51 & 12,12 & 13,15 & 52,54 & 13,13 & 4,14 & 0,295 \\
\hline 39 & 13,70 & 13,18 & 11,45 & 11,18 & 49,52 & 12,38 & 4,44 & 0,302 \\
\hline 40 & 12,75 & 12,24 & 10,71 & 12,52 & 48,24 & 12,06 & 4,67 & 0,317 \\
\hline $\begin{array}{l}\text { TOTAL } \\
\text { MÉDIA }\end{array}$ & 529,28 & 514,82 & 449,02 & 539,70 & 2032.82 & & & \\
\hline$Y i$ & 13,23 & 12,87 & 11,23 & 13,49 & & & & \\
\hline
\end{tabular}


Tabela 26. Valores médios da porcentagem de fibra de quatro cultivares, avaliados em quarenta ambientes; médias gerais de ambientes $(Y j)$ e de cultivares ( $Y i$ ); quadrados médios residuais (QMR) e coeficientes de variação (CV务).

\begin{tabular}{|c|c|c|c|c|c|c|c|c|}
\hline \multirow[t]{2}{*}{ AMBIENTE } & \multicolumn{4}{|c|}{ CULTIVARES } & \multirow[b]{2}{*}{ TOTAL } & \multirow[b]{2}{*}{$\begin{array}{c}\text { MEDIA } \\
Y j\end{array}$} & \multirow[b]{2}{*}{$\begin{array}{r}\mathrm{CV} \\
\text { \%음 }\end{array}$} & \multirow[b]{2}{*}{ QMR } \\
\hline & IAC 19 & IAC 20 & $\begin{array}{c}\text { CNPA } \\
\text { Prec. } 1\end{array}$ & $\begin{array}{l}\text { CNPA } \\
\text { AC. } 1\end{array}$ & & & & \\
\hline 1 & 40,38 & 39,77 & 40,67 & 35,25 & 156,08 & 39,02 & 2,54 & 0,989 \\
\hline 2 & 39,68 & 39,37 & 38,52 & 34,17 & 151,75 & 37,93 & 1,93 & 0,538 \\
\hline 3 & 38,91 & 38,52 & 38,08 & 34,08 & 149,61 & 37,40 & 1,99 & 0,558 \\
\hline 4 & 43,12 & 42,85 & 40,92 & 38,64 & 165,55 & 41,38 & 1,90 & 0,622 \\
\hline 5 & 37,97 & 38,70 & 37,64 & 35,30 & 149,61 & 37,40 & 1,92 & 0,518 \\
\hline 6 & 38,12 & 38,12 & 37,54 & 34,41 & 148,21 & 37,05 & 2,63 & 0,956 \\
\hline 7 & 39,48 & 39,10 & 38,12 & 33,48 & 150,19 & 37,54 & 2,55 & 0,920 \\
\hline 8 & 40,04 & 39,12 & 39,37 & 34,71 & 153,25 & 38,31 & 3,19 & 1,500 \\
\hline 9 & 37,90 & 37,82 & 36,57 & 34,48 & 146,78 & 36,69 & 2,01 & 0,547 \\
\hline 10 & 36,94 & 36,71 & 36,48 & 32,58 & 142,72 & 35,68 & 3,04 & 1,179 \\
\hline 11 & 38,20 & 37,74 & 36,07 & 33,52 & 145,54 & 36,38 & 4,16 & 2,297 \\
\hline 12 & 38,12 & 38,41 & 37,27 & 34,78 & 148,60 & 37,15 & 2,32 & 0,748 \\
\hline 13 & 39,24 & 38,77 & 40,78 & 35,54 & 154,34 & 38,58 & 3,63 & 1,963 \\
\hline 14 & 38,72 & 38,29 & 40,85 & 33,30 & 151,18 & 37,79 & 1,96 & 0,554 \\
\hline 15 & 38,15 & 38,07 & 39,21 & 34,35 & 149,80 & 37,45 & 2,12 & 0,634 \\
\hline 16 & 37,32 & 35,81 & 39,82 & 30,90 & 143,87 & 35,96 & 2,55 & 0,842 \\
\hline 17 & 40,92 & 39,81 & 40,92 & 34,90 & 156,57 & 39,14 & 2,12 & 0,678 \\
\hline 18 & 38,57 & 38,05 & 37,35 & 36,21 & 150,19 & 37,54 & 3,46 & 1,695 \\
\hline 19 & 40,77 & 39,72 & 40,48 & 33,81 & 154,80 & 38,70 & 2,26 & 0,768 \\
\hline 20 & 39,32 & 39,70 & 39,00 & 35,34 & 153,37 & 38,34 & 1,37 & 0,275 \\
\hline 21 & 39,11 & 37,51 & 37,58 & 33,14 & 147,35 & 36,83 & 1,97 & 0,530 \\
\hline 22 & 40,62 & 39,27 & 41,68 & 35,58 & 157,17 & 39,29 & 2,14 & 0,711 \\
\hline 23 & 41,74 & 41,90 & 41,37 & 36,52 & 161,54 & 40,38 & 1,60 & 0,421 \\
\hline 24 & 38,58 & 37,78 & 38,05 & 33,87 & 148,30 & 37,07 & 2,75 & 1,043 \\
\hline 25 & 39,01 & 38,91 & 39,60 & 35,15 & 152,68 & 38,17 & 2,64 & 1,015 \\
\hline 26 & 38,18 & 37,77 & 36,52 & $35,5.1$ & 148,00 & 37,00 & 2,32 & 0,737 \\
\hline 27 & 38,37 & 38,82 & 38,37 & 34,32 & 149,89 & 37,47 & 2,35 & 0,781 \\
\hline 28 & 39,95 & 40,35 & 42,38 & 36,70 & 159,39 & 39,84 & 1,88 & 0,564 \\
\hline 29 & 39,57 & 39,05 & 38,80 & 34,11 & 151,54 & 37,88 & 2,13 & 0,655 \\
\hline 30 & 35,87 & 35,18 & 34,40 & 32,30 & 137,75 & 34,43 & 3,86 & 1,770 \\
\hline 31 & 38,21 & 37,67 & 38,74 & 36,17 & 150,79 & 37,69 & 2,50 & 0,894 \\
\hline 32 & 35,91 & 36,77 & 34,98 & 33,88 & 141,55 & 35,38 & 3,35 & 1,412 \\
\hline 33 & 40,21 & 40,14 & 39,97 & 36,22 & 156,55 & 39,13 & 2,53 & 0,983 \\
\hline 34 & 41,74 & 41,50 & 43,91 & 39,70 & 166,85 & 41,71 & 2,26 & 0,895 \\
\hline 35 & 37,38 & 37,72 & 37,10 & 31,24 & 143,45 & 35,86 & 3,48 & 1,561 \\
\hline 36 & 39,27 & 39,71 & 38,95 & 36,78 & 154,72 & 38,68 & 2,58 & 0,999 \\
\hline 37 & 35,72 & 35,18 & 34,55 & 31,01 & 136,48 & 34,12 & 2,67 & 0,833 \\
\hline 38 & 38,88 & 38,15 & 37,92 & 35,11 & 150,08 & 37,52 & 1,72 & 0,416 \\
\hline 39 & 38,15 & 38,20 & 38,74 & 33,42 & 148,52 & 37,13 & 3,36 & 1,562 \\
\hline 40 & 42,40 & 41,88 & 42,70 & 40,57 & 167,55 & 41,88 & 1,49 & 0,391 \\
\hline
\end{tabular}


Tabela 27. Valores médios do comprimento da fibra de quatro cultivares, avaliados em quarenta ambientes; médias gerais de ambientes $(Y j)$ e de cultivares (Yi) quadrados médios residuais (QMR) e coeficientes de variação (CVq).

\begin{tabular}{|c|c|c|c|c|c|c|c|c|}
\hline \multirow[t]{3}{*}{ AMBIENTE } & \multicolumn{4}{|c|}{ CULTIVARES } & \multirow{3}{*}{ TOTAL } & \multirow{3}{*}{$\begin{array}{c}\text { MÉDIA } \\
Y j\end{array}$} & \multirow{3}{*}{$\begin{array}{r}\mathrm{CV} \\
\frac{8}{6}\end{array}$} & \multirow{3}{*}{ QMR } \\
\hline & IAC 19 & IAC 20 & CNPA & CNPA & & & & \\
\hline & & & Prec. 1 & AC. 1 & & & & \\
\hline 1 & 28,84 & 28,44 & 28,08 & 33,35 & 118,72 & 29,68 & 1.86 & 0,307 \\
\hline 2 & 27,22 & 27,02 & 27,84 & 30,58 & 112,68 & 28,17 & 2,50 & 0,495 \\
\hline 3 & 27,37 & 27,32 & 28,08 & 31,35 & 114,14 & 28,53 & 2,77 & 0,628 \\
\hline 4 & 26,04 & 25,62 & 25,82 & 30,02 & 107,52 & 26,88 & 2,41 & 0,419 \\
\hline 5 & 25,88 & 25,38 & 25,94 & 29,08 & 106,30 & 26,57 & 1,79 & 0,227 \\
\hline 6 & 28,48 & 28,87 & 28,47 & 32,11 & 117,94 & 29,48 & 1,65 & 0,237 \\
\hline 7 & 28,27 & 28,07 & 28,04 & 31,54 & 115,92 & 28,98 & 2,37 & 0,473 \\
\hline 8 & 27,71 & 27,52 & 27,02 & 31,34 & 113,61 & 28,40 & 2,21 & 0,397 \\
\hline 9 & 27,40 & 26,92 & 27,07 & 29,77 & 111,17 & 27,79 & 1,81 & 0,253 \\
\hline 10 & 27,82 & 27,60 & 27,98 & 31,14 & 114,55 & 28,63 & 1,88 & 0,290 \\
\hline 11 & 26,60 & 26,42 & 26,35 & 28,67 & 108,05 & 27,01 & 1,64 & 0,196 \\
\hline 12 & 28,68 & 28,51 & 27,92 & 31,65 & 116,78 & 29,19 & 1,93 & 0,317 \\
\hline 13 & 27,10 & 27,10 & 26,08 & 31,05 & 111,34 & 27,83 & 2,13 & 0,354 \\
\hline $14^{\circ}$ & 27,50 & 27,44 & 26,10 & 31,27 & 112,31 & 28,07 & 2,48 & 0,485 \\
\hline 15 & 28,11 & 27,85 & 27,91 & 32,00 & 115,88 & 28,97 & 1,28 & 0,137 \\
\hline 16 & 26,48 & 26,78 & 25,72 & 29,98 & 108,98 & 27,24 & 3,15 & 0,739 \\
\hline 17 & 27,57 & 27,21 & 26,88 & 30,51 & 112,18 & 28,04 & 2,03 & 0,324 \\
\hline 18 & 28,30 & 27,95 & 27,78 & 31,85 & 115,90 & 28,97 & 1,48 & 0,185 \\
\hline 19 & 25,74 & 25,88 & 25,88 & 29,97 & 107,48 & 26,87 & 3,04 & 0,668 \\
\hline 20 & 27,62 & 27,72 & 28,05 & 31,25 & 114,67 & 28,66 & 1,77 & 0,260 \\
\hline 21 & 27,55 & 27,57 & 27,80 & 30,64 & 113,57 & 28,39 & 1,91 & $0,2.96$ \\
\hline 22 & 26,40 & 26,47 & 25,54 & 29,72 & 108,14 & 27,03 & 4,04 & 1,193 \\
\hline 23 & 26,21 & 25,60 & 26,58 & 30,02 & 108,42 & 27,10 & 2,06 & 0,312 \\
\hline 24 & 27,68 & 27,14 & 26,84 & 29,97 & 111,64 & 27,91 & 2,49 & 0,485 \\
\hline 25 & 28,52 & 28,22 & 27,98 & 31,50 & 116,24 & 29,06 & 2,05 & 0,357 \\
\hline 26 & 27,51 & 27,12 & 27,30 & 30,10 & 112,04 & 28,01 & 1,70 & 0,228 \\
\hline 27 & 27,77 & 27,54 & 27,92 & 31,04 & 114,28 & 28,57 & 1,71 & $0,2.38$ \\
\hline 28 & 28,25 & 28,14 & 26,61 & 32,02 & 115,04 & 28,76 & 1,90 & 0,301 \\
\hline 29 & 26,48 & 25,97 & 25,34 & 28,70 & 106,50 & 26,62 & 2.87 & 0,584 \\
\hline 30 & 23,61 & 23,85 & 23,75 & 27,01 & 98,24 & 24,56 & 2,39 & 0,345 \\
\hline 31 & 28,55 & 28,84 & 28,17 & 32,58 & 118,15 & 29,53 & 2,32 & 0,469 \\
\hline 32 & 27,90 & 27,97 & 28,17 & 30,65 & 114,68 & 28,67 & 1,94 & 0,312 \\
\hline 33 & 27,14 & 26,57 & 26,30 & 30,65 & 110,67 & 27,66 & 1,99 & 0,304 \\
\hline 34 & 26,95 & 26,97 & 25,64 & 29,01 & 108,58 & 27,14 & 1,98 & $0,2.91$ \\
\hline 35 & 25,84 & 24,89 & 25,67 & 27,92 & 104,32 & 26,08 & 4,48 & 1,368 \\
\hline 36 & 26,97 & 26,45 & 26,20 & 29,65 & 109,28 & 27,32 & 1,79 & 0,239 \\
\hline 37 & 28,32 & 28,31 & 28,51 & 31,44 & 116,60 & 29,15 & 1,25 & 0,133 \\
\hline 38 & 27,92 & 28,30 & 28,00 & 31,84 & 116,07 & 29,01 & 2,03 & 0,350 \\
\hline 39 & 27,97 & 28,55 & 28,57 & 30,95 & 116,05 & 29,01 & 2,63 & 0,582 \\
\hline 40 & 27,31 & 27,28 & 27,38 & 31,14 & 113,12 & 28,28 & 2,01 & 0,325 \\
\hline
\end{tabular}

TOTAL $1093,58 \quad 1087,56 \quad 1081,44 \quad 1225,28 \quad 4487,86$ MÉDIA 
Tabela 28. Vàlores médios da uniformidade da fibra de quatro cultivares, avaliados em quarenta ambientes; médias gerais de ambientes $(Y j)$ e de cultivares (Yi); quadrados médios residuais (QMR) e coeficientes de variação (CVq).

\begin{tabular}{|c|c|c|c|c|c|c|c|c|}
\hline \multirow[t]{2}{*}{ AMBIENTE } & \multicolumn{4}{|c|}{ CULTIVARES } & \multirow[b]{2}{*}{ TOTAL } & \multirow[b]{2}{*}{$\begin{array}{c}\text { MEDIA } \\
Y j\end{array}$} & \multirow[b]{2}{*}{$\begin{array}{r}\mathrm{CV} \\
8\end{array}$} & \multirow[b]{2}{*}{ QMR } \\
\hline & IAC 19 & IAC 20 & $\begin{array}{c}\text { CNPA } \\
\text { Prec } 1\end{array}$ & $\begin{array}{l}\text { CNPA } \\
\text { AC. } 1\end{array}$ & & & & \\
\hline 1 & 45,48 & 45,78 & 43,37 & 42,94 & 177,58 & 44,39 & 3,02 & 1,807 \\
\hline 2 & 44,87 & 45,37 & 45,74 & 40,84 & 176,82 & 44,20 & 5,15 & 5,191 \\
\hline 3 & 45,44 & 45,64 & 44,80 & 42,65 & 178,54 & 44,63 & 3,10 & 1,925 \\
\hline 4 & 46,75 & 47,97 & 42,81 & 45,95 & 183,50 & 45,87 & 3,06 & 1,975 \\
\hline 5 & 42,78 & 43,21 & 42,12 & 40,42 & 168,55 & 42,13 & 2,51 & 1,122 \\
\hline 6 & 45,04 & 46,57 & 43,62 & 43,17 & 178,41 & 44,60 & 3,33 & 2,214 \\
\hline 7 & 45,87 & 45,94 & 44,74 & 44,72 & 181,28 & 45,32 & 2,04 & 0,857 \\
\hline 8 & 44,21 & 45,75 & 44,65 & 44,82 & 179,45 & 44,86 & 2,79 & 1,572 \\
\hline 9 & 44,64 & 45,07 & 43,04 & 42,60 & 175,35 & 43,83 & 1,91 & 0,706 \\
\hline 10 & 44,61 & 45,20 & 42,90 & 41,32 & 174,04 & 43,51 & 3,29 & 2,053 \\
\hline 11 & 43,75 & 45,32 & 44,37 & 41,01 & 174,47 & 43,61 & 2,86 & 1,556 \\
\hline 12 & 43,54 & 44,65 & 43,15 & 42,54 & 173,89 & 43,47 & 1,79 & 0,611 \\
\hline 13 & 47,58 & 48,70 & 46,24 & 44,65 & 187,18 & 46,79 & 2,08 & 0,954 \\
\hline 14 & 44,74 & 45,71 & 44,31 & 43,05 & 177,82 & 44,45 & 2,26 & 1,009 \\
\hline 15 & 45,22 & 46,82 & 44,47 & 43,87 & 180,39 & 45,09 & 1,94 & 0,765 \\
\hline 16 & 45,77 & 46,28 & 44,82 & 43,80 & 180,68 & 45,17 & 2,76 & 1,553 \\
\hline 17 & 44,40 & 45,52 & 43,92 & 41,11 & 174,97 & 43,74 & 3,08 & 1,825 \\
\hline 18 & 46,12 & 47,48 & 44,97 & 45,50 & 184,08 & 46,02 & 2,37 & 1,195 \\
\hline 19 & 45,38 & 44,78 & 43,75 & 40,90 & 174,82 & 43,70 & 2,07 & 0,823 \\
\hline 20 & 44,97 & 46,80 & 44,79 & 44,71 & 181,28 & 45,32 & 2,85 & 1,677 \\
\hline 21 & 45,04 & 45,48 & 43,50 & 42,81 & 176,84 & 44,21 & 1,80 & 0,633 \\
\hline 22 & 44,99 & 45,84 & 45,07 & 43,81 & 179,72 & 44,93 & 2,33 & 1,096 \\
\hline 23 & 45,54 & 45,69 & 44,68 & 41,37 & 177,30 & 44,32 & 2,97 & 1,737 \\
\hline 24 & 41,35 & 42,91 & 41,18 & 38,42 & 163,78 & 40,94 & 2,78 & 1,300 \\
\hline 25 & 46,18 & 47,05 & 45,60 & 43,98 & 182,82 & 45,70 & 2,99 & 1,873 \\
\hline 26 & 42,72 & 42,68 & 42,31 & 41,90 & 169,62 & 42,40 & 2,38 & 1,026 \\
\hline 27 & 44,12 & 45,35 & 44,44 & 43,18 & 177,11 & 44,27 & 2,38 & 1,119 \\
\hline 28 & 46,15 & 47,84 & 45,82 & 46,11 & 185,94 & 46,48 & 2,04 & 0,905 \\
\hline 29 & 42,12 & 42,02 & 41,18 & 39,62 & 164,97 & 41,24 & 3,92 & 2,616 \\
\hline 30 & 46,28 & 46,25 & 44,75 & 44,18 & 181,48 & 45,37 & 1,90 & 0,749 \\
\hline 31 & 45,62 & 45,85 & 44,48 & 44,78 & 180,75 & 45,18 & 2,86 & 1,674 \\
\hline 32 & 43,14 & 44,08 & 42,11 & 40,45 & 169,80 & 42,45 & 3,27 & 1,933 \\
\hline 33 & 45,29 & 45,27 & 43,67 & 41,90 & 176,14 & 44,03 & 2,99 & 1,743 \\
\hline 34 & 46,28 & 46,47 & 47,21 & 45,78 & 185,75 & 46,43 & 1,81 & 0,711 \\
\hline 35 & 42,44 & 43,10 & 42,37 & 40,70 & $168 ; 61$ & 42,15 & 2,70 & 1,296 \\
\hline 36 & 45,55 & 46,52 & 44,52 & 44,47 & 181,08 & 45,27 & 3,42 & 2,399 \\
\hline 37 & 46,45 & 47,35 & 46,20 & 43,72 & 183,74 & 45,93 & 2,42 & 1,239 \\
\hline 38 & 46,42 & 47,28 & 45,07 & 43,91 & 182,69 & 45,67 & 2,10 & 0,921 \\
\hline 39 & 48,75 & 49,11 & 48,07 & 47,55 & 193,50 & 48,37 & 1,71 & 0,687 \\
\hline 40 & 46,90 & 47,70 & 45,44 & 46,58 & 186,62 & 46,65 & 2,03 & 0,903 \\
\hline
\end{tabular}


Tabela 29. Valores médios do indice Micronaire de quatro cultivares, avaliados em quarenta ambientes; médias gerais de ambientes

(Yj) e de cultivares ( $Y i$ ); quadrados médios residuais (QMR) e coeficientes de variação (CV\&).

\begin{tabular}{|c|c|c|c|c|c|c|c|}
\hline AMB I & & CULT & IARES & & & & \\
\hline & IAC 19 & IAC 20 & $\begin{array}{c}\text { CNPA } \\
\text { Prec. } 1\end{array}$ & $\begin{array}{l}\text { CNPA } \\
\text { AC. } 1\end{array}$ & TOTAL & $\begin{array}{c}\text { MÉDIA } \\
\text { Yj }\end{array}$ & $\begin{array}{r}\mathrm{CV} \\
\text { f }\end{array}$ \\
\hline
\end{tabular}

\begin{tabular}{|c|c|c|c|c|c|c|c|c|}
\hline 1 & 5,27 & 5,37 & 4,94 & 4,20 & 19,78 & 4,94 & 2,93 & $0,02.1$ \\
\hline 2 & 5,34 & 5,18 & 4,67 & 4,17 & 19,37 & 4,84 & 3,26 & 0,025 \\
\hline 3 & 5,30 & 5,32 & 4,71 & 4,18 & 19,52 & 4,88 & 4,28 & 0,043 \\
\hline 4 & 5,48 & 5,51 & 4,35 & 4,55 & 19,91 & 4,97 & 2,75 & 0,018 \\
\hline 5 & 4,28 & 4,38 & 3,94 & 3,48 & 16,10 & 4,02 & 6,28 & 0,064 \\
\hline 6 & 4,97 & 4,91 & 4,24 & 4,04 & 18,17 & 4,54 & 4,32 & 0,038 \\
\hline 7 & 4,77 & 4,91 & 4,37 & 4,08 & 18,14 & 4,53 & 2,63 & 0,014 \\
\hline 8 & 4,65 & 4,68 & 4,48 & 3,95 & 17,78 & 4,44 & 6,49 & 0,083 \\
\hline 9 & 4,77 & 4,62 & 4,22 & 3,95 & 17,58 & 4,39 & 6,45 & 0,080 \\
\hline 10 & 4,18 & 3,94 & 3,71 & 3,44 & 15,28 & 3,82 & 9,01 & 0,118 \\
\hline 11 & 4,02 & 3,98 & 3,72 & 2,98 & 14,72 & 3,68 & 7,07 & 0,067 \\
\hline 12. & 4,41 & 4,78 & 4,30 & 3,87 & 17,37 & 4,34 & 4,40 & 0,036 \\
\hline $13^{\circ}$ & 5,22 & 5,28 & 4,02 & 4,28 & 18,82 & 4,70 & 6,42 & 0,091 \\
\hline 14 & 5,04 & 5,04 & 4,12 & 3,95 & 18,17 & 4,54 & 4,26 & 0,037 \\
\hline 15 & 4,94 & 4,87 & 3,55 & 3,87 & 17,24 & 4,31 & 5,69 & 0,060 \\
\hline 16 & 4,67 & 4,32 & 3,52 & 3,64 & 16,17 & 4,04 & 8,11 & 0,107 \\
\hline 17 & 4,78 & 4,97 & 4,01 & 3,74 & 17,51 & 4,37 & 5,57 & 0,059 \\
\hline 18 & 4,40 & 4,45 & 3,18 & 3,72 & 15,77 & 3,94 & 6,51 & 0,065 \\
\hline 19 & 5,11 & 5,14 & 4,32 & 3,78 & 18,37 & 4,59 & 3,77 & 0,030 \\
\hline 20 & 4,62 & 4,85 & 4,27 & 3,88 & 17,64 & 4,41 & 5,96 & 0,069 \\
\hline 21 & 4,91 & 5,01 & 4,28 & 3,95 & 18,17 & 4,54 & 3,59 & 0,026 \\
\hline 22 & 4,65 & 4,51 & 3,52 & 3,91 & 16,61 & 4,15 & 7,06 & 0,086 \\
\hline 23 & 5,30 & 5,48 & 4,71 & 3,88 & 19,38 & 4,84 & 4,30 & 0,043 \\
\hline 24 & 4,68 & 4,58 & 4,10 & 3,40 & 16,77 & 4,19 & 4,78 & 0,040 \\
\hline 25 & 4,45 & 4,55 & 4,01 & 3,70 & 16,72 & 4,18 & 7,49 & 0,098 \\
\hline 26 & 4,22 & 4,47 & 4,01 & 3,78 & 16,50 & 4,12 & 6,91 & 0,081 \\
\hline 27 & 3,92 & 4,04 & 3,85 & 3,31 & 15,14 & 3,78 & 8,66 & 0,107 \\
\hline 28 & 3,92 & 4,28 & 3,34 & 3,62 & 15,18 & 3,79 & 9,65 & 0.134 \\
\hline 29 & 4,18 & 4,42 & 3,51 & 3,34 & 15,47 & 3,86 & 8,57 & 0,110 \\
\hline 30 & 5,22 & 5,35 & 4,84 & 4,32 & 19,75 & 4,93 & 5,64 & 0,077 \\
\hline 31 & 4,42 & 4,52 & 3,78 & 3,60 & 16,34 & 4,08 & 5.69 & 0,054 \\
\hline 32 & 4,67 & 4,75 & 3,88 & 3,62 & 16,94 & 4,23 & 4,46 & 0,035 \\
\hline 33 & 4,75 & 4,87 & 4,00 & 4,18 & 17,81 & 4,45 & 5,70 & 0,064 \\
\hline 34 & 4,48 & 4,51 & 3,90 & 4,00 & 16,90 & 4,22 & 4,59 & 0,037 \\
\hline 35 & 4,70 & 4,64 & 4,18 & 3,28 & 16,81 & 4,20 & 10,64 & 0,200 \\
\hline 36 & 4,41 & 4,62 & 3,85 & 3,50 & 16,40 & 4,10 & 6,16 & 0,063 \\
\hline 37 & 4,88 & 4,95 & 4,48 & 3,47 & 17,80 & 4,45 & 4,96 & 0,048 \\
\hline 38 & 5,21 & 5,32 & 4,72 & 3,85 & 19,12 & 4,78 & 3,47 & 0,027 \\
\hline 39 & 5,17 & 5,25 & 4,60 & 3,54 & 18,57 & 4,64 & 5,49 & 0,065 \\
\hline 40 & 4,62 & 4,61 & 3,62 & 3,81 & 16,68 & 4,17 & 6,98 & 0,084 \\
\hline $\begin{array}{l}\text { TOTAL } \\
\text { MÉDIA }\end{array}$ & 189,16 & 191,56 & 164,02 & 152,18 & 696,92 & & & \\
\hline $\mathrm{Yi}$ & 4,73 & 4,79 & 4,10 & 3,80 & & & & \\
\hline
\end{tabular}


Tabela 30. Valores médios da tenacidade da fibra de quatro cultivares, avaliados em quarenta ambientes; média gerais de ambientes (Yj) e de cultivares (Yi); quadrados médios residuais (QMR) e coeficientes de variação (CVq).

\begin{tabular}{lrrrrrrrr}
\hline AMBIENTE & \multicolumn{9}{c}{ CULTIVARES } \\
& IAC 19 & IAC 20 & CNPA & CNPA & TOTAL & MEDIA & CV & QMR \\
& & & Prec.1 & AC.1 & & Yj & $\%$ &
\end{tabular}

\begin{tabular}{|c|c|c|c|c|c|c|c|c|}
\hline 1 & 22,44 & 22,05 & 21,54 & 27,47 & 93,51 & 23,37 & 3,86 & 0,818 \\
\hline 2 & 21,28 & 19,45 & 21,38 & 25,61 & 87,74 & 21,93 & 5,53 & 1,474 \\
\hline 3 & 21,80 & 21,04 & 20,42 & 25,88 & 89,15 & 22,28 & 2,69 & 0,361 \\
\hline 4 & 22,54 & 21,18 & 19,64 & 25,65 & 89,02 & 22,25 & 3,82 & 0,723 \\
\hline 5 & 22,20 & 21,71 & 21,02 & 26,35 & 91,30 & 22,82 & 3,06 & 0,488 \\
\hline 6 & 23,08 & 22,21 & 20,90 & 28,00 & 94,19 & 23,54 & 3,19 & 0,566 \\
\hline 7 & 23,18 & 21,41 & 21,58 & 27,20 & 93,38 & 23,34 & 3,87 & 0,819 \\
\hline 8 & 22,00 & 21,44 & 20,27 & 26,45 & 90,17 & 22,54 & 3,97 & 0,804 \\
\hline 9 & 21,81 & 21,71 & 21,22 & 25,45 & 90,21 & 22,55 & 2,54 & 0,328 \\
\hline 10 & 22,00 & 22,12 & 21,48 & 26,71 & 92,32 & 23,08 & 4,56 & 1,109 \\
\hline 11 & 23,68 & 22,78 & 23,54 & 29,40 & 99,41 & 24,85 & 4,89 & 1,480 \\
\hline 12 & 23,07 & 22,31 & 22,60 & 28,12 & 96,11 & 24,02 & 3,59 & 0,746 \\
\hline 13 & 21,97 & 21,30 & 20,71 & 27,11 & 91,10 & 22,77 & 4,93 & 1,265 \\
\hline 14 & 22,04 & 21,61 & 20,11 & 27,74 & 91,51 & 22,87 & 3,98 & 0,832 \\
\hline 15 & 24,14 & 23,12 & 23,31 & 30,28 & 100,87 & 25,21 & 3,96 & 1,000 \\
\hline 16 & 22,61 & 22,62 & 22,87 & 29,22 & 97,34 & 24,33 & 4,67 & 1,292 \\
\hline 17 & 23,27 & 23,00 & 22,72 & 29,44 & 98,44 & 24,61 & 3,62 & 0,796 \\
\hline 18 & 24,27 & 22,99 & 20,91 & 29,25 & 97,44 & 24,36 & 3,55 & 0,748 \\
\hline 19 & 23,37 & 21,82 & 21,37 & 27,17 & 93,74 & 23,43 & 6,64 & 2,427 \\
\hline 20 & 21,95 & 22,34 & 21,35 & 25,97 & 91,62 & 22,90 & 4,96 & 1,292 \\
\hline 21 & 21,07 & 20,71 & 21,15 & 25,27 & 88,21 & 22,05 & 2,62 & 0,336 \\
\hline 22 & 23,40 & 22,70 & 22,61 & 28,41 & 97,12 & 24,28 & 6,87 & 2,782 \\
\hline 23 & 22,48 & 21,78 & 20,82 & 27,81 & 92,91 & 23,22 & 5,31 & 1,521 \\
\hline 24 & 22,14 & 21,81 & 21,50 & 25,02 & 90,48 & 22,62 & 5,34 & 1,464 \\
\hline 25 & 21,90 & 21,88 & 21,18 & 24,54 & 89,51 & 22,37 & 4,73 & 1,123 \\
\hline 26 & 24,92 & 24,94 & 24,97 & 24,94 & 99,78 & 24,94 & 2,94 & 0,540 \\
\hline 27 & 23,87 & 23,68 & 22,72 & 29,12 & 99,41 & 24,85 & 4,15 & 1,065 \\
\hline 28 & 24,17 & 23,98 & 22,82 & 28,45 & 99,44 & 24,86 & 5,72 & 2,028 \\
\hline 29 & 22,70 & 20,97 & 19,42 & 26,58 & 89,68 & 22,42 & 3,89 & 0,760 \\
\hline 30 & 21,30 & 21,28 & 21,35 & 27,21 & 91,15 & 22,78 & 6,00 & 1,870 \\
\hline 31 & 24,91 & 25,15 & 24,20 & 32,60 & 106,87 & 26,71 & 2,97 & 0,630 \\
\hline 32 & 21,30 & 20,52 & 22,00 & 24,27 & 88,10 & 22,02 & 8,10 & 3,186 \\
\hline 33 & 21,48 & 21,07 & 21,01 & 25,38 & 88,95 & 22,23 & 3,40 & 0,573 \\
\hline 34 & 21,61 & 22,18 & 21,58 & 24,80 & 90,18 & 22,54 & 3,89 & 0,772 \\
\hline 35 & 21,45 & 20,52 & 20,78 & 26,48 & 89,25 & 22,31 & 3,72 & 0,690 \\
\hline 36 & 22,32 & 21,80 & 22,08 & 24,48 & 90,69 & 22,67 & 5,03 & 1,301 \\
\hline 37 & 23,00 & 22,52 & 23,24 & 30,68 & 99,45 & 24,86 & 3,87 & 0,930 \\
\hline 38 & 24,21 & 23,08 & 22,78 & 29,58 & 99,67 & 24,91 & 4,52 & 1,271 \\
\hline 39 & 23,91 & 22,55 & 22,24 & 30,55 & 99,27 & 24,81 & 3,92 & 0,950 \\
\hline 40 & 24,45 & 23,15 & 22,98 & 29,32 & 99,92 & 24,98 & 3,48 & 0,757 \\
\hline
\end{tabular}

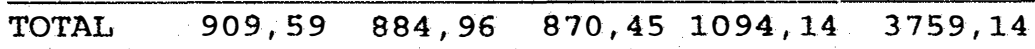
MEDIA

Yi $\quad 22,74 \quad 22,12 \quad 21,76 \quad 27,35$ 
Tabela 31. Valores médios da maturidade da fibra de quatro cultivares, avaliados em quarenta ambientes; médias gerais de ambientes (Yj) e de cultivares (Yi), quadrados médios residuais (QMR) e coeficientes de variação (CVo).

\begin{tabular}{|c|c|c|c|c|c|c|c|c|}
\hline \multirow[t]{2}{*}{ AMBIENTE } & \multicolumn{4}{|c|}{ CULTIVARES } & \multirow[b]{2}{*}{ TOTAL } & \multirow[b]{2}{*}{$\begin{array}{c}\text { MÉDIA } \\
Y j\end{array}$} & \multirow[b]{2}{*}{$\begin{array}{c}\mathrm{CV} \\
8\end{array}$} & \multirow[b]{2}{*}{ QMR } \\
\hline & IAC 19 & IAC 20 & $\begin{array}{c}\text { CNPA } \\
\text { Prec } 1\end{array}$ & $\begin{array}{l}\text { CNPA } \\
\text { AC. } 1\end{array}$ & & & & \\
\hline & & ' & & & & & & \\
\hline 1 & 77,81 & 76,31 & 70,67 & 76,07 & 300,87 & 75,21 & 4,46 & 11,284 \\
\hline 2 & 75,15 & 73,00 & 71,45 & 71,52 & 291,14 & 72,78 & 4,73 & 11,853 \\
\hline 3 & 77,71 & 78,58 & 72,50 & 73,97 & 302,77 & 75,69 & 5,34 & 16,337 \\
\hline 4 & 74,38 & 75,32 & 65,77 & 74,11 & 289,60 & 72,40 & 5,80 & 17,650 \\
\hline 5 & 70,25 & 71,51 & 67,44 & 69,48 & 278,70 & 69,67 & 5,92 & 17,039 \\
\hline 6 & 71,05 & 72,85 & 63,80 & 68,02 & 275,74 & 68,93 & 4,50 & 9,643 \\
\hline 7 & 67,78 & 68,17 & 64,91 & 68,34 & 269,21 & 67,30 & 4,64 & 9,784 \\
\hline 8 & 70,74 & 73,12 & 70,65 & 75,88 & 290,41 & 72,60 & 5,55 & 16,253 \\
\hline 9 & 71,14 & 71,61 & 68,15 & 69,67 & 280,58 & 70,14 & 6,19 & 18,869 \\
\hline 10 & 72,45 & 69,32 & 67,45 & 68,55 & 277,79 & 69,44 & 6,73 & 21,857 \\
\hline 11 & 57,87 & 59,64 & 56,57 & 53,75 & 227,84 & 56,96 & 7,60 & 18,761 \\
\hline 12 & 65,02 & 65,42 & 60,30 & 63,71 & 254,47 & 63,61 & 3,33 & 4,489 \\
\hline 13 & 76,77 & 78,87 & 68,65 & 75,85 & 300,15 & 75,03 & 4,58 & 11,849 \\
\hline 14 & 73,00 & 75,55 & 65,12 & 70,57 & 284,25 & 71,06 & 5,22 & 13,797 \\
\hline 15 & 68,51 & 68,98 & 57,64 & 65,88 & 261,02 & 65,25 & 4,84 & 9,998 \\
\hline 16 & 67,18 & 64,87 & 54,71 & 59,67 & 246,44 & 61,61 & 7,79 & 23,037 \\
\hline 17 & 75,01 & 74,12 & 67,25 & 69,41 & 285,81 & 71,45 & 4,80 & 11,765 \\
\hline 18 & 63,75 & 68,45 & 54,08 & 65,68 & 251,98 & 62,99 & 6,56 & 17,112 \\
\hline 19 & 74,28 & 74,04 & 67,15 & 67,98 & 283,47 & 70,86 & 4,94 & 12,253 \\
\hline 20 & 65,31 & 67,65 & 61,87 & 65,87 & 260,71 & 65,17 & 6,38 & 17,332 \\
\hline 21 & 72,77 & 72,65 & 68,10 & 72,45 & 285,98 & 71,49 & 2,65 & 3,614 \\
\hline 22 & 68,94 & 66,98 & 60,28 & 64,80 & 261,01 & 65,25 & 5,89 & 14,774 \\
\hline 23 & 77,25 & 75,31 & 71,97 & 69,78 & 294,32 & 73,58 & 3,35 & 6,104 \\
\hline 24 & 64,12 & 63,68 & 60,64 & 57,80 & 246,25 & 61,56 & 6,21 & 14,658 \\
\hline 25 & 64,31 & 68,78 & 61,78 & 64,87 & 259,75 & 64,93 & 7,41 & 23,184 \\
\hline 26 & 72,51 & 71,20 & 69,37 & 71,97 & 285,05 & 71,26 & 4,65 & 11,022 \\
\hline 27 & 69,74 & 66,80 & 66,17 & 65,99 & 268,71 & 67,17 & 4,29 & 8,305 \\
\hline 28 & 70,74 & 67,79 & 62,97 & 71,51 & 273,02 & 68,25 & 6,08 & 17,266 \\
\hline 29 & 62,38 & 63,45 & 52,62 & 54,74 & 233,21 & 58,30 & 9,04 & 27,797 \\
\hline 30 & 69,95 & 71,81 & 66,65 & 66,94 & 275,37 & 68,84 & 5,54 & 14,559 \\
\hline 31 & 68,82 & 71,65 & 61,35 & 70,44 & 272,28 & 68,07 & 4,23 & 8,309 \\
\hline 32 & 65,25 & 68,88 & 60,47 & 60.41 & 255,02 & 63,75 & 7,31 & 21,729 \\
\hline 33 & 76,98 & 75,21 & 68,75 & 74,58 & 295,54 & 73,88 & 5,65 & 17,448 \\
\hline 34 & 71,00 & 70,61 & 63,65 & 68,00 & 273,27 & 68,31 & 5,24 & 12,837 \\
\hline 35 & 62,07 & 63,05 & 59,17 & 54,60 & 238,89 & 59,72 & 9,40 & 31,576 \\
\hline 36 & 68,00 & 70,58 & 63,71 & 66,45 & 268,75 & 67,18 & 5,02 & 11,391 \\
\hline 37 & 77,21 & 76,45 & 74,40 & 72,51 & 300,58 & 75,14 & 3,63 & 7,467 \\
\hline 38 & 70,57 & 69,64 & 64,07 & 64,31 & 268,60 & 67,15 & 4,99 & 11,235 \\
\hline 39 & 67,88 & 70,87 & 64,32 & 61,31 & 264,39 & 66,09 & 4,22 & 7,789 \\
\hline 40 & 76,57 & 76,00 & 67,00 & 71,91 & 291,48 & 72,87 & 4,02 & 8,591 \\
\hline
\end{tabular}

TOTAL $2812,412828,82 \quad 2583,602699,25 \quad 109214,08$ MEDIA 
Tabela 32. Valores médios da tenacidade do fio de quatro cultivares, avaliados em quarenta ambientes; médias gerais de ambientes (Yj) e de cultivares (Yi); quadrados médios residuais (QMR) e coeficientes de variação (CVờ).

\begin{tabular}{|c|c|c|c|c|c|c|c|c|}
\hline \multirow[t]{2}{*}{ AMBIENTE } & \multicolumn{4}{|c|}{ CULT IVARES } & \multirow[b]{2}{*}{ TOTAL } & \multirow[b]{2}{*}{$\begin{array}{c}\text { MEDIA } \\
Y j\end{array}$} & \multirow[b]{2}{*}{$\begin{array}{c}\mathrm{CV} \\
8\end{array}$} & \multirow[b]{2}{*}{ QMR } \\
\hline & IAC 19 & IAC 20 & $\begin{array}{c}\text { CNPA } \\
\text { Prec. } 1\end{array}$ & $\begin{array}{l}\text { CNPA } \\
\text { AC. } \quad 1\end{array}$ & & & & \\
\hline 1 & 14,57 & 13,65 & 13,38 & 17,15 & 58,77 & 14,69 & 3,69 & 0,294 \\
\hline 2 & 12,77 & 11,64 & 15,08 & 16,14 & 55,64 & 13,91 & 10,42 & 2,102 \\
\hline 3 & 13,90 & 13,17 & 13,72 & 16,97 & 57,77 & 14,44 & 7,39 & 1,141 \\
\hline 4 & 14,04 & 12,67 & 11,02 & 17,32 & 55,07 & 13,76 & 5,57 & 0,588 \\
\hline 5 & 13,42 & 12,02 & 12,44 & 16,17 & 54,07 & 13,51 & 2,44 & 0,108 \\
\hline 6 & 14,75 & 13,55 & 14,00 & 17,25 & 59,57 & 14,89 & 5,65 & 0,707 \\
\hline 7 & 14,24 & 13,54 & 13,35 & 17,34 & 58,48 & 14,62 & 5,20 & 0,579 \\
\hline 8 & 14,17 & 14,02 & 13,45 & 17,67 & 59,32 & 14,83 & 4,11 & 0,371 \\
\hline 9 & 15,24 & 14,00 & 13,90 & 18,08 & 61,22 & 15,30 & 4,18 & 0,409 \\
\hline 10 & 14,77 & 13,90 & 13,44 & 17,04 & 59,15 & 14,78 & 4,66 & 0,475 \\
\hline 11 & 14,82 & 14,07 & 14,55 & 17,70 & 61,15 & 15,28 & 3,25 & 0,247 \\
\hline 12 & 14,92 & 13,77 & 13,40 & 16,95 & 59,05 & 14,76 & 6,65 & 0,966 \\
\hline 13 & 14,24 & 13,78 & 13,85 & 17,32 & 59,21 & 14,80 & 7,58 & 1,259 \\
\hline 14 & 14,77 & 13,75 & 12,94 & 17,88 & 59,35 & 14,83 & 3,91 & 0,337 \\
\hline 15 & 15,22 & 13,94 & 14,38 & 18,75 & 62,31 & 15,57 & 5,16 & 0,648 \\
\hline 16 & 14,98 & 14,55 & 14,00 & 17,92 & 61,47 & 15,36 & 6,73 & 1,069 \\
\hline 17 & 15,02 & 14,15 & 13,18 & 18,04 & 60,41 & 15,10 & 4,81 & 0,528 \\
\hline 18 & 15,64 & 15,18 & 14,25 & 18,88 & 63,97 & 15,99 & 4,93 & 0,621 \\
\hline 19 & 13,92 & 12,87 & 13,08 & 18,10 & 57,98 & 14,49 & 5,12 & 0,551 \\
\hline 20 & 14,01 & 12,97 & 13,12 & 16,90 & 57,01 & 14,25 & 3,93 & 0,315 \\
\hline 21 & 14,67 & 13,34 & 13,95 & 17,45 & 59,42 & 14,85 & 4,88 & 0,527 \\
\hline 22 & 13,91 & 13,04 & 12,94 & 18,21 & 58,11 & 14,52 & 5,88 & 0,730 \\
\hline 23 & 13,74 & 11,87 & 12,57 & 17,35 & 55,54 & 13,88 & 4,20 & 0,341 \\
\hline 24 & 13,80 & 12,90 & 12,61 & 15,42 & 54,73 & 13,69 & 6,49 & 0,790 \\
\hline 25 & 14,24 & 13,45 & 13,61 & 17,11 & 58,42 & 14,60 & 5,25 & 0,588 \\
\hline 26 & 14,65 & 13,62 & 13,74 & 16,75 & 58,78 & 14,69 & 4,20 & 0,381 \\
\hline 27 & 15,87 & 15,04 & 14,77 & 18,87 & 64,55 & 16,13 & 13,87 & 0,390 \\
\hline 28 & 14,65 & 13,87 & 13,18 & 16,52 & 58,24 & 14,56 & 7,44 & 1,175 \\
\hline 29 & 14,04 & 12,41 & 12,37 & 16,01 & 54,84 & 13,71 & 6,48 & 0,791 \\
\hline 30 & 12,78 & 12,50 & 12,98 & 18,07 & 56,34 & 14,08 & 4,39 & 0,383 \\
\hline 31 & 15,85 & 15,34 & 14,65 & 19,24 & 65,10 & 16,27 & 3,63 & 0,350 \\
\hline 32 & 14,81 & 13,01 & 13,45 & 17,22 & 58,51 & 14,62 & 4,89 & 0,512 \\
\hline 33 & 14,54 & 13,18 & 13,00 & 16,92 & 57,65 & 14,41 & 4,68 & 0,456 \\
\hline 34 & 14,87 & 13,87 & 13,31 & 16,60 & 58,65 & 14,66 & 3,48 & 0,261 \\
\hline 35 & 13,54 & 13,17 & 13,40 & 18,08 & 58,20 & 14,55 & 5,64 & 0,674 \\
\hline 36 & 14,88 & 13,58 & 14,07 & 16,72 & 59,27 & 14,81 & 4,54 & 0,454 \\
\hline 37 & 16,44 & 15,54 & 15,54 & 19,58 & 67,11 & 16,77 & 4,86 & 0,664 \\
\hline 38 & 15,42 & 15,50 & 14,50 & 19,05 & 63,48 & 15,87 & 2,92 & 0,215 \\
\hline 39 & 16,20 & 15,02 & 15,22 & 18,32 & 64,78 & 16,19 & 5,32 & 0,743 \\
\hline 40 & 15,18 & 14,45 & 14,75 & 17,15 & 61,55 & 15,38 & 8,87 & 1,867 \\
\hline
\end{tabular}

\begin{tabular}{lllllll}
\hline TOTAL & 583,61 & 544,82 & 545,24 & 700,19 & 2273,86
\end{tabular}

MEDIA

Yi

$14,59 \quad 13,62$

13,63

17,50 
Tabela 33. Valores médios da elongação do fio de quatro cultivares, avaliados em quarenta ambientes, médias gerais de ambientes (Yj) e de cultivares (Yi); quadrados médios residuais (QMR) e coeficientes de variação (CV\%).

AMBIENTE CULTIVARES

IAC 19 IAC 20 CNPA

Prec. 1
CNPA

AC. I
TOTAL

MÉDIA
Yj
$\mathrm{CV}$
के

QMR

\begin{tabular}{|c|c|c|c|c|c|c|c|c|}
\hline 1 & 6,57 & 6,97 & 6,58 & 6,51 & 26,64 & 6,66 & 6,89 & 0,210 \\
\hline 2 & 5,80 & 5,87 & 6,85 & 6,21 & 24,74 & 6,18 & 9,18 & 0,322 \\
\hline 3 & 6,37 & 6,94 & 7,04 & 6,91 & 27,27 & 6,81 & 6,80 & 0,215 \\
\hline 4 & 6,50 & 6,61 & 6,35 & 7,18 & 26,65 & 6,66 & 7,20 & 0,230 \\
\hline 5 & 6,28 & 6,50 & 6,90 & $6,6 \lambda$ & 26,30 & 6,57 & 6,57 & 0,187 \\
\hline 6 & 6,71 & 7,30 & 7,58 & 6,77 & 28,37 & 7,09 & 6,70 & 0,226 \\
\hline 7 & 6,68 & 6,71 & 6,74 & 6,57 & 26,71 & 6,67 & 5,09 & 0,115 \\
\hline 8 & 6,50 & 6,95 & 7,15 & 6,52 & 27,12 & 6,78 & 4,92 & 0,111 \\
\hline 9 & 6,50 & 6,58 & 6,67 & 6,44 & 26,20 & 6,55 & 4,16 & 0,074 \\
\hline 10 & 6,67 & 6,64 & 6,58 & 6,22 & 26,12 & 6,53 & 8,12 & 0,281 \\
\hline 11 & 6,82 & 7,22 & 7,12 & 7,02 & 28,21 & 7,05 & 4,13 & 0,085 \\
\hline 12 & 6,68 & 6,65 & 6,58 & 6,51 & 26,44 & 6,61 & 3,92 & 0.067 \\
\hline 13 & 6,87 & 7,32 & 7,77 & 6,67 & 28,64 & 7,16 & 6,90 & 0,244 \\
\hline 14 & 6,80 & 7,04 & 7,72 & 6,55 & 28,12 & 7,03 & 4,35 & 0,093 \\
\hline 15 & 6,61 & 6,72 & 7,68 & 6,60 & 27,62 & 6,90 & 4,83 & 0,111 \\
\hline 16 & 6,44 & 6,51 & 7,30 & 6,72 & 26,98 & 6,74 & 7,02 & 0,224 \\
\hline 17 & 6,55 & 6,92 & 7,31 & 6,48 & 27,28 & 6,82 & 3,86 & 0,069 \\
\hline 18 & 6,88 & 6,88 & 8,01 & 6,68 & 28,47 & 7,11 & 5,56 & 0,156 \\
\hline 19 & 5,80 & 5,95 & 6,24 & 6,04 & 24.04 & 6,01 & 7,87 & 0,224 \\
\hline 20 & 6,45 & 6,98 & 7,17 & 6,58 & 27,20 & 6,80 & 7,69 & 0,273 \\
\hline 21 & 6,85 & 6,68 & 6,95 & 6,57 & 27,07 & 6,76 & 5,21 & 0,124 \\
\hline 22 & 6,44 & 6,91 & 8,17 & 6,80 & 28,32 & 7,08 & 4,17 & 0,087 \\
\hline 23 & 6,27 & 6,04 & 6,60 & 6,64 & 25,55 & 6,38 & 3,07 & 0,038 \\
\hline 24 & 6,45 & 6,68 & 7,17 & 6,74 & 27,04 & 6,76 & 4,64 & 0,098 \\
\hline 25 & 6,84 & 6,94 & 7,37 & 6,50 & 27,65 & 6,91 & 4,98 & 0,118 \\
\hline 26 & 6,68 & 6,85 & 6,97 & 7,03 & 27,52 & 6,88 & 5,85 & 0,162 \\
\hline 27 & 6,80 & 7,45 & 7,55 & 7,25 & 29,07 & 7,26 & 9,32 & 0,459 \\
\hline 28 & 7,55 & 7,85 & 8,58 & 7,68 & 31,68 & 7,92 & 4,82 & 0,145 \\
\hline 29 & 6,34 & 6,30 & 6,74 & 6,34 & 25,72 & 6,43 & 6,67 & 0,184 \\
\hline 30 & 5,48 & 5,78 & 5,92 & 5,94 & 23,14 & 5,78 & 6,08 & 0,124 \\
\hline 31 & 6,87 & 6,95 & 7,80 & 6,94 & 28,57 & 7,14 & 4,39 & 0,098 \\
\hline 32 & 6,75 & 6,70 & 7,37 & 6,75 & 27,58 & 6,89 & 3,56 & 0,060 \\
\hline 33 & 6,88 & 6,80 & 7,10 & 6.37 & 27,15 & 6,78 & 7,22 & 0,240 \\
\hline 34 & 7,20 & 7,22 & 8,31 & 7,10 & 29,84 & 7,46 & 4,12 & 0,094 \\
\hline 35 & 5,52 & 5,88 & 6,20 & 6,38 & 24,00 & 6,00 & 5,12 & 0,094 \\
\hline 36 & 7,01 & 6,97 & 7,74 & 7,13 & 28,86 & 7,21 & 3,86 & 0,077 \\
\hline 37 & 7,05 & 7,02 & 7,35 & 6,90 & 28,34 & 7,08 & 7,07 & 0,251 \\
\hline 38 & 6,37 & 6,45 & 6,84 & 6,17 & 25,84 & 6,46 & 4,42 & 0,081 \\
\hline 39 & 7,14 & 7,17 & 7,55 & 6,77 & 28,64 & 7,16 & 4,68 & 0,112 \\
\hline 40 & 6,61 & 6,77 & 7,30 & 6,52 & 27,21 & 6,80 & 6,46 & 0,193 \\
\hline $\begin{array}{l}\text { TOTAL } \\
\text { MEDIA }\end{array}$ & 263,65 & 270,88 & 286,87 & 266,45 & 1087,85 & & & \\
\hline Yi & 6,59 & 6,77 & 7,17 & 6,66 & & & & \\
\hline
\end{tabular}

